LBL -32853

DE93 002557

\title{
The Effect of Rhenium, Sulfur and Alumina on the Conversion of Hydrocarbons over Platinum Single Crystals: Surface Science and Catalytic Studies
}

\author{
Changmin Kim \\ Ph.D. Thesis \\ Department of Chemistry \\ University of California \\ and \\ Center for Advanced Materials \\ Materials Sciences Division \\ Lawrence Berkeley Laboratory \\ University of California \\ Berkeley, CA 94720
}

April 1992

This work was supported by the Director, Office of Energy Research, Office of Basic Energy Sciences, Materials Sciences Division, of the U.S. Department of Energy under Contract No. DE-AC03-76SF00098.

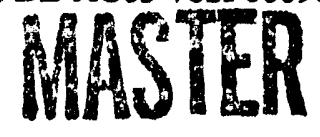

BISTRIBUTION OF THIS DOCUMENT IS UNLIMITED 


\title{
The Effect of Rhenium, Sulfur and Alumina on the Conversion of Hydrocarbons over Platinum Single Crystals: Surface Science and Catalytic Studies
}

\section{Changmin Kim}

\author{
Department of Chemistry \\ University of California \\ Berkeley, CA 94720
}

\section{Abstract}

Conversion reactions of hydrocarbons over the platinum-rhenium model catalyst surfaces have been studied. The Pt-Re bimetallic surfaces were prepared by depositing $\operatorname{Re}$ onto $\mathrm{Pt}(111)$ or $\mathrm{Pt}$ onto $\operatorname{Re}(0001)$ in ultrahigh vacuum. These model catalyst surfaces were modified by sulfur and alumina and the effects of these modification on the conversion of hydrocarbons were also studied.

A plasma deposition source has been developed to deposit platinum, rhenium, and aluminum on the metal substrates. The deposition source has proven to be very effective for the deposition of refractory metals with variable coverage in ultrahigh vacuum without excessive heating. 
Conversion of $\mathrm{n}$-hexane was performed over the Re-covered $\mathrm{Pt}$ and $\mathrm{Pt}$ covered Re surfaces. The presence of the second metal increased hydrogenolysis activity of both Pt-Re surfaces. Addition of sulfur on the model catalyst surfaces suppressed hydrogenolysis activity and increased the cyclization rate of $\mathbf{n}$-hexane to methylcyclopentane over $\mathrm{Pt}$-Re surfaces. It was also observed that sulfiding increased the dehydrogenation rate of cyclohexane to benzene over Pt-Re surfaces. It has been proposed that the PtRe bimetallic catalysts show unique properties when combined with sulfur, and electronic interactions exist between platinum, rhenium and sulfur. Decomposition of hydrocarbons on the sulfur-covered Pt-Re surfaces supported that argument.

The planar $\mathrm{Pt} / \mathrm{AlO}_{x}$ catalyst was prepared by oxidizing the surface of aluminum foil followed by deposition of atomic platinum onto the aluminum oxide surface. For the conversion of 1-butene over this catalyst, the addition of platinum increased the selectivity of hydrogenation over isomerization. 


\title{
Table of Contents
}

\author{
List of Figures
}

List of Tables

Acknowledgements

$\begin{array}{lll}\text { Chapter } 1 \text { Introduction } & 1\end{array}$

1.1 Surface Science Studies of Heterogeneous Catalysis 1

1.2 Refining Process and Reforming Reaction 4

1.3 Reforming Catalysts 9

1.4 Dual Functional Properties of Reforming Catalysts 11

1.5 General Overview of This Thesis Work 13

$\begin{array}{lll}\text { Chapter } 2 \text { Experimental } & 17\end{array}$

$\begin{array}{lll}2.1 & \text { Equipment } & 17\end{array}$

2.1.1 Ultrahigh Vacuum System

2.1.2 Sample Manipulator and Sample Mounting

2.1.3 Catalytic Reactor System

2.1.4 Reaction Product Separation and Analysis

2.1.5 Pulsed Metal Plasma Deposition Source 
2.1.6 Electrochemical Sulfur Source

2.2 Surface Analysis Methods 27

2.2.1 Auger Electron Spectroscopy

2.2.2 Low-Energy Electron Diffraction

2.2.3 Temperature Programmed Desorption

2.3 Materials

2.3.1 Single crystals and Polycrystalline Foils

2.3.2 Reagents

2.4 Procedure

2.4.1 Preparation of Single Crystal Samples

2.4.2 Sample Cleaning

2.4.3 Deposition of Metals

2.4.4 Deposition of Sulfur

2.4.5 High Pressure Reactions

Chapter 3 Preparation of Thin Metal Films: Plasma Deposition Source 51

3.1 Introduction 51

3.2 Vacuum Arc Discharge 52

3.3 Pulsed Metal Plasma Deposition Source 54

3.4 Deposition of $\operatorname{Re}$ on $\mathrm{Pt}(111)$ and $\mathrm{Pt}$ on $\operatorname{Re}(0001)$

$\begin{array}{lll}3.5 & \text { Summary } & 67\end{array}$

Chapter 4 Conversion of Hydrocarbons over the Pt/Re/S Model

Catalyst

$\begin{array}{ll}4.1 \text { Introduction } & 70\end{array}$

4.2 Conversion of Hydrocarbons over $\mathrm{Pt} / \mathrm{Re} / \mathrm{S} \quad 75$

4.2.1 Conversion of $\mathrm{n}$-Hexane over $\mathrm{Pt}(111) / \mathrm{Re}$ and iii 
$\mathrm{Pt}(111) / \operatorname{Re} / \mathrm{S}$

4.2.2 Conversion of $\mathrm{n}-\mathrm{Hexane}$ over $\operatorname{Re}(0001) / \mathrm{Pt}$ and $\operatorname{Re}(0001) / \mathrm{Pt} / \mathrm{S}$

4.2.3 Conversion of Cyclohexane over $\mathrm{Pt}(111) / \operatorname{Re}$ and $\mathrm{Pt}(111) / \mathrm{Re} / \mathrm{S}$

4.2.4 Conversion of Methylcyclopentane over Pt-Covered $\operatorname{Re}(0001)$

4.3 Decomposition of Hydrocarbons over the $\mathrm{Pt} / \mathrm{Re} / \mathrm{S}$ Surfaces

4.3.1 H2 TPD from the Sulfur-Covered Pt(111) Surfaces

4.3.2 Decomposition of Hydrocarbons on the Sulfur-Covered Pt(111) Surfaces

4.4 Desorption of Sulfur from $\mathrm{Pt} / \mathrm{Re}$ Surfaces 105

$\begin{array}{lll}4.5 & \text { Summary } & 109\end{array}$

Chapter 5 Conversion of 1-Butene over Planar Pt/AlO ${ }_{x}$ Model

Catalysts $\quad 114$

5.1 Introduction 114

$\begin{array}{ll}5.2 & \text { Oxidation of Aluminum Foils } \\ \end{array}$

$\begin{array}{ll}\text { 5.3 Deposition of } \mathrm{Pt} \text { on } \mathrm{AlO}_{\mathrm{x}} & 121\end{array}$

5.4 Conversion of 1-Butene on $\mathrm{Pt} / \mathrm{AlO}_{\mathrm{x}}$ 


\section{List of Figures}

1.1 The rate of ammonia synthesis over iron single crystals 3

1.2 Refining flow diagram 5

1.3 Reforming reactions of $\mathrm{C}_{6}$ hydrocarbons $\quad 8$

1.4 Dual functional property of the reforming catalyst 12

2.1 Schematic diagram of an ultrahgh vacuum/high pressure reactor $\begin{array}{ll}\text { system. } & 19\end{array}$

2.2 Schematic diagram of a manipulator and sample mounting. 20

2.3 Schematic diagram of a bath reactor system. 23

2.4 Gas chromatogram of a light hydrocarbon standard. 24

2.5 Schematic diagram of an electrochemical sulfur source. 26

2.6 The mean free path of electrons in solids as a function of their kinetic energy (Universal Curve).

2.7 Energy level diagrams showing the Auger process 30

2.8 Auger electron spectra the Pt surfaces 33

2.9 Three different models of thin film growth mechanisms 34

2.10 Auger electrons from adsorbate layers on a substrate 36

2.11 Scattering of a plane wave at an one-dimensional periodic lattice. 38

2.12 Schematic representation of the LEED experiment 39

2.13 Backscattered Laue X-ray diffraction patterns 43 
3.1 The multiple cathode-spot arcs 53

3.2 A photograph of a plasma deposition source 55

3.3 A schematic diagram of a plasma deposition source. 56

3.4 A set-up for a measurement of the plasma current 58

3.5 The change of the Re plasma current collected by a Pt substrate as a function of 'he bias potential on the substrat.

$\begin{array}{lll}3.6 & \text { Oscillograms of Re plasma current } & 60\end{array}$

3.7 Representative AES spectra of the Pt surfaces covered by Re overlayers

3.8 Variation of the intensity of the $\mathrm{Pt} 158 \mathrm{eV}$ Auger signal as a function of the number of pulses of Re plasma

3.9 LEED patterns of the Re-covered Pt(111) surfaces

3.10 Representative AES spectra of the Re surfaces covered by $\mathrm{Pt}$ overlayers.

4.1 Comparison of $\mathrm{Pt}$ and Pt-Re catalysts in reforming 71

$\begin{array}{lll}\text { 4.2 Preparation of the Pt-Re bimetallic model catalyst surfaces. } & 74\end{array}$

4.3 Rate of $n$-hexane conversion on the $\operatorname{Re} / \mathrm{Pt}(111)$ surfaces 77

4.4 Carbon left of the Pt-Re catalyst surface after the reaction 78

4.5 Rate of $\mathrm{n}$-hexane conversion on the sulfided $\mathrm{Re} / \mathrm{Pt}(111)$ surfaces 79

4.6 Cyclization of $n$-hexane on sulfided and unsulfided $\operatorname{Re} / \mathrm{Pt}(111)$ surfaces

4.7 Change of $\mathrm{CO}$ adsorption area of the $\mathrm{Re} / \mathrm{Pt}(111)$ surfaces 84

4.8 Rate of $\mathrm{n}$-hexane conversion on the $\mathrm{Pt} / \operatorname{Re}(0001)$ surfaces 86

4.9 Rate of $n$-hexane conversion on the sulfided $\mathrm{Pt} / \operatorname{Re}(0001)$ surfaces 87 
4.10 Rate of cyclohexane conversion on sulfided and unsulfided $\operatorname{Re} / \operatorname{Pt}(111)$

4.11 Rate of methylcyclopentane conversion on $\mathrm{Pt} / \operatorname{Re}(0001)$

4.12 Hydrogen TPD spectra from sulfur-modified Pt(111) 96

4.13 Schematic diagram of sulfur adatoms on $\mathrm{Pt}(111) \quad 97$

$4.14 \mathrm{n}$-Hexane TPD spectra from sulfur-modified Pt(111) 98

4.15 Hydrogen TPD spectra corresponding to the decomposition of n-hexane

4.16 Hydrogen TPD spectra corresponding to the decomposition of cyclic compounds

4.17 Hydrogen TPD spectra corresponding to the decomposition of methylcyclopentane on $\mathrm{Pt} / \operatorname{Re}(0001) \quad 104$

$\begin{array}{ll}\text { 4.18 The removal of sulfur from } \mathrm{Pt}(111) & 107\end{array}$

4.19 The activation energy plots for the process of sulfur removal in hydrogen and n-hexane

5.1 Decomposition sequence of aluminum hydroxide

5.2 Change of AES signal of aluminum foil as a function of oxidation time

$\begin{array}{lll}\text { 5.3 Auger spectra of } \mathrm{Pt} / \mathrm{AlO} \text { x Figure } & 119\end{array}$

5.4 Change of $\mathrm{Pt}$ coverage on $\mathrm{AlO}_{x}$ upon heating 121

5.5 Arrhenius plets for 1-butene isomerization 123

$\begin{array}{ll}5.6 \text { Conversion of 1-butene over } \mathrm{Pt} / \mathrm{AlO}_{\mathrm{x}} & 124\end{array}$ 


\section{List of Tables}

1.1 Composition of the feed and product of a reforming reaction $\quad 7$

$\begin{array}{lll}1.2 & \text { Octane numbers of pure hydrocarbons } & 7\end{array}$

1.3 Thermodynamic data on reactions of C6 hyärocarbons 8

$2.1 \quad$ Reagents used 44

4.1 Rate of $\mathrm{n}$-hexane conversion over the $\mathrm{S} / \mathrm{Re} / \mathrm{Pt}(111)$ surfaces 81

4.2 Rate of cyclohexane conversion over the $\mathrm{S} / \mathrm{Re} / \mathrm{Pt}(111)$ surfaces 90

4.3 Rate of methylcyclopentane conversion over the $\mathrm{Pt} / \operatorname{Re}(0001)$ surfaces $\quad 93$

5.1 Hexane isomerization on catalyst mixtures 114 


\section{Acknowledgements}

I would like to thank my advisor, Gabor Somorjai, for his advice, s'upport, and patience. The research freedom I had while I was working with him made me confused at first but it was a great opportunity to build scientific way of thinking. I also would like to thank Miquel Salmeron for his kind instructions in every subject and Ian Brown for teaching me how to make and use the plasma deposition source.

I would thank to all of the Somorjai group members for their help, discussion, and friendship. I would especially like to thank Michael Quinlan, David Ginter, Fabio Riebeiro, and Colin Stanners for proof-reading this thesis.

This thesis work could not have been accomplished without excellent support of the electronic, machine, and ceramic shop at the Lawrence Berkeley Laboratory.

Finally, I would like to thank my family. My wife, Sunah, encouraged and helped me at difficult times with great patience. Special thanks to my son, Jahyung, whose sweet and cute smile always gave me refreshment.

This work was supported by the Director, Office of Energy Research, Office of Basic Energy Sciences, Materials Sciences Division, of the U. S. Department of Energy under Contract No. DE-AC03-76SF00098. 


\section{CHAPTER 1}

\section{Introduction}

\subsection{Surface Science Studies of Heterogeneous Catalysis}

Heterogeneous catalysis is of centra' importance in the chemical industry. Advances in catalysis science have led the progress of the chemical industry since the introduction of ammonia oxidation on platinum (Ostwald), olefin hydrogenation on nickel (Sabatier), and ammonia synthesis on iron (Haber and Mittasch) in the early twentith century [1]. The development of the surface science techniques during the last 20 years accelerated fundamental studies of catalytic processes. The development of electron spectroscopies used in surface science studies made it possible to study the atomic structure of metal surfaces, surface composition, and adsorption and desorption process which control heterogeneous catalysis [2]. This has shifted the major research in heterogeneous catalysis from the chemical kinetics and mechanism studies to the direct investigation of surface components on the molecular level [3].

Surface science has evolved from the study of surface structure and surface-gas interaction in ultrahigh vacuum (UHV, $<10^{-9}$ Torr). Catalytic 
reactions, on the other hand, take place in very high pressure range $\left(10^{3}-10^{5}\right.$ Torr). The development of the UHV system equipped with an internal or an external high pressure reactor bridged the gap between UHV and highpressure reaction [4]. The instrumentation of combined UHV/high-pressure reactor systems has been extensively reviewed [5].

For UHV/high-pressure reaction studies, single crystal catalysts are generally used. Single crystal catalysts have about $1 \mathrm{~cm}^{2}$ surface area and they have very uniform surface structure and composition. These model catalysts are easily fabricated by cutting the single crystal by different angles They can be also easily modified by depositing second or third materials on the catalyst surfaces. These surfar's can be characterized by modern surface science techniques. By performing the reactions over catalysts of known surface structure and composition, the effect of surface structure and composition on catalytic reactions can be studied on the molecular level.

Figure 1.1 shows the results of an excellent catalytic reaction study which was performed using single crystal catalysts [6]. Figure 1.1 (a) is the rate of ammonia synthesis over different faces of iron single crystals. The schematic of the five iron crystal surfaces are shown in Figure 1.1 (b). The numbers on iron atoms in Figure 1.1 (b) indicate the coordination number (the number of the nearest neighbors) for each surface atoms. From the result, it was suggested that $C_{7}$ coordination sites were responsible for high activity of $\mathrm{Fe}(111)$ toward the ammonia synthesis. That argument was supported by theoretical work [7] which showed that highly coordinated metal atoms experience the largest electronic charge fluctuations within the solid resulting in the greatest catalytic activity. 
(a)

(b)
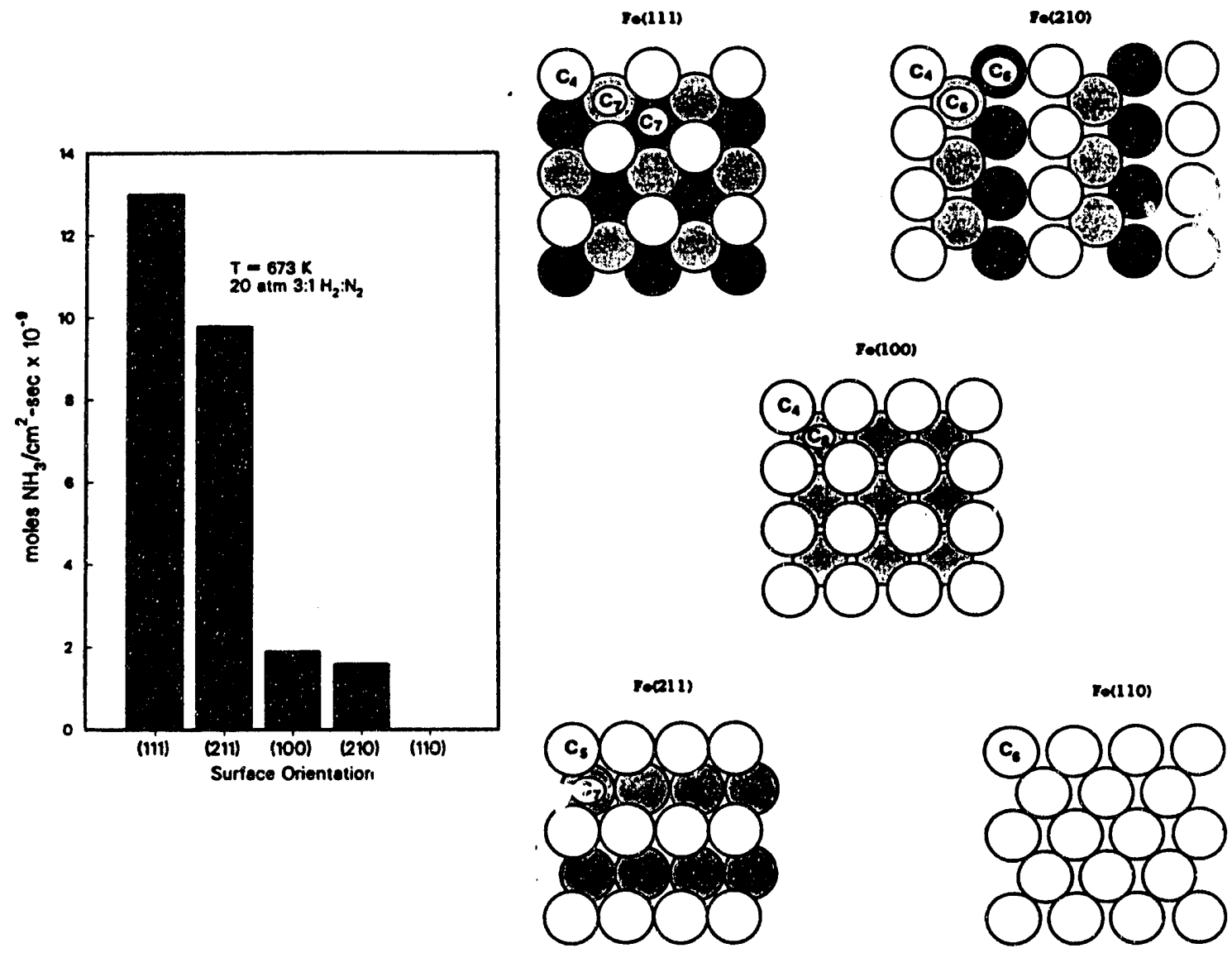

Figure 1.1 (a) The rate of ammonia synthesis over the five surfaces of iron single crystals. (b) Schematic representations of the five iron single crystal surfaces. The coordination number for each surface atom is indicated (from ref. [6]). 
The small surface area model catalysts were compared with dispersed high surface area catalysts in the same reaction under identical experimental conditions. The same turnover rates, product distributions, and activation energies were obtained for the hydrogenation of benzene over platinum [8] and for carbon monoxide hydrogenation over rhodium [9]. Goodman and Rodriguez recently reviewed the catalytic studies which utilized UFIV/high pressure reactior system [10].

\subsection{Refining Process and Reforming Reaction}

The refining process refines and separates the crude oil which is the mixture of enormous number of different chemical species. Crude oils are composed of hydrocarbons and inorganic compounds. Hydrocarbons in the crude oil range from methane to very large molecules that contain more than sixty carbon atoms. These hydrocarbons often contain heteroatoms such as sulfur, nitrogen, or oxygen. Other inorganic components include nickel, vanadium, and sodium. The complex mixture is separated by atmospheric and vacuum distillation. Distillation products undergo further separations and catalytic reactions to produce LPG, naphtha, gasoline, kerosene, jet fuel, diesel oil, lube oil, grease, wax, and asphalt. Figure 1.2 shows a simplified refinery flow diagram.

Catalytic reforming produces gasoline from naphtha and is a key process in petroleum refining. In reforming, the naphtha fraction of crude oil distillates, including those formed from larger hydrocarbons by cracking, are 

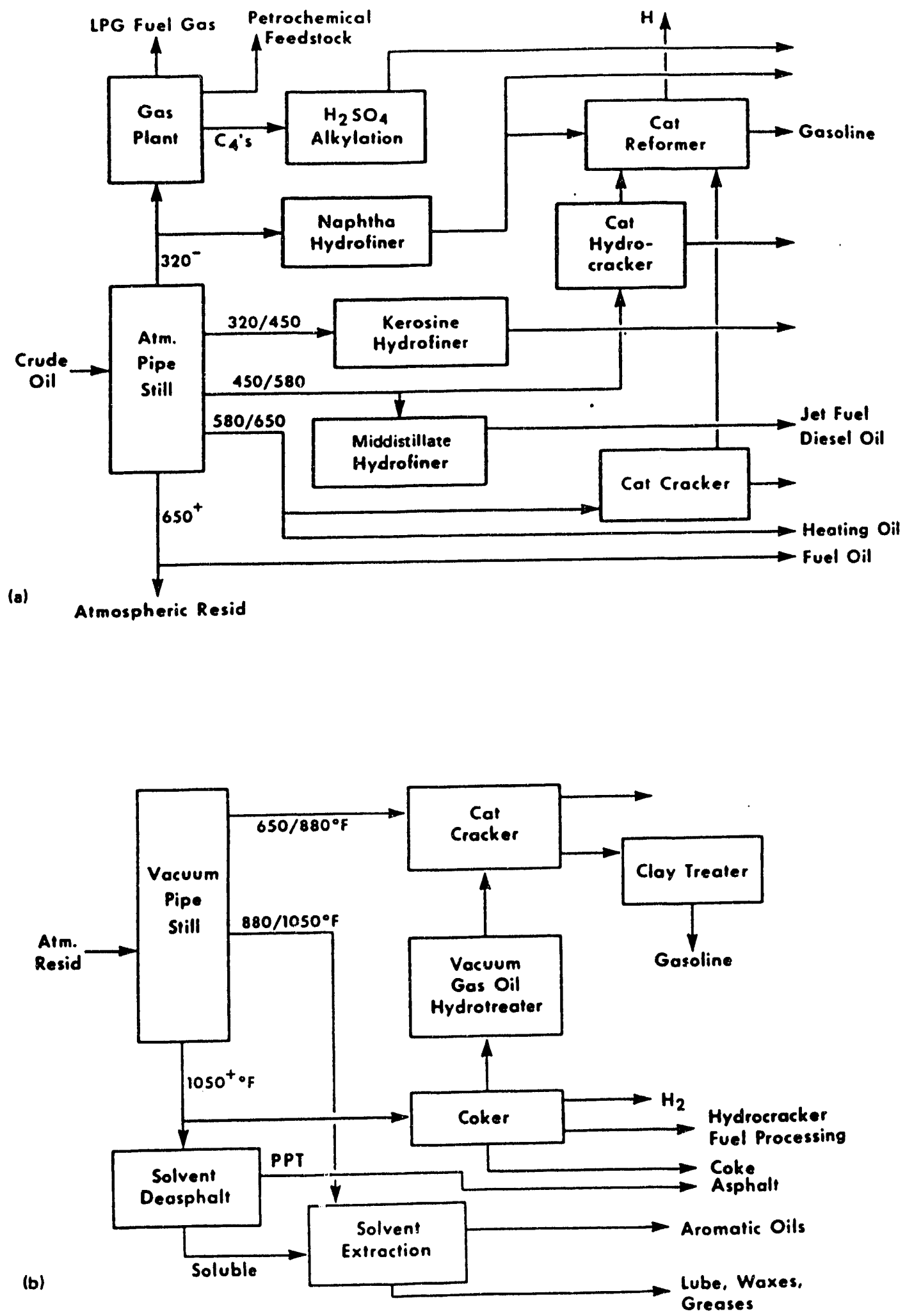

Figure 1.2 Refining flow diagram (from ref. [11]). 
reformed without changing the carbon numbers in a molecule [12]. The typical composition of the feed and product of the reforming process is given in Table 1.1.

The octane number indicates the anti-knocking property of a gasoline. The octane number of iso-octane is 100 and that of $n$-heptane is 0 by definition. The octane number of a gasoline is determined by comparing its anti-knocking engine performance with mixtures of $n$-heptane and iso-octane; the octane number 94 of a gasoline means its anti-knocking property is the same as the anti-knocking property of $n$-heptane and iso-octane mixture with $94 \%$ of isooctane. Octane numbers of representative hydrocarbons in the gasoline range are given in Table 1.2

The major reactions of the reforming process are dehydrogenation, dehydrocyclization, cyclization, isomerization, and hydrogenolysis as shown in Figure 1.3. The thermodynamic data on these reactions for $\mathrm{C}_{6}$ hydrocarbons are given in Table 1.3. Dehydrogenation of cyclohexane is a very fast reaction and isomerization is rather slow. Dehydrocyclization is the most important reaction from the view point of improving octane numbers. Hydrogenolysis or hydrocracking is the most undesirable reaction because it produces gaseous products.

The typical catalyst temperature is $460-525^{\circ} \mathrm{C}$ and the reaction pressure ranges from 8.5 to $50 \mathrm{~atm}$. Hydrogen to hydrocarbon ratios vary from 5 to 10 . 


\section{Chapter 1. INTRODUCTION 7}

Table 1.1 Typical composition of the feed and product of a reforming reaction.

\begin{tabular}{lcc}
\hline & Feed & Reformer Product \\
\hline Carbon numbers & $\mathrm{C}_{5}-\mathrm{C}_{11}$ & $\mathrm{C}_{5}-\mathrm{C}_{11}$ \\
Boiling range & $50-250^{\circ} \mathrm{C}$ & $50-250^{\circ} \mathrm{C}$ \\
Paraffins, vol \% & 58 & 53 \\
Olefins, vol \% & $<1$ & - \\
Naphthenes, vol \% & 28 & 2 \\
Aromatics, vol \% & 14 & 45 \\
Octane numbers & - & 94 \\
\hline
\end{tabular}

Table 1.2 Octane numbers of pure hydrocarbons (from ref. [12]).

\begin{tabular}{lc}
\hline Hydrocarbon & Research Octane Number \\
\hline Paraffins: & \\
n-Pentane & 62 \\
n-Hexane & 19 \\
n-Heptane & 0 \\
2-Methylpentane & 73 \\
2,2,4-Trimethylpentane & 100 \\
Naphthenes (cycloparaffins): & \\
Methylcyclopentane & 96 \\
Cyclohexane & 110 \\
Aromatics: & \\
Benzene & 99 \\
Toluene & 124 \\
\hline
\end{tabular}




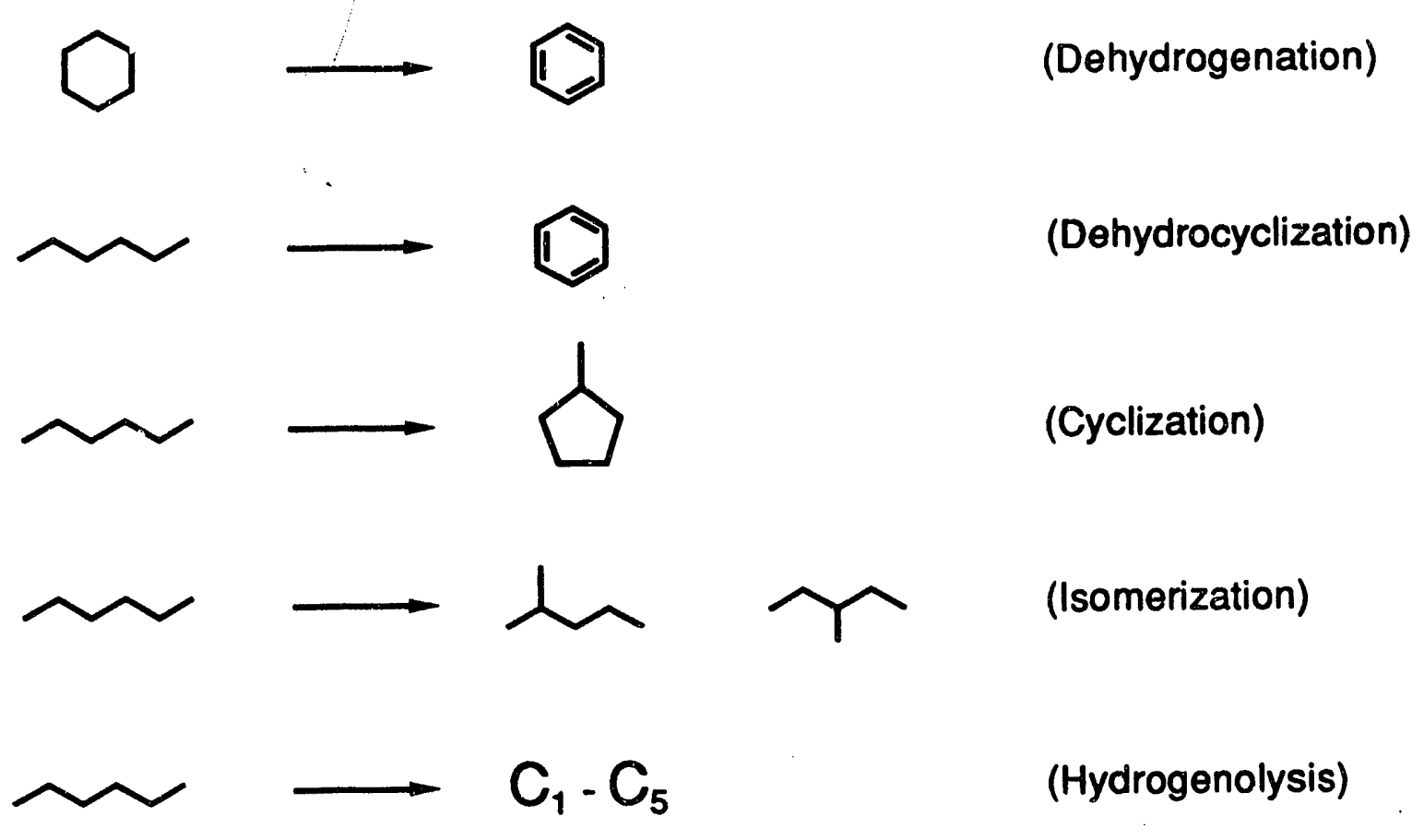

Figure 1.3 Reforming reactions of $\mathrm{C}_{6}$ hydrocrabons.

Table 1.3 Thermodynamic data on reactions of $\mathrm{C}_{6}$ hydrocarbons (from ref. [13]).

\begin{tabular}{lcc}
\hline \multicolumn{1}{c}{ Reaction } & $K($ at $773 \mathrm{~K})$ & $\Delta \mathrm{H}_{\mathrm{R}}(\mathrm{kcal} /$ mole $)$ \\
\hline Cyclohexane $\rightarrow$ Benzene $+3 \mathrm{H}_{2}$ & $6 \times 10^{5}$ & 52.9 \\
Methylcyclopentane $\rightarrow$ Cyclohexane & 0.086 & -3.8 \\
n-Hexane $\rightarrow$ Benzene $+4 \mathrm{H}_{2}$ & $0.78 \times 10^{5}$ & 63.6 \\
n-Hexane $\rightarrow$ 2-Methylpentane & 1.1 & -1.4 \\
n-Hexane $\rightarrow$ 3-Methylpentane & 0.76 & -1.1 \\
n-Hexane $\rightarrow$ 1-Hexene $+\mathrm{H}_{2}$ & 0.037 & 31.1 \\
\hline
\end{tabular}




\subsection{Reforming Catalysts}

The first reforming catalyst was developed by Standard Oil Co. in 1939 [14]. The catalyst was composed of $9 \%$ molybdenum oxide supported on activated alumina granules or pellets. However, the molybdenum oxide catalyst was not very practical because it deactivated so quickly. It was necessary to regenerate the catalyst every day.

In 1949, Universal Oil Products Co. Neveloped the first modern reforming catalyst using platinum supported on alumina [15]. The development of the platinum based reforming catalyst was one of the most important breakthroughs in the history of catalyst development [16] and the reforming process is still called platforming.

A major innovation was made by Chevron in 1967 by adding rhenium to $\mathrm{Pt} / \mathrm{Al}_{2} \mathrm{O}_{3}$ system [17]. The presence of $\mathrm{Re}$ in the bimetallic catalyst significantly enhanced the stability and reactivity of the catalyst. Since then, many bimetallic reforming catalysts have been studied and developed including Pt-Ir [18], Pt-Sn [19], Pt-Rh [20], Pt-Ni [21], Pt-Te/Se [22], Pt-Au [23], Pt$\mathrm{Cu}[24]$, and Pt-Fe [25].

Since the introduction of the Pt-Re bimetallic reforming catalyst, many ideas have been proposed to explain the superior performance of the bimetallic catalyst. When he first developed the Pt-Re catalyst, Kluksdahl proposed that Re prevents the sintering of the metal catalysts: Rhenium impedes loss of active metal surface area by forming Pt-Re alloy particles having higher melting points [17]. Kuznetsov and Yermakov proposed that Re slowed down sintering by anchoring small $\mathrm{Pt}$ particles to Re cations 
strongly bound to the support surface [26]. Those ideas are generally accepted but resistance to sintering can explain only a part of the superior performance of the Pt-Re bimetallic catalyst.

The Pt-Re bimetallic catalysts show unique properties of naphtha reforming when they are combined with sulfur, and the reason for superior performance of the bimetallic catalyst has been explained with the connection with sulfur. Because of the high hydrogenolysis activity of $\mathrm{Re}$, the pure $\mathrm{Pt}-\mathrm{Re}$ alloy does not function as a naphtha reforming catalyst, and sulfiding of the catalyst is critical. The sulfiding process had been used in reforming catalysts to suppress the initial hydrogenolysis activity of fresh catalysts by poisoning the active hydrogenolysis sites. However, the role of sulfur in the Pt-Re catalysts is more than just poisoning the active sites for hydrogenolysis, as revealed by studies of the Pt-Re system in the presence of sulfur [27-31]. Shortly after his invention of the Pt-Re bimetallic reforming catalyst, Kluksdahl showed that sulfiding of the catalyst prior to reforming significantly decreased the deactivation rate of the Pt-Re catalyst [27]. Sachtler and co-workers proposed that sulfur divides the $\mathrm{Pt}-\mathrm{Re}$ surface into small $\mathrm{Pt}$ ensembles by forming stable Re-S bonds; these $\operatorname{ReS}_{x}$ species suppress the conversion of the carbonaceous species into harmful graphitic carbon layer, resulting in enhanced activity maintenance (ensemble size effect) [28, 29]. Hartog et al. [30] showed that sulfiding of the $\mathrm{Pt}-\mathrm{Re} / \mathrm{Al}_{2} \mathrm{O}_{3}$ catalysts increased the relative role of acid-catalyzed reactions. A "ligand effect" was proposed by Barbier and co-workers [31]; sulfur, as an electron acceptor, changes the electronic density of the unpoisoned metallic surface area, resulting in the change of the selectivity and reactivity of the catalysts. The independent role 
of rhenium was also proposed; rhenium, in the metallic $\left(\operatorname{Re}^{0}\right)$ or ionic $\left(\operatorname{Re}^{4+}\right)$ form, strongly catalyses a process that converts coke precursors to harmless compounds [32, 33].

\subsection{Dual Functional Properties of Reforming Catalysts}

Typical industrial reforming catalysts have metal components dispersed on $\gamma$ $\mathrm{Al}_{2} \mathrm{O}_{3}$. The surface area of $\gamma-\mathrm{Al}_{2} \mathrm{O}_{3}$ is about $200 \mathrm{~m}^{2} / \mathrm{g}$ and about 0.3 to $0.6 \%$ (by weight) of $\mathrm{Pt}$ is used to make a supported reforming catalyst. In general, supported catalysts are made by impregnating a metal salt with aluminum oxide. The metal/alumina complex is dried, oxidized and reduced to give a final product. The metal crystallite size is controlleled by calcination and reduction processes [34] and the performance of the catalyst is greatly affected by those processes.

The surface of the alumina support used in reforming catalysts has acidic property [35]. The alumina surface shows the affinity for basic molecules such as ammonia, trimethylamine, n-butylamine, pyridine and quinoline [36]. It was also shown that pure alumina catalyzed the conversion

of 1-butene to iso-butenes [37]. Olefin isomerization proceeds through a carbonium ion intermediate and is considered a typical acid-catalyzed reaction. 


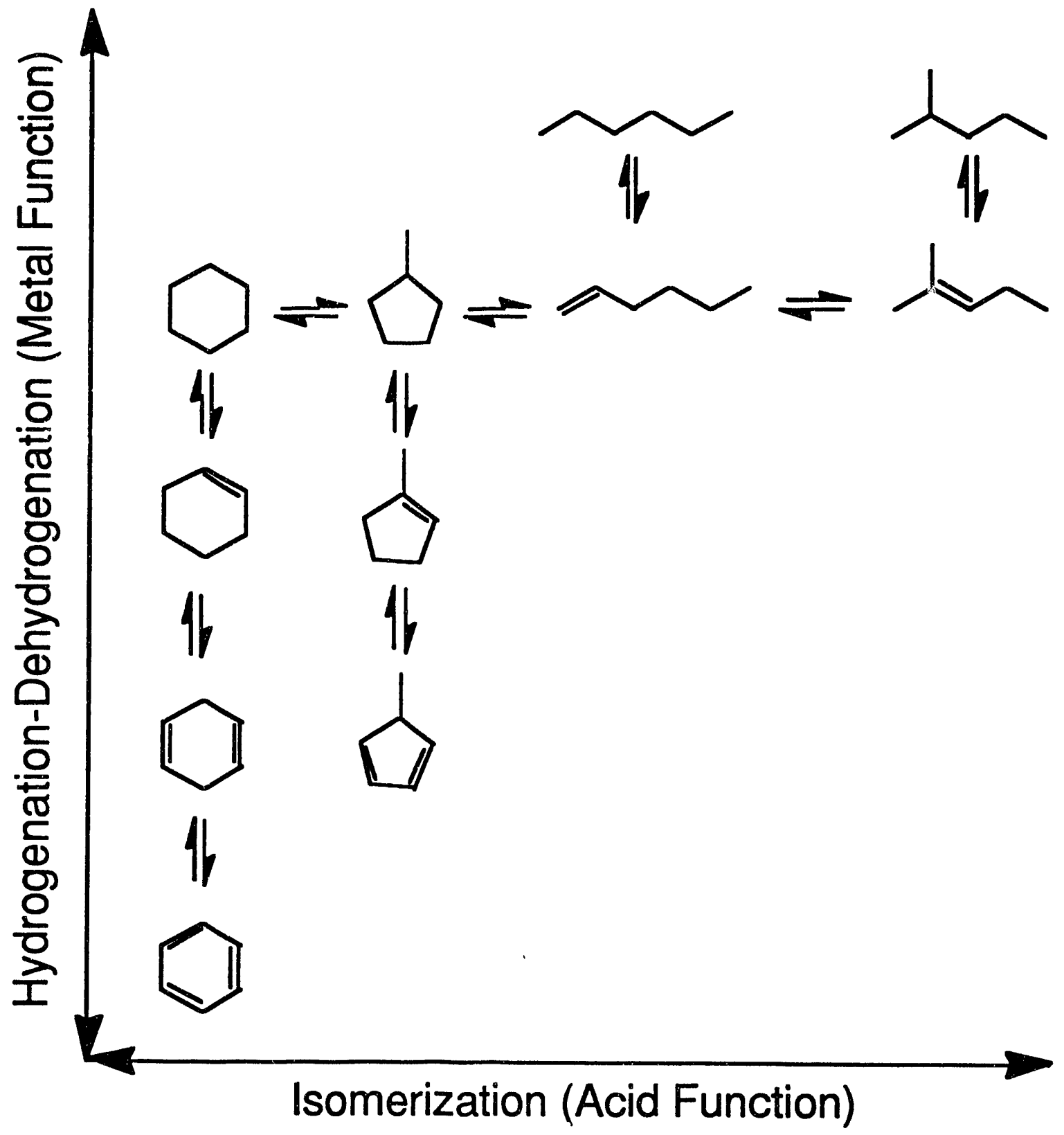

Figure 1.4 Dual functional property of the reforming catalyst (from ref. [39]). Vertical reactions take place on the metal part of the catalyst and horizontal reactions take place on alumina. 
Because of its acidic property, alumina support is not only a catalyst carrier but a catalyst itself. For this reason reforming catalyst have been called dual functional or bifunctional [38]. Figure 1.4 shows dual functionality of reforming catalysts for the conversion of $n$-hexane to benzene. The scheme was first proposed by Mills and coworkers [39]. In the scheme, vertical paths are hydrogenation-dehydrogenation reactions and horizontal paths are isomerization reactions. Hydrogenation-dehydrogenation reactions take place on the metallic sites and isomerization reactions are catalyzed by acidic sites. However, there is not much experimental evidence for the dual functionality of the reforming catalyst.

\subsection{General Overview of This Thesis Work}

The objective of this thesis work is to better understand the Pt-Re bimetallic reforming catalyst. Single crystal model catalysts have been used for this study. Model catalysts have been prepared either by depositing $\operatorname{Re}$ on $\mathrm{Pt}(111)$ or by depositing $\mathrm{Pt}$ on $\operatorname{Re}(0001)$. Other components, sulfur and alumina, have been added one by one. This approach makes it possible to utilize modern surface science techniques to investigate the catalyst surfaces and to study the catalytic function of each component of the complicated reforming catalyst.

Chapter 2 describes the experimental apparatus and experimental techniques employed in this study. Chapter 3 describes a newly developed plasma deposition source which has been used to deposit metals to fabricate Pt-Re bimetallic surfaces. Chapter 4 discusses hydrocarbon conversion 
reactions over the Pt-Re bimetallic catalysts surfaces coadsorbed with sulfur. Chapter 5 discusses the preparation of planar $\mathrm{AlO}_{\mathrm{x}}$ catalysts and the conversion of 1-butene over $\mathrm{Pt} / \mathrm{AlO}_{\mathrm{x}}$ model catalysts.

\section{References}

[1] B.H. Davis and W.P. Hettinger, Jr., "Heterogeneous Catalysis: Selectied American Histories", ACS, Washington DC (1983).

[2] G.A. Somorjai, "Chemistry in Two Dimensions: Surfaces", Cornell Univ. Press, Itchaca, New York (1981).

[3] G.A. Somorjai, Science 227 (1985) 902.

[4] D.W. Blakeley, E. Kozak, B.A. Sexton, and G.A. Somorjai, J. Vac. Sci. Technol 13 (1976) 1091.

[5] C.T. Campbell, Adv. Catal. 36 (1989) 1.

[6] D.R. Strongin, J. Carrazza, S.R. Bare, and G.A. Somorjai, J. Catal. 103 (1987) 213.

[7] L. Falicov and G.A. Somorjai, Proc. Nat. Acad. Sci. USA 82 (1985) 2207.

[8] S.M. Davis and G.A. Somorjai, J. Catal. 65 (1980) 78.

[9] B.A. Sexton and G.A. Somorjai, J. Catal, 46 (1977) 167.

[10] J.A. Rodriguez and D.W. Goodman, Surface Science Reports 14 (1991) 1.

[11] J. H. Gary and G.E. Handwerk, "Petroleum Refining", Marcel Dekker, New York ().

[12] B.C. Gates, J.R, Katzer, and G.C.A. Schuit, "Chemistry of Catalytic Processes", McGraw-Hill, New York (1979) Chapter 3.

[13] J.H. Sinfelt, Advan. Chem. Engng. 5 (1964) 37.

[14] R.L. Davidson, Petroleum Processing (August, 1955) 1175. 
[15] V. Hansel, U.S. Patent 2,479,109 (1949).

[16] H. Heinemann, in J.R. Anderson and M. Boudard (eds.), "CatalysisScience and Technology" Vol 1 (1981) 1.

[17] H.E. Kluksdahl, U.S. Patent 3,415,787 (1968).

[18] J.H. Sinfelt, U.S. Patent 3,953,368 (1976).

[19] R. Burch and A.J. Mitchell, Applied Catalysis 6 (1983) 121.

[20] T.C. Wong, L.C. Chang, G.L. Haller, J.A. Oliver, N.R. Scaife, and C. Kemball, J. Catal. 87 (1984) 389.

[21] J. Assardier and J.C. Bertolini, J. Catal. 90 (1984) 358.

[2] K.M. Dooley and B.L. Price, J. Catal., 116 (1989) 325.

[23] J.W.A. Sachtler and G.A. Somorjai, J. Catal. 89 (1984) 35.

[24] R.C. Yeates and G.A. Somorjai, Surf. Sci. 34 (1983) 729.

[25] Y.X. Li and K.J. Klabunde, New J. Chem. 12 (1988) 691.

[26] Kuznetsov and Yermakov

[27] H.E. Kluksdahl, U.S. Patent 3,617,520 (1971).

[28] P. Biloen, J.N. Helle, H. Verbeek, F.M. Dautzenberg, and W.M.H. Sachtler, J. Catal. 63 (1980) 112.

[29] W.M.H. Sachtler, J. Mol. Catal. 63 (1984) 112.

[30] A.J. den Hartog, P.J.M. Botman, C. de Vreugd, and V. Ponec, Langmuir 4 (1988) 1100.

[31] J. Barbier, E. Lamy-Pitara, P.Marecot, J.P. Boitiaux, J. Cosyns, and F. Verna, Adv. Catal. 37 (1990) 279.

[32] M.F.L. Johnson and V.M. LeRoy, J. Catal. 35 (1974) 434.

[33] R.J. Betolacinni and R.J. Pellet, "Catalyst Deactivation", Elsevier, Amsterdam, the Netherlands (1980). 
[34] M. Guenin, M. Breysse, and R. Frety, J. Molec. Catal. 15 (1984) 119.

[35] J.H. Sinfelt in J.R. Anderson and M. Boudard (eds.), "Catalysis-Science and Technology", Vol 1 (1981) 257

[36] A.G. Oblad, T.H. Milliken, and G.A. Mills, Advan Catal. 3 (1951) 199.

[37] J.W. Hightower and W.K. Hall, J. Phys. Chem. 71 (1967) 1014.

[38] F.G. Ciapetta and D.N. Wallace, Catal. Rev. 5 (1971) 67.

[39 G.A. Mills, H. Heinemann, T.H. Milliken, and A.G. Oblad, Ind. Engng. Chem. 45 (1953) 134. 


\section{CHAPTER 2}

\section{Experimental}

\subsection{Equipment}

\subsubsection{Ultrahigh Vacuum System}

All of the experiments described in this thesis were conducted in a combined ultrahigh vacuum/ high pressure reactor system. This system was designed for both surface science studies in ultrahigh vacuum and catalytic reaction studies in high pressure [1]. The schematic diagram of the system is shown in Figure 2.1.

The UHV chamber was equipped with the following:

- A nude ion gauge (Varian 971-5008) for monitoring the chamber pressure.

- An ion gun (Phi 4-161) for sample cleaning with argon ion sputtering.

- A quadrupole mass spectrometer (UTI 100C) for residual gas analysis and temperature programmed desorption experiment.

- An electron gun (Varian 954-5012) for Auger electron spectroscopy.

- An off-axis electron gun (Varian 981-2125) for low energy electron diffraction. 
- Four grid electron optics for Auger electron spectroscopy and low energy electron diffraction.

- Two leak valves (Varian 951-5106) for dosing gases.

- A plasma deposition source for the deposition of metals.

- An electrochemical sulfur source for the deposition of sulfur.

- Internal isolation cell (high pressure cell) for catalytic reaction studies.

The stainless steel ultrahigh vacuum (UHV) chamber was pumped with a liquid nitrogen trapped diffusion pump (Varian VHS-6). After "bakeout" for 24 hours at $100^{\circ} \mathrm{C}$, the system attained a normal operating pressure of $1 \times 10^{-9}$ Torr.

\subsubsection{Sample Manipulator and Sample Mounting.}

The single crystal sample used in this work was mounted on a rotatable manipulator. The mounting is shown schematically in Fig. 2.2. Platinum and r henium single crystal samples were spot welded to platinum wires ( 0.5 $\mathrm{mm}$ ) which were then spot welded to gold support rods $(1.0 \mathrm{~mm})$. Aluminum foil samples were spot welded directly to gold rods. Both gold rods were mechanically clamped to copper heating tubes mounted on ceramic feedthroughs. Samples mounted on this manipulator were resistively heated by DC current. Samples could be heated easily up to their annealing temperatures; $1300 \mathrm{~K}$ for $\mathrm{Pt}, 1600 \mathrm{~K}$ for $\mathrm{Re}$, and $800 \mathrm{~K}$ for $\mathrm{Al}$. Whenever the sample was annealed, a flow of nitrogen gas was passed through Teflon tubes which ran into copper heating tubes to cool the manipulator. 


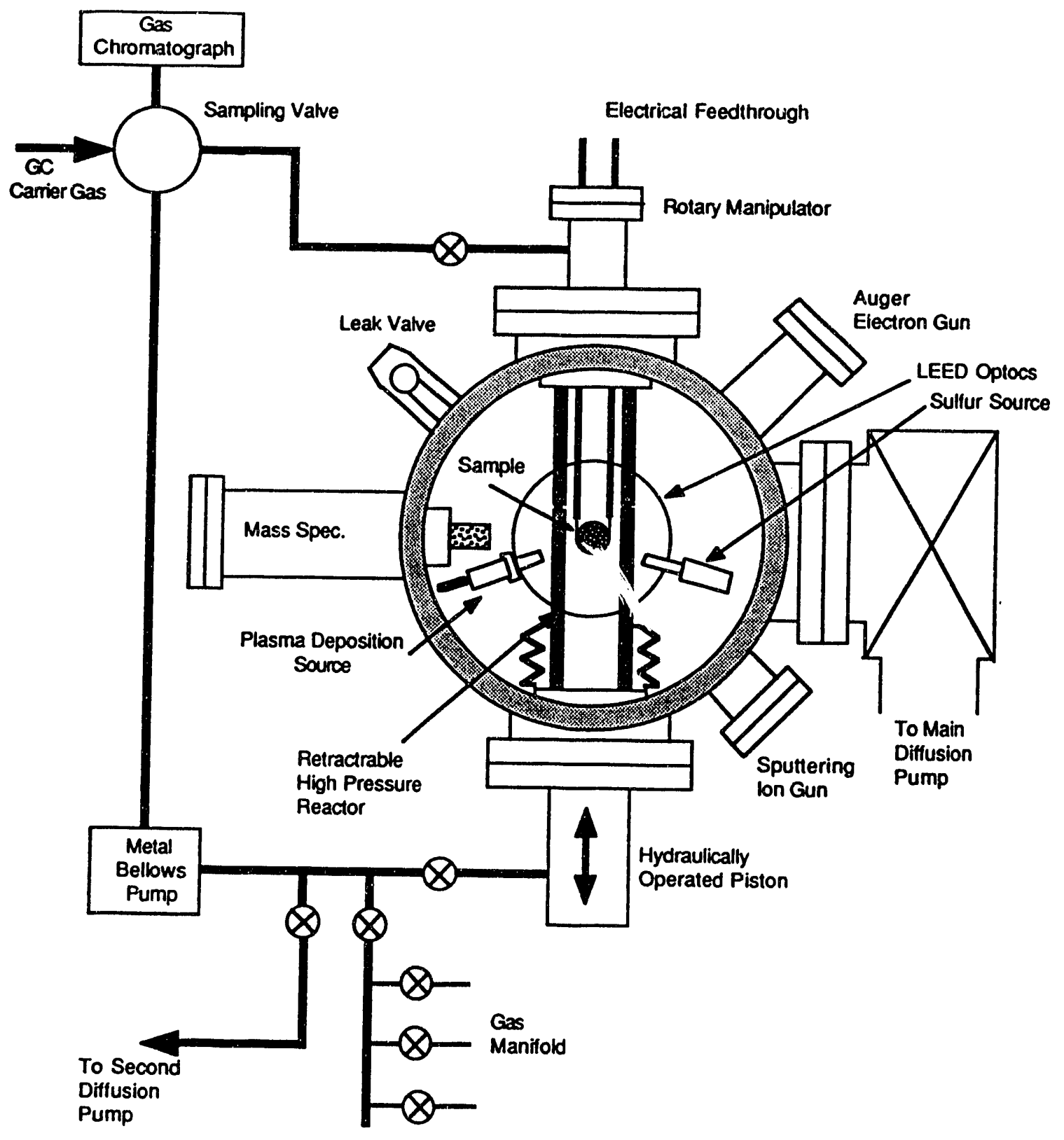

Figure 2.1 Schematic diagram of an ultrahgh vacuum/high pressure reactor system. 
Chapter 2. EXPERIMENTAL 20

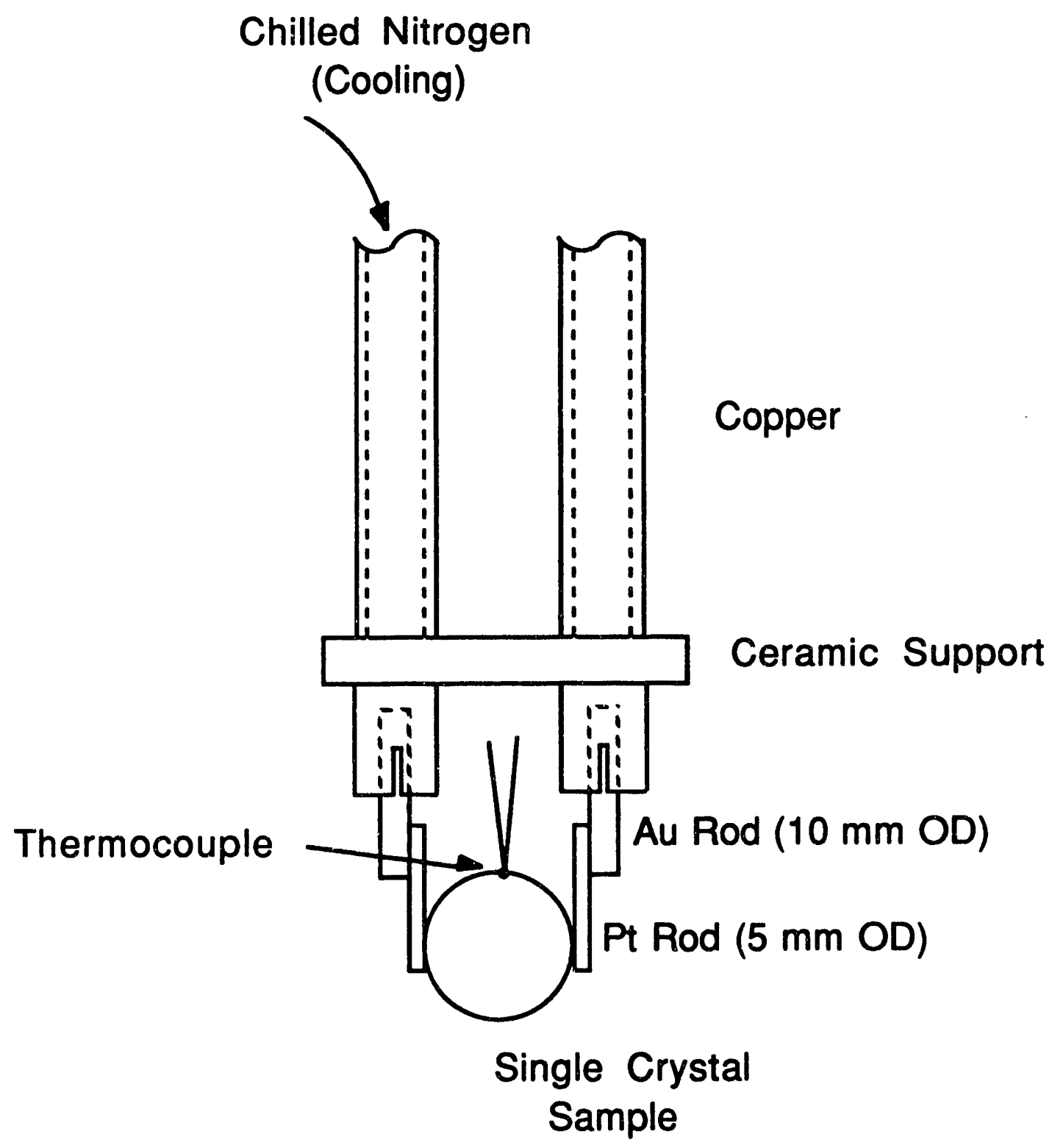

Figure 2.2 Schematic diagram of a manipulator and sample mounting. 
Liquid nitrogen-chilled nitrogen was also used to cool the sample to less than $100 \mathrm{~K}$ for temperature programmed desorption experiments.

The temperature of the sample was measured using either a platinumplatinum/10 \% rhodium thermocouple (S-type) or a chromel-alumel thermocouple (K-type) which was spot-welded to the edge of the sample.

\subsubsection{Catalytic Reactor System}

The UHV system used in this work was equipped with an internal isolation cell which was used as a batch reactor (Figure 2.1). The high pressure cell (internal isolation cell) is made of two pieces of 1 inch stainless steel tube. The inner walls of the tubes are gold-plated to minimize the possible reactivity of stainless steel. The high pressure cell is closed by lifting the lower tube mounted on a hydraulically operated piston. When it is closed, it isolates the sample from the UHV environment for the reaction at high pressure. This way, the sample, which is prepared and characterized in UHV, can be transferred into a reactor without being contaminated by external gases. Sealing of the cell is made by pressing knifed-edge $d$ tubes against a copper gasket with about 2000 psi of pressure. The copper gasket could be used for more than 100 closing and opening cycles without significant leaking. The pressure of the UHV chamber was maintained at less than $1 \times 10^{-8}$ Torr when the cell was pressurized to 200 Torr.

The high pressure cell is connected to the reaction loop through two Nupro valves. The reaction loop is made of $1 / 4$ inch stainless steel tubing. When the high pressure cell is closed, the cell and the reaction loop constitute a batch reactor whose total volume is $290 \mathrm{~cm}^{3}$. The micro reactor system is 
equipped with a circulation pump (Metal Bellows Corp., MB-21), two pressure gauges for the pressure ranges of $0-760$ Torr and $0-8 \mathrm{~atm}$, a six-port sampling valve with a sampling loop of $0.5 \mathrm{~cm}^{3}$, and a gas manifold for introducing reactants. The reaction loop is pumped by a liquid nitrogen trapped diffusion pump (Varian VHS-2) and a liquid nitrogen cooled sorption pump. The schematic diagram of a batch reactor system is shown in Figure 2.3.

\subsubsection{Reaction Product Separation and Analysis}

A gas chromatograph (Hewlett-Packard 5890) was used to monitor the product distribution during the reaction. Gas samples were injected to the column using a six-port gas sampling valve which was operated automatically. A PONA (HP 190915-001, Cross-Linked Methyl Silicone) capillary column (50 m $\times 0.2 \mathrm{~mm}$ od $\times 0.5 \mu \mathrm{m}$ film) was used to separate hydrocarbon products. This column was very effective in separating light hydrocarbons; most $C_{1}-C_{6}$ hydrocarbon compounds could be separated in 15 minutes. Figure 2.4 shows the chromatogram of a standard hydrocarbon sample separated by a PONA column. A flame ionization detector (FID) was used to detect separated hydrocarbons. The peaks of GC were calibrated using reported response factors [2] of a flame ionization detector.

\subsubsection{Pulsed Metal Plasma Deposition Source}

A pulsed metal vapor plasma deposition source was used to deposit metals including platinum, rhenium and aluminum. The principle and operation of the source is described in detail in Chapter 3. 
Chapter 2. EXPERIMENTAL 23

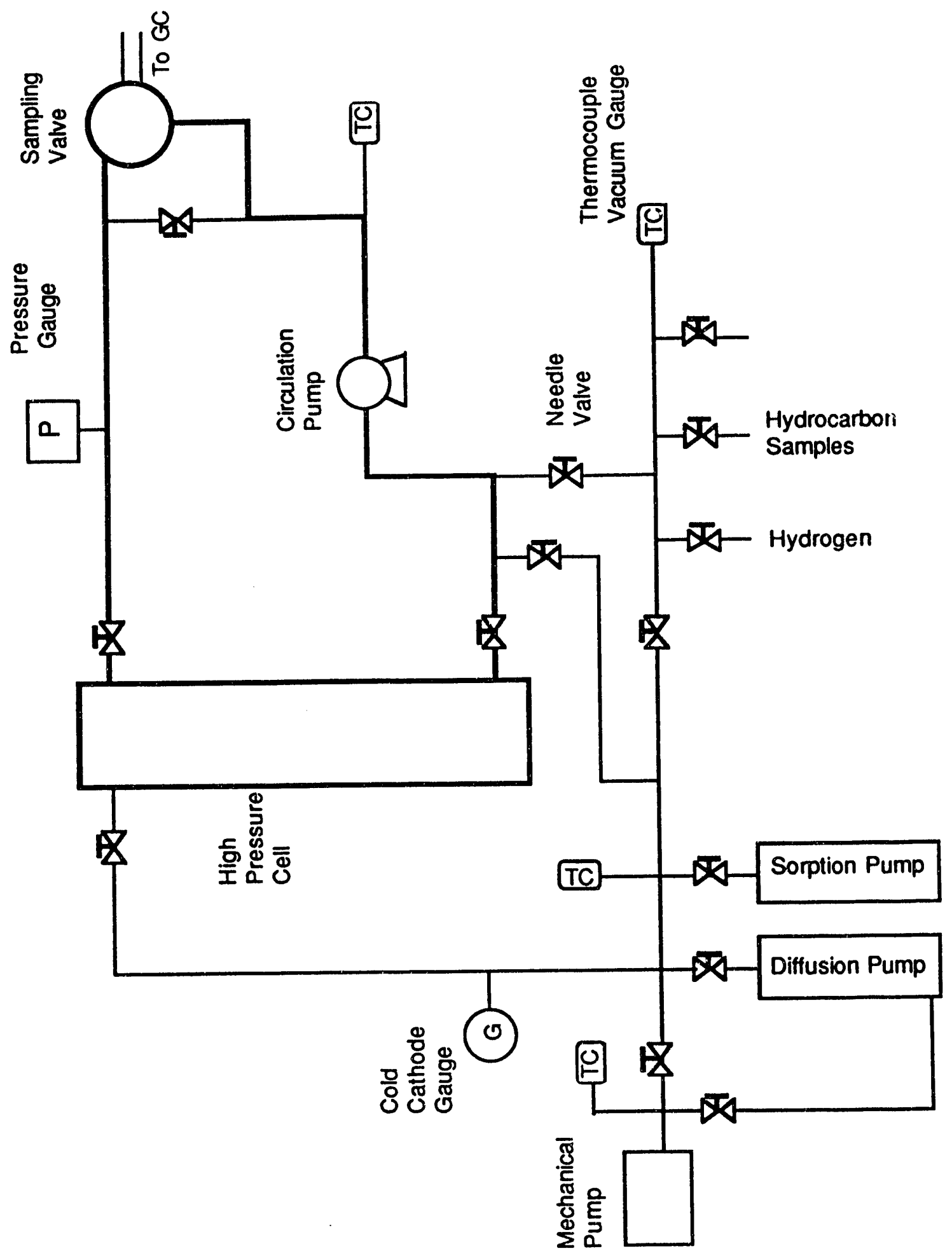

Figure 2.3 Schematic diagram of a bath reactor system. 
Column: PONA

(Cross-Linked Methyl Silicone) $50 \mathrm{~m} \times 0.2 \mathrm{~mm} \times 0.5 \mu \mathrm{m}$ film

Carrier: Helium

Oven: $\quad 50^{\circ} \mathrm{C}$

Injection: Split 200:1, 10 $\mathrm{L}$

Detector: FID

1. n-Pentane

2. 2,2-Dimethylbutane

3. 2,3-Dimethylbutane

4. 2-Methylpentane

5. 3-Methylpentane

6. n-Heaxne

7. t-2-Hexene

8. c-2-Hexene

9. Methylcyclopentane

10. 1-Methylcyclopentene

11. Benzene

12. Cyclohexane

$\underset{1}{L}$

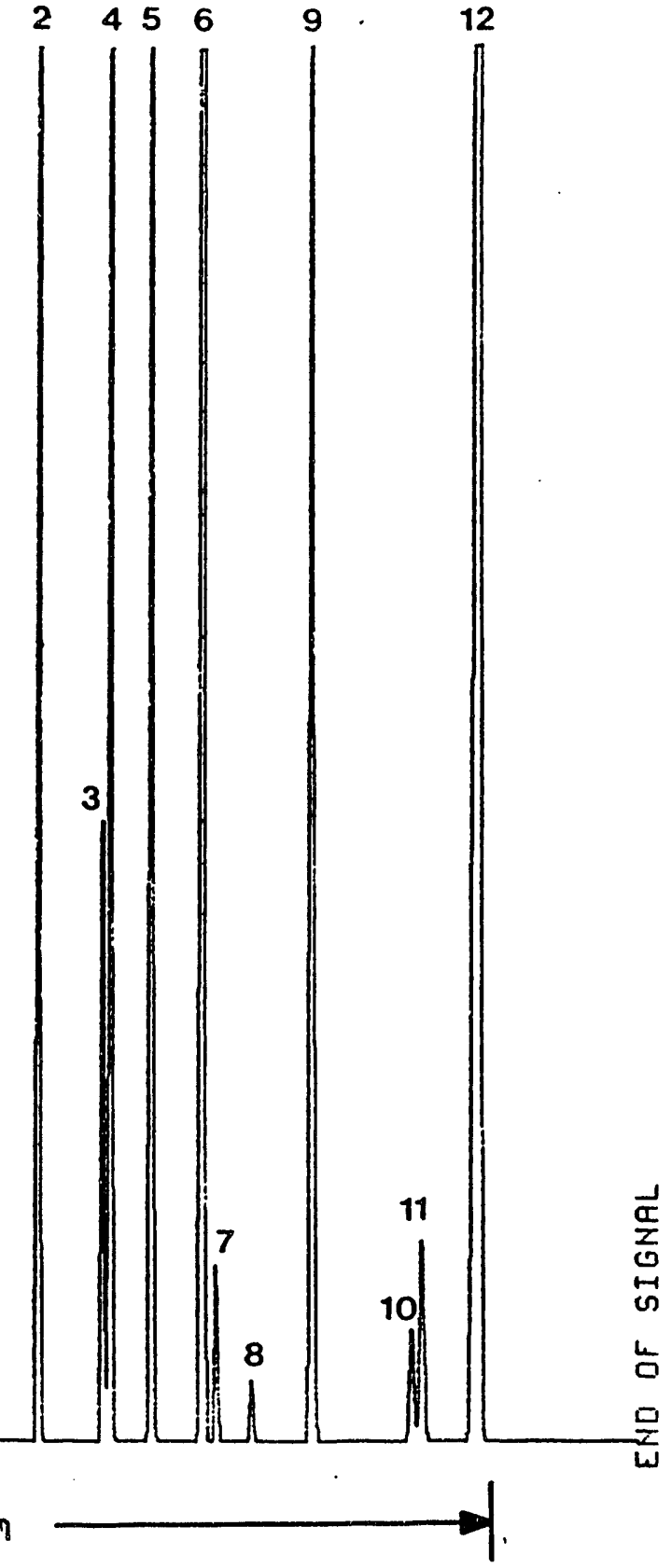

Figure 2.4 Gas chromatogram of a light hydrocarbon standard. 


\subsubsection{Electrochemical Sulfur Source}

Sulfur was deposited onto metal substrate using an electrochemical sulfur source [3]. A schematic diagram of the sulfur source is shown in Fig. 2.5. By applying a potential, silver sulfide is decomposed into sulfur and Ag. Produced sulfur is ejected from the source to the sample by diffusion. Mass spectrometer data indicated that most of sulfur produced from the source had a dimeric form. The half cell reactions are

$$
\begin{array}{ll}
\text { (Anode) } & \mathrm{Ag}_{2} \mathrm{~S} \longrightarrow 2 \mathrm{Ag}^{+}+\frac{1}{2} \mathrm{~S}_{2}+2 \mathrm{e}^{-} \\
\text {(Cathode) } & 2 \mathrm{Ag}^{+}+2 \mathrm{e}^{-} \longrightarrow 2 \mathrm{Ag}
\end{array}
$$

and the overall cell reaction is

$$
\mathrm{Ag}_{2} \mathrm{~S} \longrightarrow 2 \mathrm{Ag}+\frac{1}{2} \mathrm{~S}_{2} \quad \mathrm{E}_{\text {cell }}=-0.197 \mathrm{~V}
$$

A potential of $0.2 \mathrm{~V}$ was applied across the cell to induce the cell reaction. The cell was heated to a temperature of $\sim 150^{\circ} \mathrm{C}$ to increase the conductivity of the solid AgI electrolyte. 


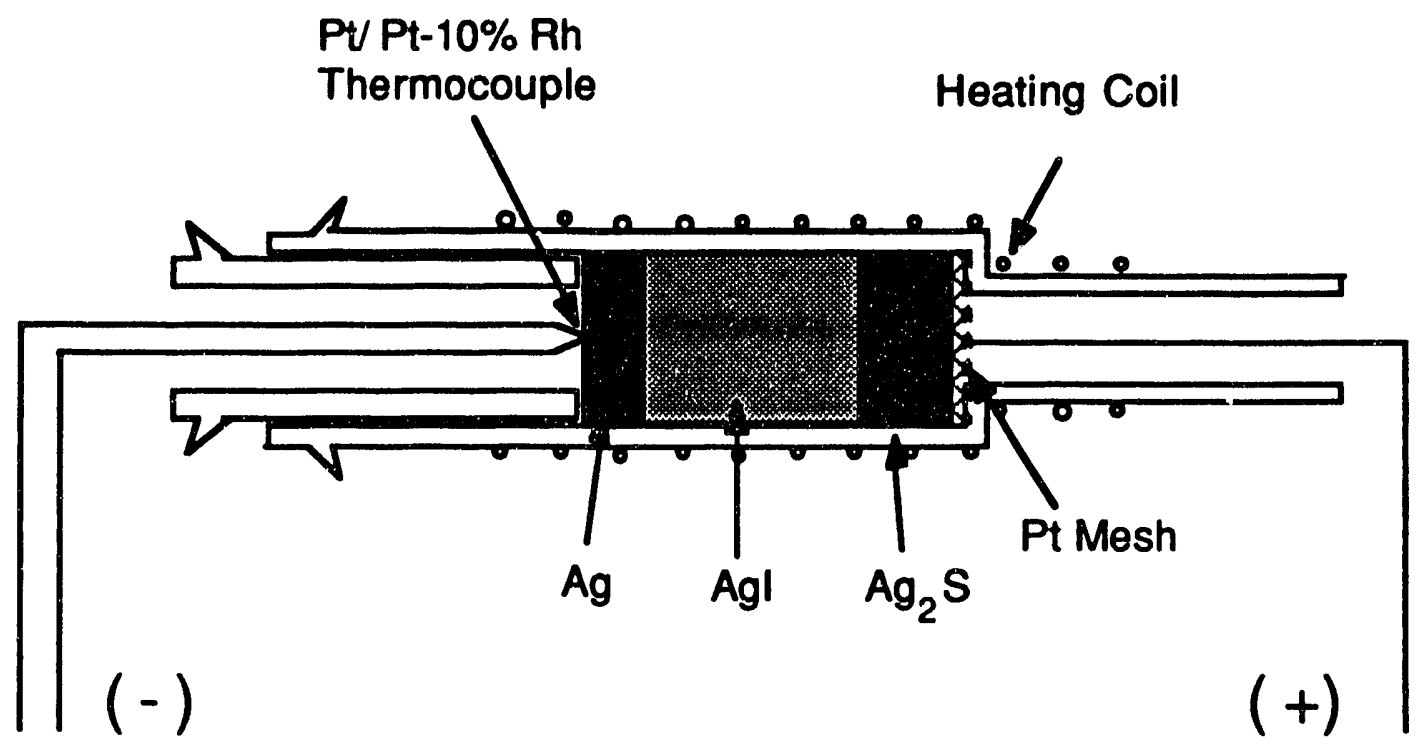

Figure 2.5 Schematic diagram of an electrochemical sulfur source. 


\subsection{Surface Analysis Methods}

Many analytical techniques, which are surface sensitive, have been developed over the past 25 years $[4,5]$. Most of these techniques analyze the interaction between incident electrons of low energies $(20-1000 \mathrm{eV})$ and surface atoms to determine surface composition and structure. Electrons with energie; of 20$1000 \mathrm{eV}$ are ideal to investigate the surface of solids because their mean free path in the solid is less than $20 \AA$ (the order of a few interatomic spacing). Figure 2.6 shows the experimental results of the mean free path of electrons in solids; the curve indicating the mean free path of electrons as a function of electron energy is called a Universal Curve.

Auger electron spectroscopy (AES) and low energy electron diffraction (LEED) are the most extensively used experimental techniques in this work. For both techniques, the sample surface is bombarded by a monoenergetic electron beam. Low energy electron diffraction detects diffraction patterns of elastically diffracted electrons from the ordered surface, which gives the information of surface structure. Auger electron spectroscopy is used to investigate surface composition by detecting Auger electrons produced from the surface atoms by incident electrons. The two techniques are described in more detail in following sections.

\subsubsection{Auger Electron Spectroscopy}

Auger electron spectroscopy (AES) has become a routine tool in surface science for determining the elemental composition of the near surface region of materials [4]. In this work, AES was used to monitor the cleanness of the 
sample surface throughout the experiments. When second or third elements, such as $\mathrm{Pt}, \mathrm{Re}, \mathrm{Al}$ and $\mathrm{S}$, were deposited on the sample surface, AES was a primary technique to determines the amount of the adlayer. It was also used to determine the degree of oxidation of aluminum oxide.

Auger electron spectroscopy analyzes the kinetic energies of Auger electrons which are characteristic to each element. The Auger process was first observed in 1925 [6] and it was applied to electron spectroscopy as a tool for surface analysis in the late 1960's [7]. In Auger electron spectroscopy, the sample surface is bombarded with a high energy electron beam ( $E=1-2 \mathrm{keV})$, which causes the ejection of core level electrons. The ionized atom relaxes through two different processes as shown in Figure 2.7:

1) The higher level electron transits to the core hole resulting in the emission of photon (X-ray radiation).

2) The core hole is filled by an upper energy level electron and the available energy causes the emission of a second electron (Auger Process).

The kinetic energy of an Auger electron depends on the energy levels of the atoms from which the electron is ejected and it is distinct for each element. The AES spectra of the different elements of the Periodic Table have been tabulated [8].

The kinetic energy of an Auger electron produced from condensed matter can be described as

$$
E_{\text {Auger }}=E_{1}-E_{2}-\left(E_{3}+e \phi_{s p}\right)
$$




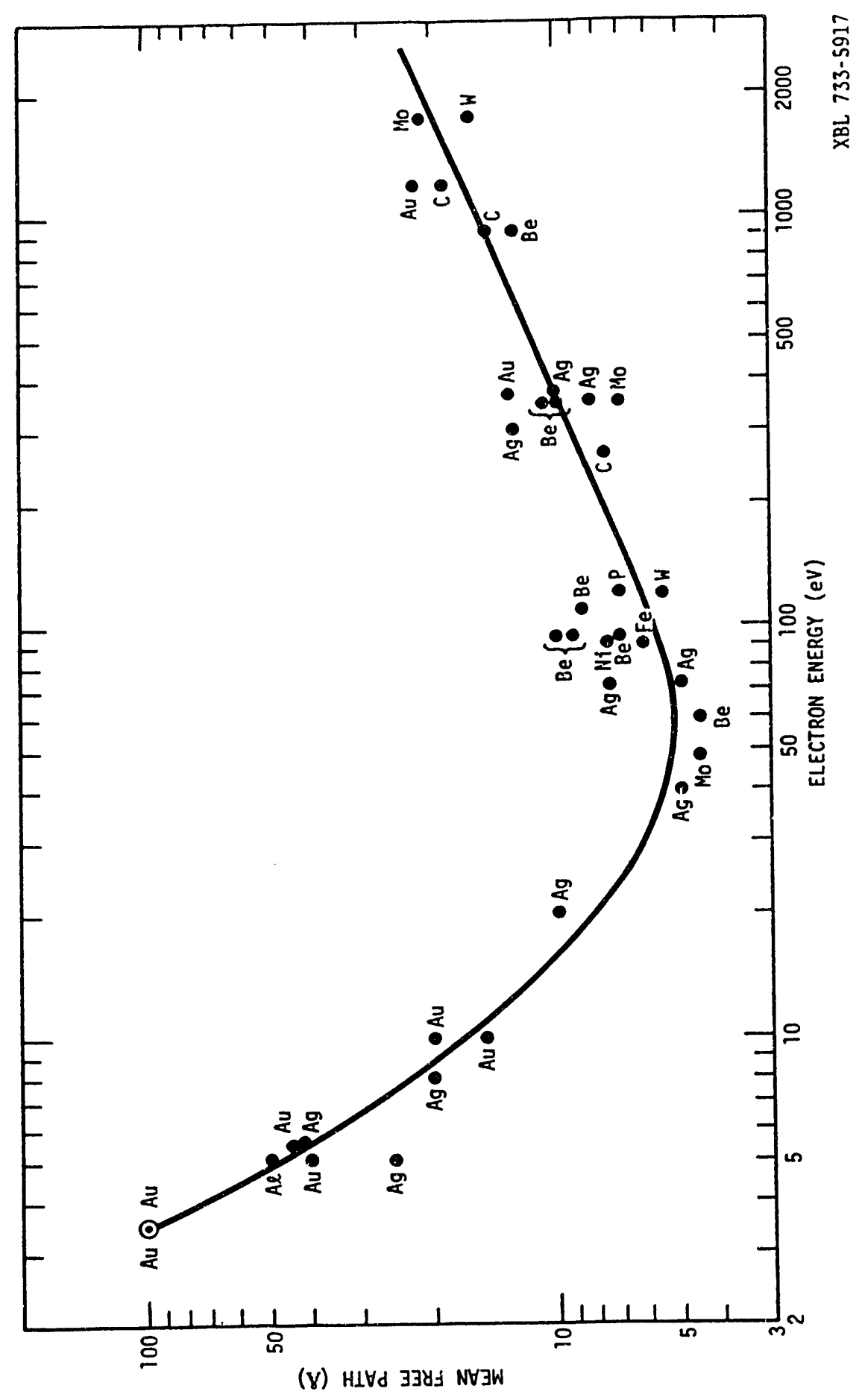

Figure 2.6 The mean free path of electrons in solids as a function of their kinetic energy (Universial Curve). 


\section{EXCITATION}

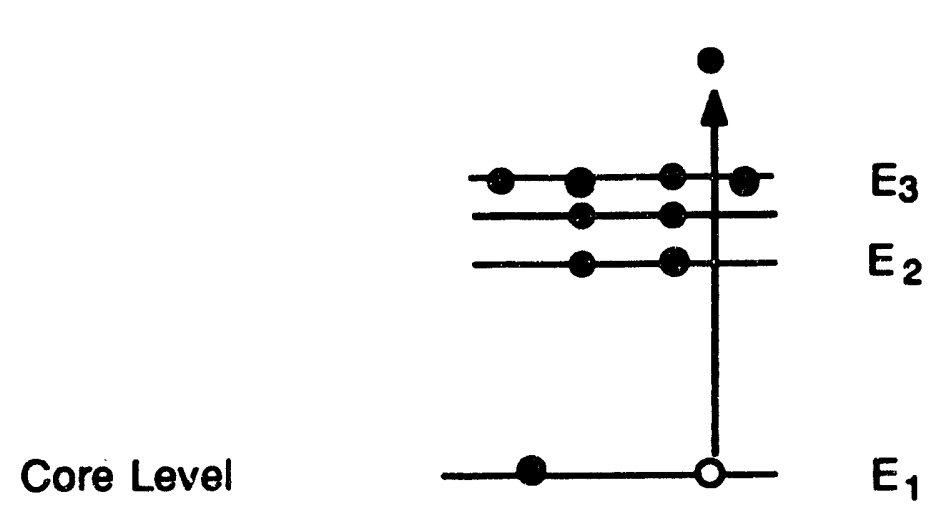

\section{DE-EXITATION}
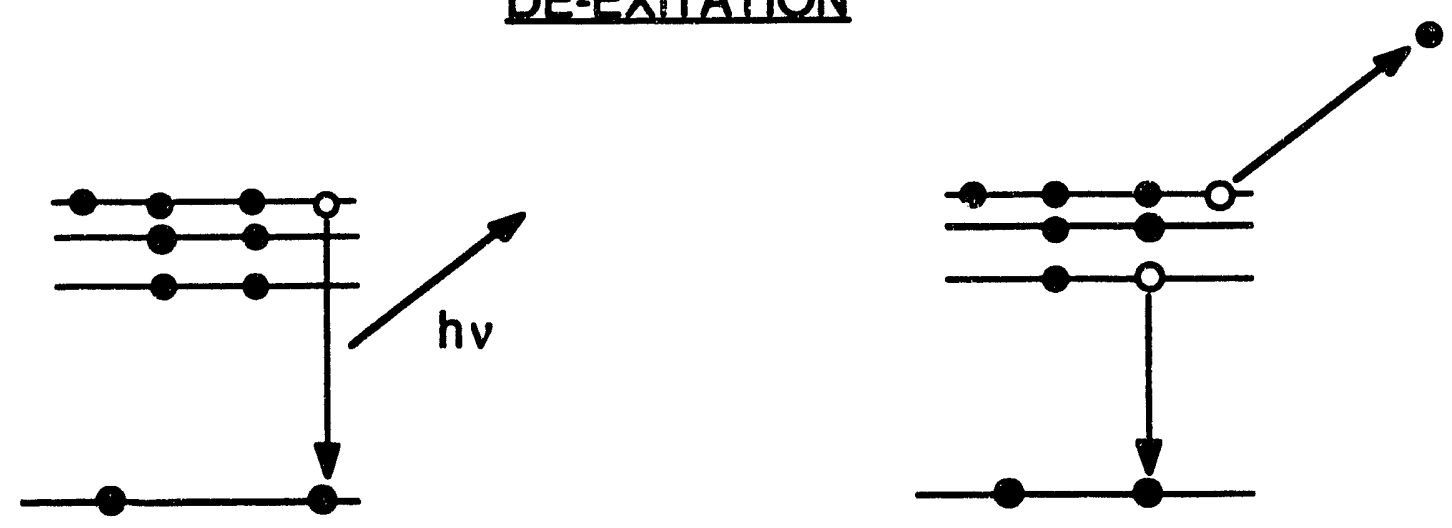

Emission of

Emission of an

X-ray radiation

\section{Auger electron}

Figure 2.7 Energy level diagrams showing two mechanisms for de-excitation of an ex.ed ion: (a) X-ray radiation, (b) the emission of an Auger electron. 
where $E_{1}$ is the binding energy of the core level electron, $E_{2}$ is the binding energy of the higher level electron which fills the core hole, $E_{3}$ is the binding energy of the ejected Auger electron, and $\phi_{\mathrm{sp}}$ is the work function of the spectrometer.

Experimentally, a grazing angle incident electron gun was used to ionize atoms. The incident angle was adjusted to minimize charging and maximize signal to noise ratio; generally the incident angle was $15-30^{\circ}$ to the surface. The energy of the electron beam was $1500 \mathrm{eV}$ and a beam current was $10-20 \mu \mathrm{A}$. The kinetic energy of Auger electrons produced was analyzed using a four grid retarding field analyzer (RFA). For an AES experiment, the retarding field $(35-600 \mathrm{~V})$ was applied to the second and third grids, and the first and fourth grids were grounded. Electrons, whose kinetic energies are greater than the retarding potential are collected by a collector. The collector was biased positively by $300 \mathrm{~V}$ to accelerate the electrons which overcame the retarding potential. The collector current is a function of the retarding potential and is given by

$$
I\left(V_{r}\right) \propto \int_{e V_{s}}^{\infty} N(E) d E
$$

where $V_{r}$ is the potential applied to the retarding grid and $N(E)$ is the energy distribution of electrons emitted from the sample. Then the energy distribution $N(E)$ is

$$
N(E) \propto \frac{d I\left(V_{r}\right)}{d V_{r}}
$$


This operation is performed electronically. To do this a small AC modulation voltage $(1-10 \mathrm{~V}, 5 \mathrm{kHz})$ is added to the retarding potential $\mathrm{V}_{\mathrm{r}}$ and a phasesensitive detector (lock-in amplifier) is used to monitor the signal. The manipulation of AES signal is described in detail in the literature [4, 9]. Auger electron peaks in the $\mathrm{N}(\mathrm{E})$ distribution appears as small steps on a slowly varying background. So, the derivative $d N(E) / d E$ is generally recorded as Auger spectra to get sharp and intense peaks. Figure 2.8 shows Auger spectra of the clean $\mathrm{Pt}(111)$ surface and the $\mathrm{Pt}$ surface covered by 0.3 monolayer of sulfur.

Auger electron spectroscopy not only gives qualitative information of the elements present on the surface but can be used to estimate the amount of each element on the surface. If the cross section of Auger process does not change by adsorbate, the peak-to-peak height of Auger peak is proportional to the quantity of the element on the surface. It is also possible to determine the thin film growth modes on the solid substrate by careful analysis of Auger signal change as a function of adsorbate dosing. Figure 2.9 shows commonly observed thin film growth mechanisms; (1) Frank-van der Merwe (layer by layer growth), (2) Stranski-Krastanov (three dimentional growth after completing one monolayer), (3) Volmer-Weber (three dimentional growth) modes. Characteristic change of Auger signal as a function of deposition time for each growth mode is also shown in Figure 2.9. 
Chapter 2. EXPERIMENTAL 33

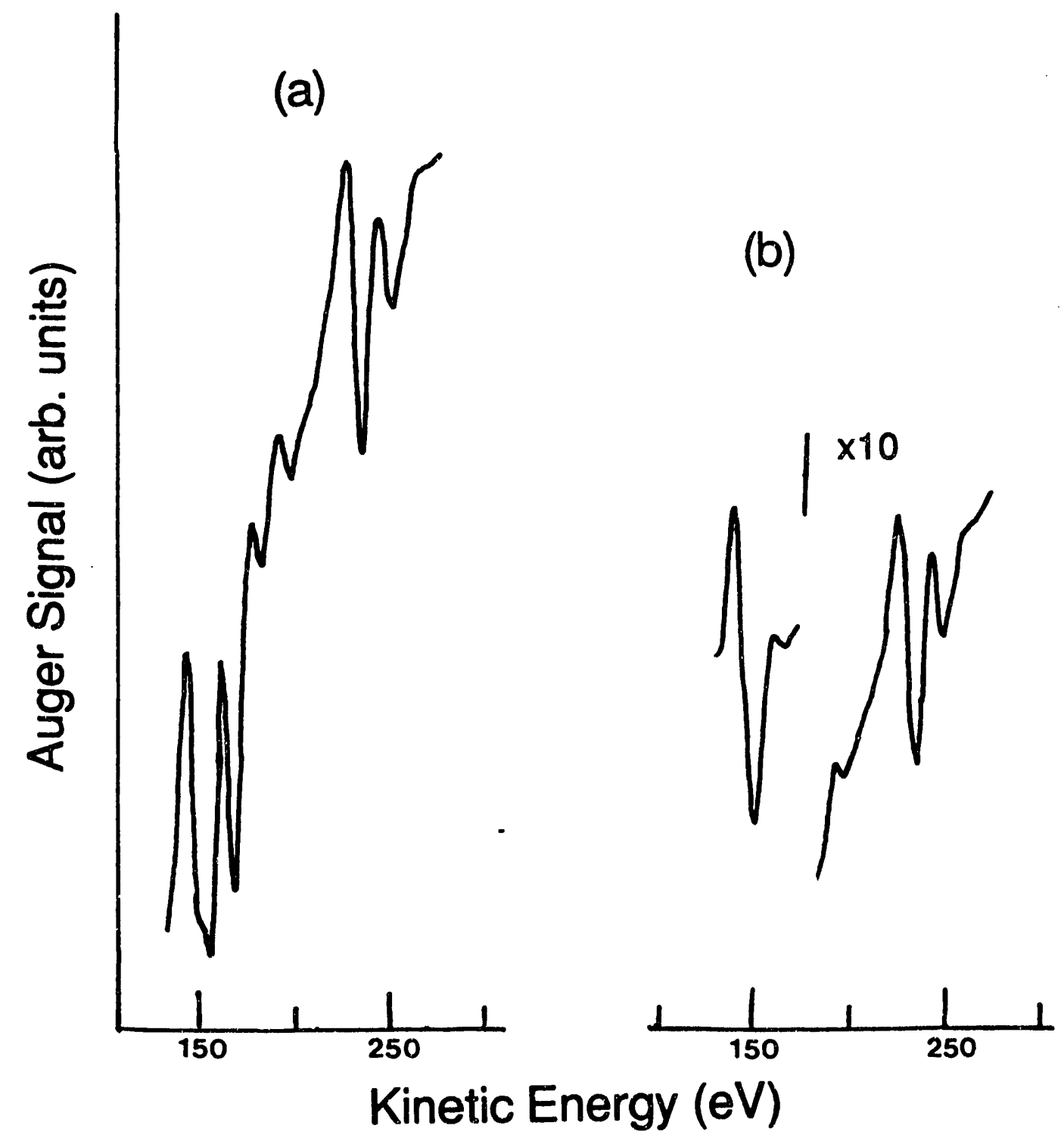

Figure 2.8 Auger electron spectra of (a) the clean Pt surface and (b) the platinum surface covered by $0.3 \mathrm{ML}$ of sulfur. 
Chapter 2. EXPERIMENTAL 34

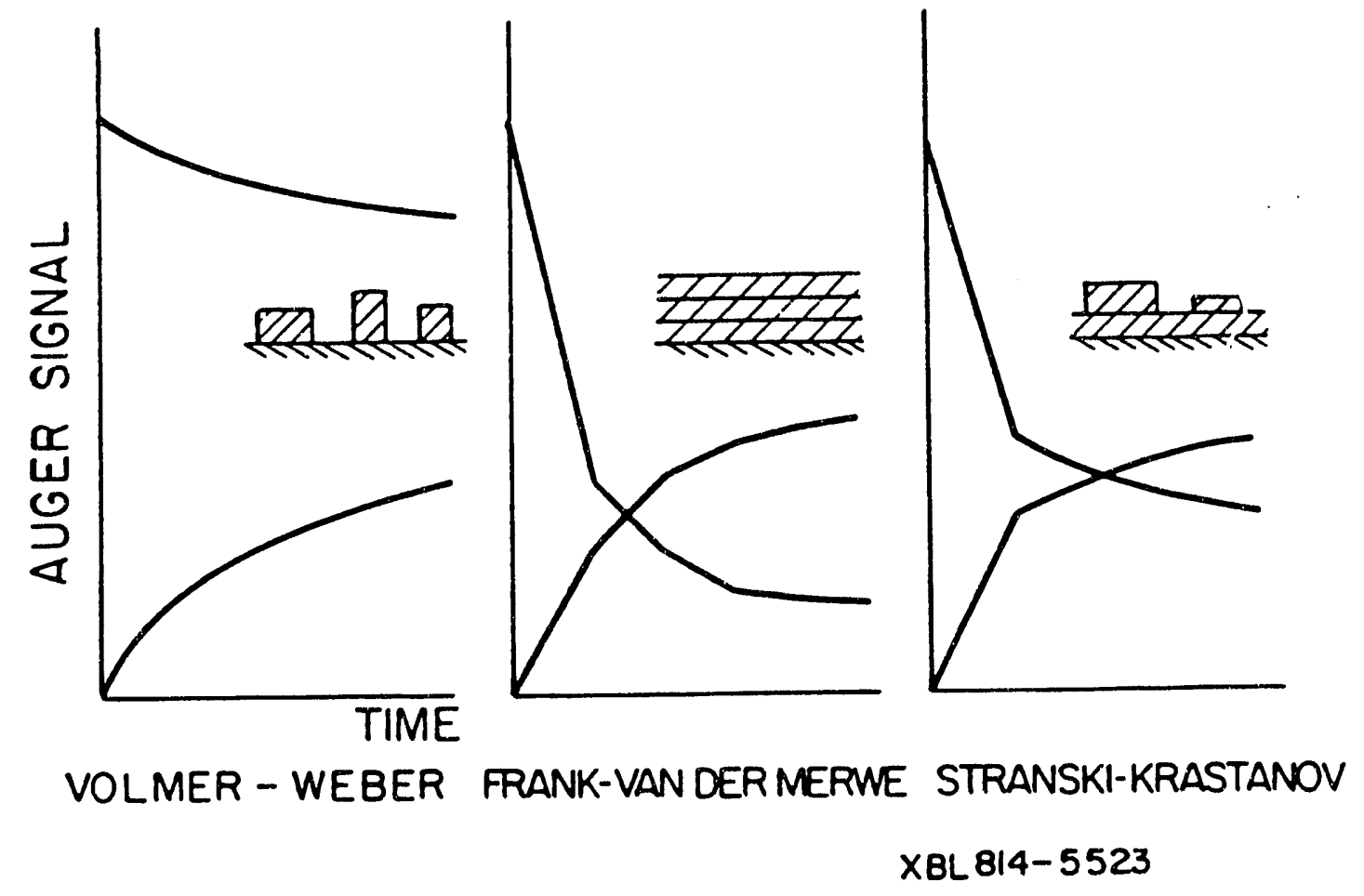

Figure 2.9 Three different models of thin film growth mechanisms and the characteristic change of the Auger signals as a function of deposition time for each model. 
As shown in Chapter 3, a layer-by layer growth mode was observed when rhenium was deposited on $\operatorname{Pt}(111)$ and platinum on $\operatorname{Re}(0001)$. Gallon [10] proposed a simple model for the dependence of Auger intensity on adsorbate thickness, which fits to the layer by layer growth mechanism.

When the substrate is covered by $\mathbf{n}$ monolayers of the adsorbate (Figure 2.10 (a)), the Auger intensities of the substrate $\left(I_{S}\right)$ and the adsorbates $\left(I_{A}\right)$ can be represented as

$$
\begin{aligned}
& I_{S}(n)=I_{S}(0)\left\{\frac{I_{S}(1)}{I_{S}(0)}\right\}^{n} \\
& I_{A}(n)=I_{A}(\infty)\left[1-\left\{1-\frac{I_{A}(1)}{I_{A}(\infty)}\right\}\right]^{n}
\end{aligned}
$$

where $n$ is the number of adsorbate layers, and $I_{A}(n)$ and $I_{S}(n)$ is the adsorbate and substrate intensities with $n$ adsorbate layers, respectively . If $(n+1)$ th layer was incomplete (Figure 2.10 (b)), then the Auger signal would be a linear combination of the signals for $(n+1)$ and $n$ monolayers.

$$
\begin{aligned}
I_{S} & =\delta I_{S}(n+1)+(\delta-1) I_{S}(n) \\
& =I_{S}(0)\left[\delta\left\{\frac{I_{S}(1)}{I_{S}(0)}\right\}^{n+1}+(1-\delta)\left\{\frac{I_{S}(1)}{I_{S}(0)}\right\}^{n}\right]
\end{aligned}
$$

where $\delta$ is the portion of the surface covered by $(n+1)$ monolayers of the adsorbate. 
Chapter 2. EXPERIMENTAL 36

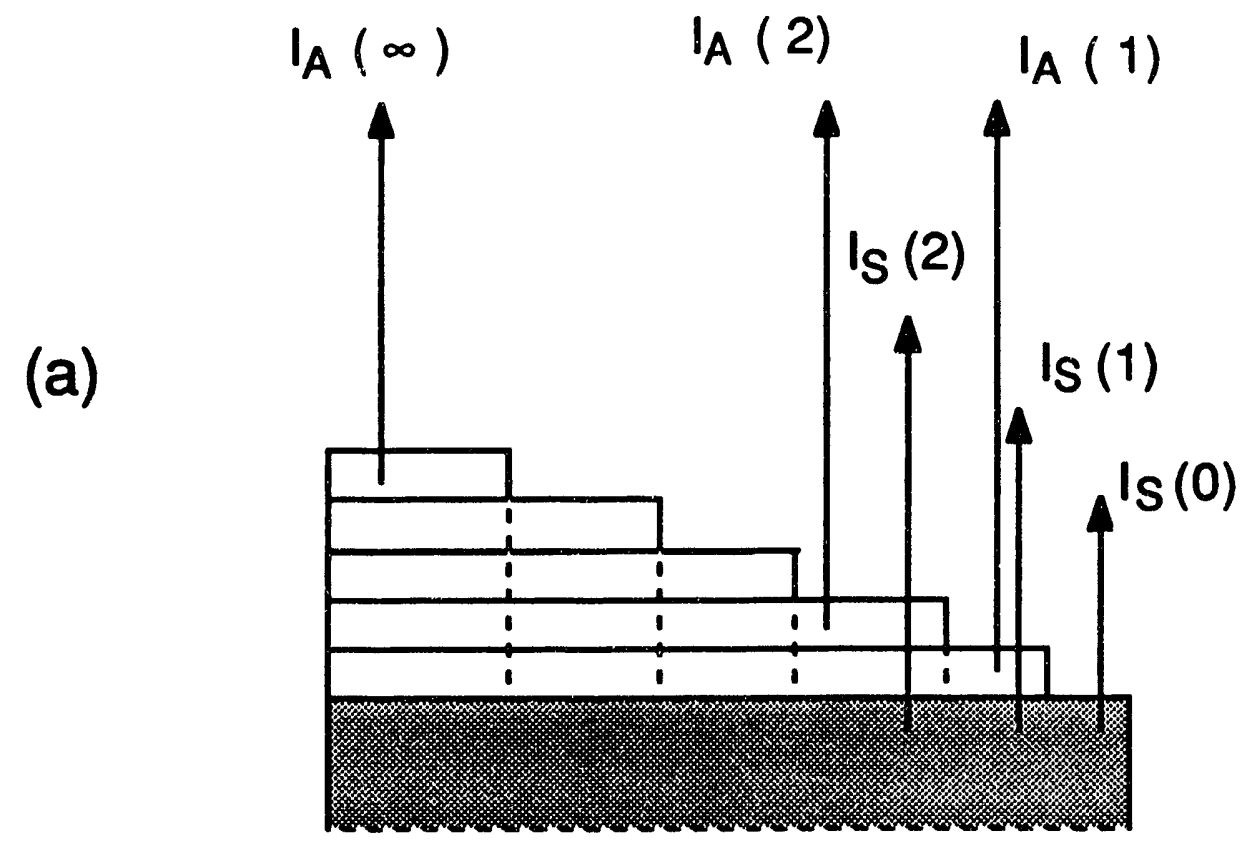

(b)

$$
I_{S}(n+1) \quad I_{S}(n)
$$

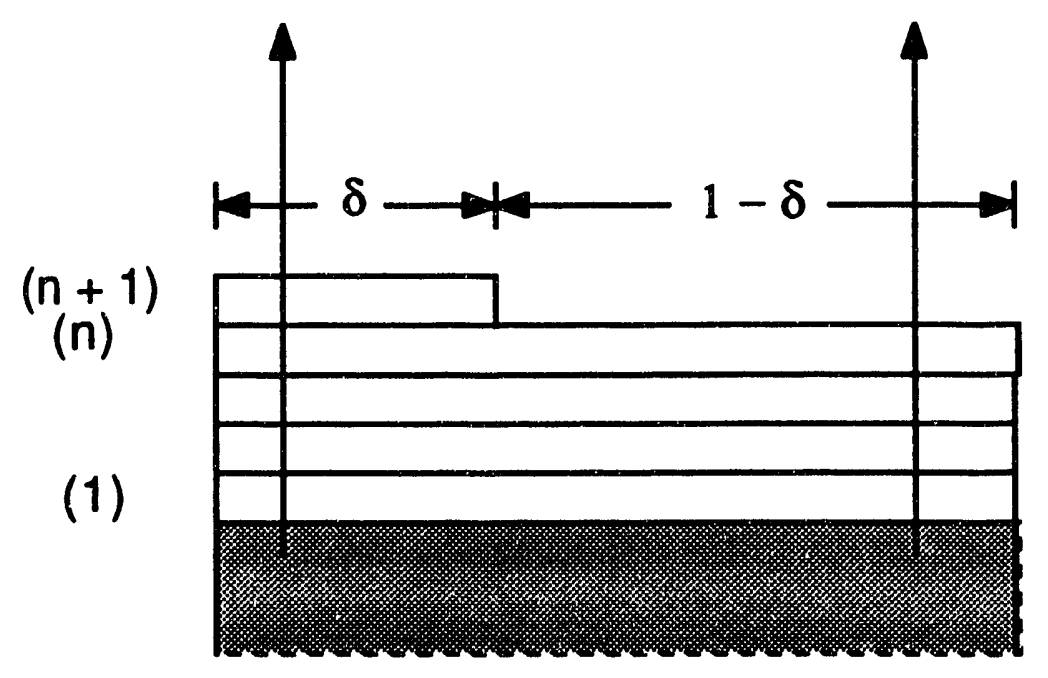

Figure 2.10 Adsorbate layers on a substrate. The arrows represent Auger electrons emitted from each layer. $I_{A}(n)$ is the intensity of Auger electrons emitted from $n$th adsrobate layer, and $I_{s}(n)$ is the intensity from the substrate covered by $n$ adsrobate overlayers (from ref. [11]). 


\subsubsection{Low Energy Electron Diffraction}

Low energy electron diffraction (LEED) is used to study the two dimensional structure of ordered or partially disordered surfaces. In the LEED experiment, a monoenergetic electron beam is impinged on the surface and the diffraction pattern of elastically diffracted electrons are analyzed.

The wavelength of electrons is by the de Broglie equation

$$
\lambda=\frac{h}{\mathrm{mv}}=\frac{\mathrm{h}}{\sqrt{2 \mathrm{meV}}} \approx \sqrt{\frac{150.4}{\mathrm{E}(\mathrm{eV})}}
$$

where $\lambda$ is the wavelength of the electron wave in $\AA$ and $E$ is the energy of the electrons in $\mathrm{eV}$. For the scattering of a plane wave occurring at a onedimensional periodic lattice, construction interference takes place if the path difference of the waves scattered from neighboring lattice points is the multiples of the wavelength. This Bragg's condition is given by

$$
\mathrm{a}\left(\sin \phi-\sin \phi_{0}\right)=\mathrm{n} \lambda
$$

where $a$ is the lattice constant, $\phi_{0}$ is the incident angle of a plane wave, $\phi$ is the angle to the normal of the scattered wave, $\mathrm{n}$ is an integer, and $\lambda$ is the wavelength of the wave (Figure 2.11). For the wave of normal incidence $\left(\phi_{0}=\right.$ $0)$, the diffraction angle $\phi$ is

$$
\sin \phi=\frac{\mathrm{n}}{\mathrm{a}} \lambda
$$


Chapter 2. EXPERIMENTAL 38

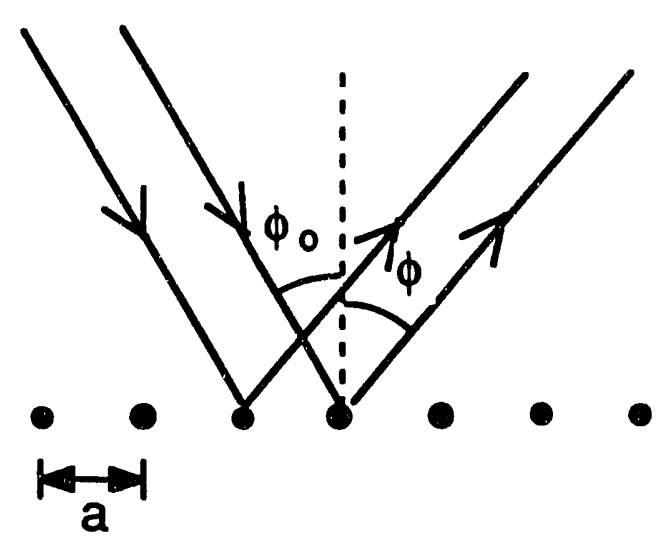

Figure 2.11 Scattering of a plane wave at an one-dimensional periodic lattice.

Similarly, the diffraction angle of backscattered electrons at two dimensional lattice can be given by

$$
\sin \phi=\frac{n \lambda}{d_{h k}}=\frac{n}{d_{h k}} \sqrt{\frac{150.4}{E}}
$$

where, $\mathbf{n}$ is an integer, $d_{h, k}$ is the distance between parallel rows of scatters in the $[h, k]$ direction in $\AA$, and $E$ is the energy of the incident electron beam in eV. The principle of the LEED experiment has been well described in the literature $[4,12]$.

Figure 2.12 shows the schematic of the LEED experiment. The four grid retarding field analyzer used for AES was also used for LEED experiments. Grids 2 and 3 are negatively charged to repel inelastically scattered electrons. The screen was coated with a phosphor and biased positively by about $6 \mathrm{kV}$ to accelerate elastically scattered electrons. The diffraction pattern was observed 


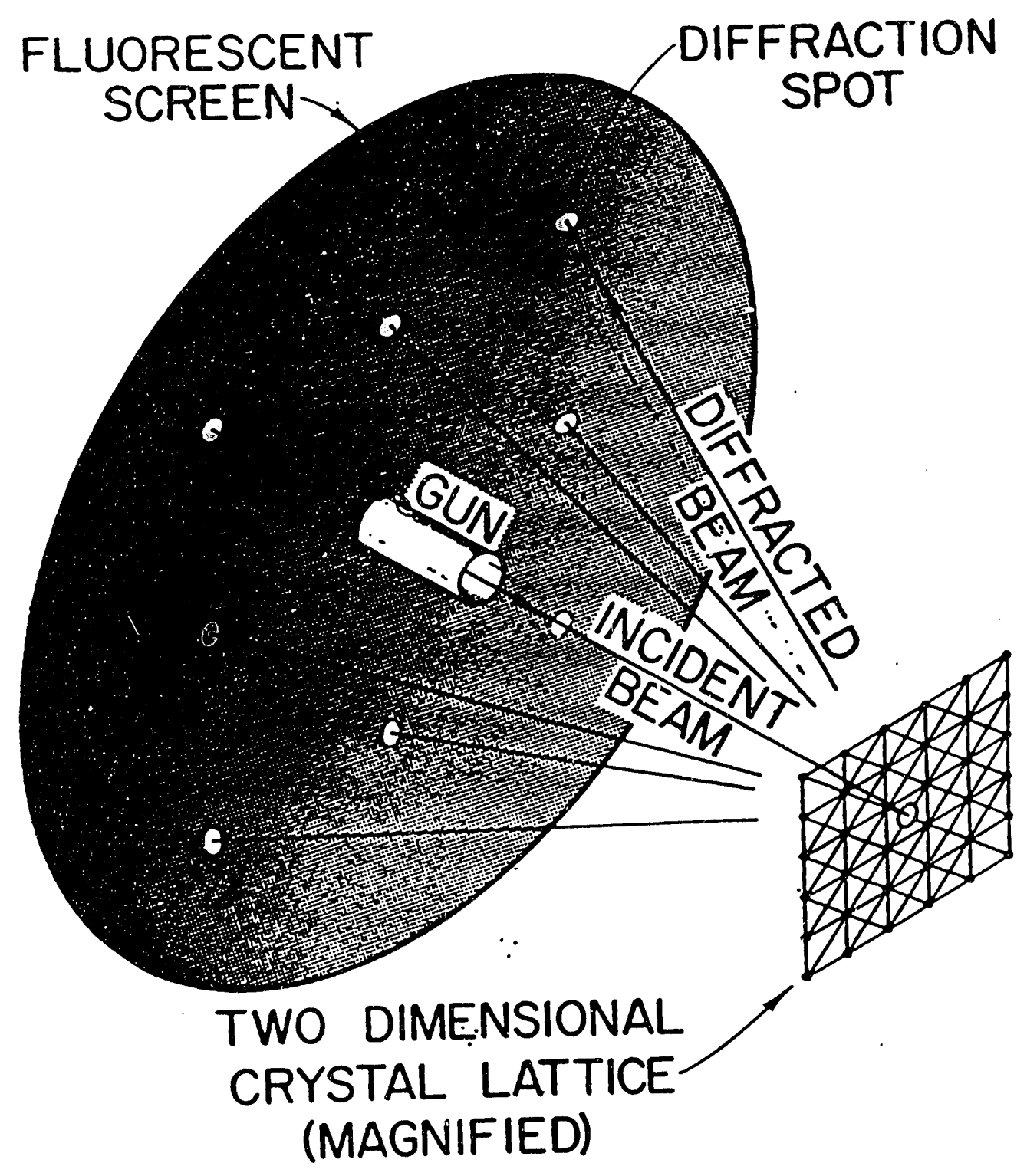

$$
\underset{\sim}{\mathbf{k}^{\prime}}=\underset{\sim}{\mathbf{k}}+\underset{\sim}{\mathbf{G}}
$$

Figure 2.12 Schematic representation of the LEED experiment showing the backscattering of an incident electron beam into a series of diffraction beams. 
Chapter 2. EXPERIMENTAL 40

visually in a dark room and was recorded by taking a photograph.

\subsubsection{Temperature Programmed Desorption}

Temperature programmed desorption (TPD) provides information on binding energetics between adsorbed species (adsorbates) and solid surfaces (adsorbent). It also yields information on surface area, chemical reactions on surfaces, and adsorbate-adsorbate interactions.

In the TPD experiment, gas molecules are adsorbed on the solid surface and the solid sample is heated at a constant heating rate. The increase of pressure due to the desorption of adsorbed gas molecules is monitored. In most cases, however, the desorption of different chemical species is monitored using a mass spectrometer instead of measuring pressure change.

The rate of desorption from unit surface area may be written as

$$
N(t)=-d q / d t=v_{n} \theta_{n} \exp (-E / R T)
$$

where, $\mathrm{n}$ is the degree of the desorption reaction,

$\theta$ is the surface coverage (molecules $/ \mathrm{cm}^{2}$ ),

$v_{n}$ is the rate constant,

and $E$ is the activation energy of desorption [13].

Redhead [14] showed that the activation energy of desorption can be written as

$$
\frac{E}{R T_{p}}=\frac{v_{1}}{\beta} \exp \left(-E / R T_{p}\right) \quad \text { (first order) }
$$


Chapter 2. EXPERIMENTAL 41

$$
\left.\frac{E}{R T_{p}^{2}}=\frac{V_{2} \theta_{0}}{\beta} \exp \left(-E / R T_{p}\right) \quad \text { isecond order }\right)
$$

where $\theta_{0}$ is the initial coverage, $\beta$ is the sample heating rate, and $T_{p}$ is the temperature at which the desorption rate is maximum. For the first order process, Redhead also showed that the activation energy can be given by

$$
\frac{E}{R T_{p}}=\ln \frac{V_{1} T_{p}}{\beta}-3.64
$$

for $10^{8}<v_{1} / \beta<10^{13}\left(K^{-1}\right)$. If we assume $n_{1}=10^{13}$ and the desorption process is not an activated process, then we can easily estimate the heat of desorption (surface bond energy, in other words) from the temperature of the desorption peak maxima for the first order desorption.

In a second order process $T_{p}$ depends upon the initial coverage. So the coverage should be determined to get activation energy. Rearrangement of eq. 2.15 yields

$$
\ln \left(\theta_{\mathrm{o}} \mathrm{T}_{\mathrm{p}}^{2}\right)=\frac{\mathrm{E}}{\mathrm{RT} \mathrm{T}_{\mathrm{p}}}+\ln \left(\frac{\mathrm{E}}{\mathrm{R}}\right)-\ln \left(\frac{2}{\mathrm{~b}}\right)
$$

Plotting $\ln \left(\theta_{0} T_{p}{ }^{2}\right)$ versus $1 / T_{p}$ for a series of TPD experiments gives a line with a slope of $E_{a} / R$ [13].

In TPD experiments described in this work, the sample were heated at linear rates $(20-50 \mathrm{~K} / \mathrm{sec})$ using a linear temperature ramp controller, and the species desorbed from the sample surface were detected using a quadrupole 
mass spectrometer. The change of mass peak intensity was recorded as a function of the sample temperature using an $X-Y$ chart recorder.

\subsection{Materials}

\subsubsection{Single Crystals and Polycrystalline Foils}

The platinum and rhenium single crystals used in this work were cut from rods (6 - $8 \mathrm{~mm}$ diameter) to disks of about $0.8 \mathrm{~mm}$ thickness. Spark erosion was used to slice disks within $1^{\circ}$ of the desired orientation. Laue $\mathrm{X}$-ray back diffraction was used to get the right orientation. Figure 2.13 shows the Laue diffraction patterns of $\mathrm{Pt}(111)$ and $\operatorname{Re}(0001)$. The procedure of single crystal sample preparation is described in detail in the following section. The rhenium single crystal rod was bought from Atomergic Chemicals Corporation. The reported purity was $99.999 \%$ and major impurities were carbon, calcium and sulfur. The platinum single crystal was cut from a rod that existed in the group.

The aluminum foil sample was cut from a sheet with $99.999 \%$ purity. The foil sample has $1.2 \mathrm{~cm}^{2}$ area (sum of both sides) and $0.05 \mathrm{~mm}$ thickness. The aluminum foil was cleaned by etching in $1 \%$ HF solution just before putting in the UHV system. 
Chapter 2. EXPERIMENTAL 43

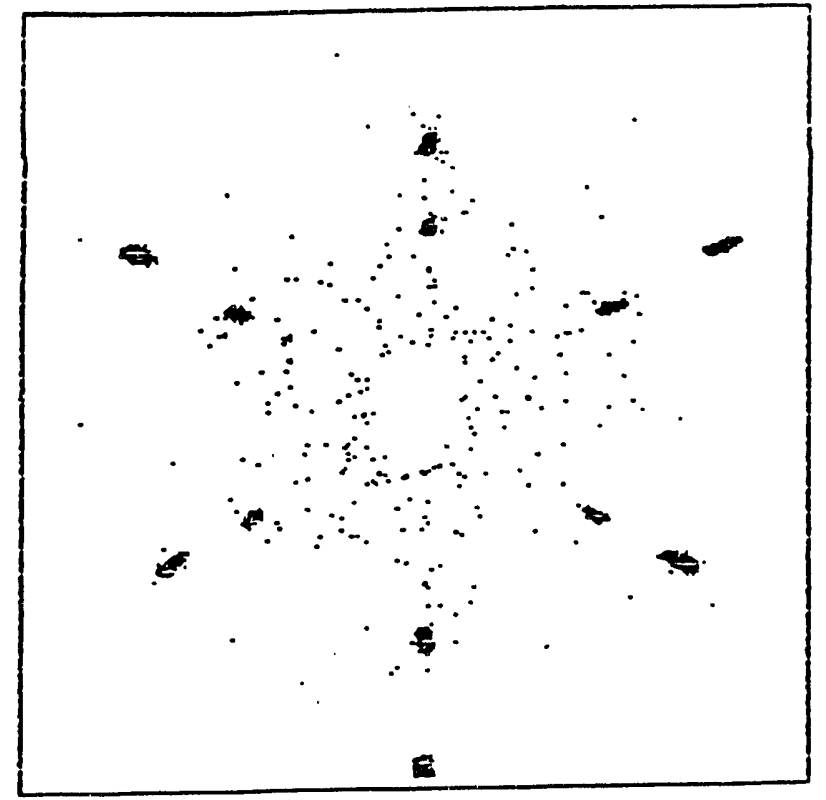

(a)

$\operatorname{Pt}(111)$

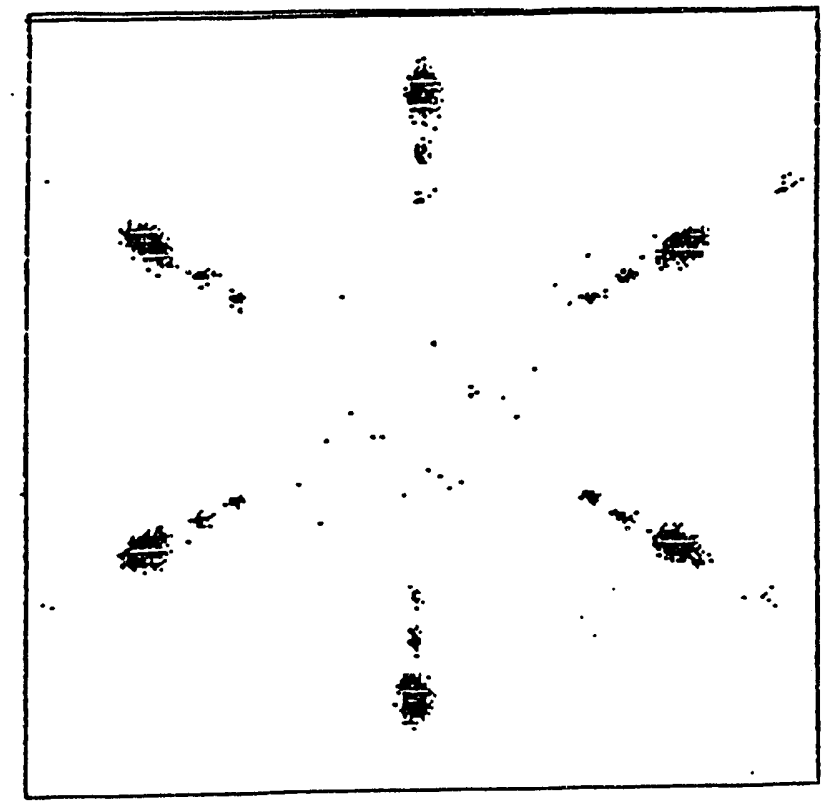

(b)

$\operatorname{Re}(0001)$

Figure 2.13 Backscattered Laue X-ray diffraction patterns. (a) $\mathrm{Pt}(111)$, (b) $\operatorname{Re}(0001)$. 


\subsubsection{Reagents}

The purest hydrocarbins available were purchased if they were to be used for reactants. All of the reagents were used without further purification. Table 2.1 lists the source and purity of the reagents used in this work.

Table 2.1 Reagents used in this work.

\begin{tabular}{lcc}
\hline Reagent & Source & Purity, \% \\
\hline n-Hexane & Fluka & 99.7 \\
Methylcyclopentane & Fluka & 99.7 \\
Cyclohexane & Fluka & 99.7 \\
1-Methyl-1-cyclopentene & Fluka & 99.0 \\
1-Butene & Aldrich & 99.0 \\
Oxygen & Matheson & 99.9 \\
Hydrogen & Matheson & 99.9 \\
Carbon Monoxide & Matheson & 99.5 \\
Argon & Matheson & 99.9 \\
\hline
\end{tabular}




\subsection{Procedure}

\subsubsection{Preparation of Single Crystal Samples}

The single crystal rod was orientated to the desired angle using a Laue diffractometer (MLW 100 real-time back-reflection Laue) and a goniometer. To obtain a good Laue diffraction pattern, one face of a rod was polished up to $1 \mu$. The oriented rod was cut to disks of about $10 \mathrm{~mm}$ thickness using an Electro Discharge Machine (EDM model \#1000). A 0.014 mil brass wire was used as an electrode of the EDM machine. After cutting, the crystal disk was mounted in epoxy (Koldmount) to grind and polish.

The mounted sample was ground on the series of abrasive papers. The abrasive papers had four different grit sizes; about 30, 22, 15, and $10 \mu$. The ground sample was polished using diamond paste. Diamond paste was spread on the polishing cloth and mixed with polishing oil on the polishing cloth. The particle sizes of diamond paste were $6 \mu, 1 \mu$ and $0.25 \mu$.

After the polishing process was completed, the Laue pattern of the crystal was obtained. The orientation was readjusted using the goniometer on the $x$-ray machine. The corrected sample on the goniometer was ground using a facing wheel to get a right orientation within 0.5 degree of the desired angle. The sample was ground and polished again to get a final single crystal sample.

\subsubsection{Sample Cleaning}

Newly polished single crystals have very rough surfaces with accumulation of impurities on the surface. Major impurities were carbon, sulfur, oxygen 
and calcium. The samples were cleaned by cycles of oxygen treatment, argon ion sputtering, and annealing. The samples were flashed for 2-3 minutes in $5 \times 10^{-7}$ Torr of oxygen at $1000 \mathrm{~K}$. After oxygen treatment, the single crystal samples were sputtered in $5 \times 10^{-5}$ Torr of argon at $900 \mathrm{~K}$. The energy of argon ion beam was $1.5 \mathrm{kV}$ and the ion current through the sample was 2-3 $\mu \mathrm{A}$. Annealing of the sample was followed after sputtering. Platinum was annealed at $1300 \mathrm{~K}$ and rhenium was annealed at $1600 \mathrm{~K}$ for 10 minutes. The cycle of oxygen treatment, sputtering and annealing was continued until no impurities were detected and a sharp (1x1) LEED pattern was obtained.

Aluminum foil was cleaned by argon ion sputtering at room temperature and annealed at $500^{\circ} \mathrm{C}$. New aluminum foil was covered by a thick layer of aluminum oxide. It was necessary to sputter with an argon ion beam of $2 \mathrm{kV}$ energy for more than 10 hours to remove this initial aluminum oxide layer. The sample was cleaned until the $58 \mathrm{eV}$ AES peak (oxidized aluminum) was not detected.

\subsubsection{Deposition of metals}

Metals, $\mathrm{Pt}, \mathrm{Re}$ and $\mathrm{Al}$, were deposited using a plasma deposition source described in Chapter 3. The cathode of the source is the material to be deposited and the cathode can be easily replaced. The procedure of metal deposition is described in detail in Chapter 3.

\subsubsection{Deposition of Sulfur}

Sulfur was deposited using an electrochemical sulfur source described in 2.1.6. Deposition rate was controlled by changing the potential applied to the cell. A 
potential of $0.2 \mathrm{~V}$ was used throughout the experiment. That is the minimum potential which should be applied to induce the cell reaction. With that potential, deposition rate was controlled to approximately 1 monolayer per minute. Figure 2.14 shows the Auger up-take curve for the deposition of sulfur on $\mathrm{Pt}(111)$. It shows the change of sulfur $152 \mathrm{eV}$ peak as a function of deposition time. The result implies that deposited sulfur forms first monolayer on the surface of $\mathrm{Pt}(111)$ and produces three dimentional bulk structure after that (Stranski-Krastanov growth mode).

\subsubsection{High Pressure Reactions}

The single crystal or foil catalysts were prepared in UHV. After the surface composition was characterized by AES, the sample was enclosed by an internal isolation cell for reaction studies. The high pressure cell was first pressurized by 5 Torr of $\mathrm{H}_{2}$ before introducing hydrocarbons to prevent the hydrocarbons from being adsorbed on the fresh catalyst surface and decomposed immediately upon heating. The hydrocarbon vapor and hydrogen were introduced to the desired total pressure. The reaction mixture was circulated for $5 \mathrm{~min}$ to ensure complete mixing of hydrocarbon and hydroben. The catalyst sample was then heated resistively to the reaction temperature. Zero reaction time was started when the temperature became higher than $100^{\circ} \mathrm{C}$. It took additional 15 seconds to reach the reaction temperature and to be stabilized. The reaction temperature was regulated to $\pm 1 \mathrm{~K}$ using a Eurotherm temperature controller. Gas chromatograph samples were taken using a six-port sampling valve. Samples were taken every $7-15$ minutes depending on the retention time of separation. Reactions usualiy 
lasted for 60 - 120 minutes. After the reaction the sample was cooled down and the gas mixture was pumped out. The high pressure cell was pumped down up to $10^{-4}$ Torr using either a sorption pump cooled by liquid nitrogen or a diffusion pump. Pumping was continued for 30-60 minutes before opening the high pressure cell in UHV. If the cell was opened without sufficient pumping, the pressure of the UHV chamber rose up to $10^{-7}$ Torr and it was very difficult to recover high vacuum for AES and TPD experiments. After the reaction, Auger spectra were taken to investigate the surface composition change during the reaction. Hydrogen TPD experiment was performed to investigate the carbon/hydrogen ratio of adsorbed hydrocarbon species. In some cases CO TPD spectrum was taken to estimate the area of the active catalyst surface after the reaction.

The initial turnover frequency (in molecules/sec/site) was generally used to compare the performance of different catalysts. It was assumed that the surface atom density of $\mathrm{Pt}(111)$ and $\operatorname{Re}(0001)$ was $1.5 \times 10^{15}$ atoms (sites) $/ \mathrm{cm}^{2}$ and the amount of hydrocarbon introduced into the reactor was $3.2 \times 10^{-4}$ moles at room temperature. The single crystal catalysts were deactivated so quickly that it was sometimes very difficult to determine the initial turnover frequency. In that case, the first one of two GC samples were used to determine initial reactivities.

Blank reactions were performed to determine the background catalytic activity or thermal decomposition of hydrocarbons originated from the sample holders and the stainless steel reactor wall. For the blank reactions, gold foil was used instead of catalyst samples. Back ground reactivities were less than $1 \%$ of the catalyzed reaction. 
Chapter 2. EXPERIMENTAL 49

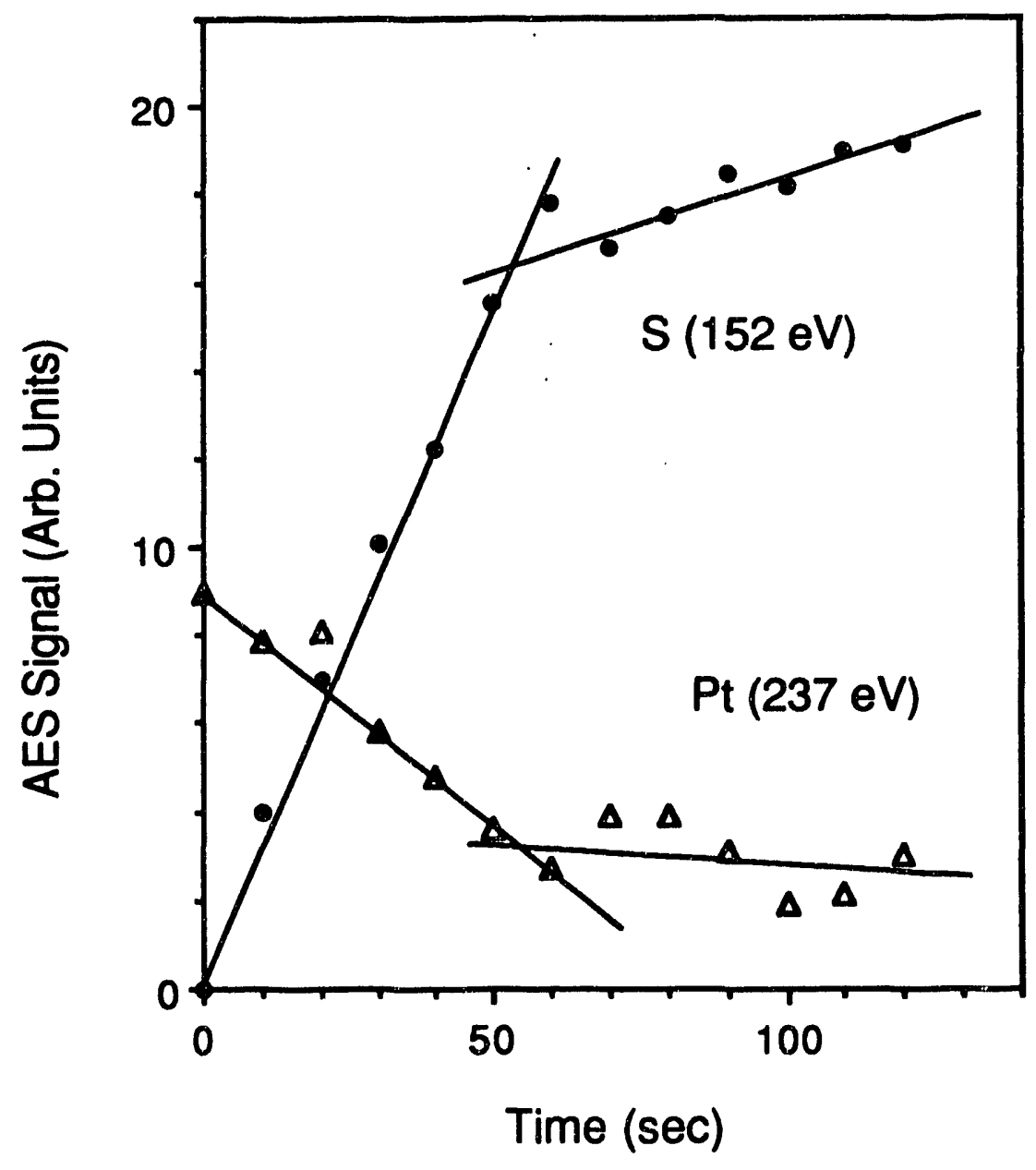

Figure 2.14 Auger uptake curve for deposition of sulfur on $\mathrm{Pt}(111)$. It shows the change of sulfur $152 \mathrm{eV}$ peak and platinum $237 \mathrm{eV}$ peak as a function of sulfur deposition time. 
Chapter 2. EXPERIMENTAL 50

\section{References}

[1] D.W. Blakely, E. Kozak, B.A. Sexton, and G.A. Somorjai, J. Vac. Sci. Technol. 13 (1976) 1091.

[2] W.A. Dietz, J. Gas. Chro. 5 (1967) 68.

[3] W. Heegemann, K.H. Meoster, E. Bechtold, and K. Hayek, Surf. Sci. 49 (1975) 161.

[4] G. Ertl and J Kuppers, "Low Energy Electrons and Surface Chemistry", Verlag-Chemie, Weinheim, Germany (1974).

[5] G.A. Somorjai, "Chemistry in Two Dimensions:Surfaces", Cornell University Press, Ithaca (1981).

[6] P. Auger, J. Phys. Radium 6 (1925) 205.

[7] L.N. Tharp and E.J. Scheibner, J. Appl. Phys. 38 (1967) 4355.

[8] L.E. Davis, N.C. MacDonald, P.W. Palmberg, G.E. Riach, and R.E. Weber, Eds., "Handbook of Auger Electron Spectroscopy", 2nd ed., Physical electronics Ind., Eden Prairie, MN (1976).

[9] F.J. Szalkowski and G.A. Somorjai, Adv. High. Temp. Chem. 4 (1971) 137.

[10] T.E. Gallon, Surface Sci., 17 (1969) 486.

[11] F.C.M.J.M. Van Delft, A.D. Van Laaangeveld, and B.E. Bieuwenhuys, Thin Solid Films 123 (1985) 333.

[12] L.J. Clarke, "Surface crystallography, An Introduction to Low Energy Electron Diffraction", J. Wiley \& Sons, Chichester, England (1985).

[13] K. Christmann, G. Ertl, and T. Pignet, Surface Sci. 54 (1976) 365.

[14] P.A. Redhead, Vacuum 12 (1962) 203. 


\section{CHAPTER 3}

\section{Preparation of Thin Metal Films: Plasma Deposition Source}

\subsection{Introduction}

The ability to controllably synthesize thin films is becoming of increasing importance in both laboratory and industry. The thin-film deposition technology in modern fabrication processes has been used for a large variety of applications; electronic components, electronic displays, optical coatings, magnetic film for data storage, optical data storage devices, antistatic coatings and hard surfaces coatings [1]. The ability to controllably synthesize thin films is also important in studying the physics and chemistry of films, surfaces, interfaces and microstructures. There are many dozens of deposition technologies for thin-film fabrication but the most commonly used techniques on the laboratory scale include resistive heating vaporization [2], electron-beam evaporation [3], sputtering [4], laser evaporation [5], and molecular beam epitaxy (MBE) [6].

Metallic films and coatings can also be fabricated by the metal vapor vacuum arc plasma discharge [7-10]. A plasma generator in the form of a 
miniature plasma gun was developed to deposit precise amounts of refractory metals, ranging from submonolayer to tens of monolayers in UHV. The plasma gun deposition source was originally developed at the Lawrence Berkeley Laboratory $[11,12]$ as part of a continuing program to upgrade the heavy ion accelerator facilities at LBL. The deposition source used in this experiment was designed to fit into the UHV chamber described in Chapter 2 and to deposit metals in a submonolayer quantity.

\subsection{Vacuum Arc Discharge}

The metal vapor vacuum arc is a plasma discharge that takes place between metallic electrodes in a high vacuum environment and that is a prolific producer of dense metal plasma [13]. In the vacuum arc, the discharge current is concentrated at the cathode surface to a small number of very tiny spots which are called "cathode spots". The diameter of a cathode spot is

typically $1-10 \mu \mathrm{m}$ and the current at the cathode spot is in the range of $10^{10}-10^{14}$ $\mathrm{A} / \mathrm{m}^{2}$ [13-15]. The origin of the cathode spots and the mechanism that maintains them have not yet been fully understood. These local concentrations of very high energy density serves to vaporize and ionize the cathode material which is then ejected away from the cathode in the form of a dense metal plasma plume. This process is schematically shown in Figure 3.1. The plasma plume is composed of electrons and positive metal ions. Metal ions are generally multiply ionized and the charge state distribution depends on the material and plasma source configuration [12]. Two models 


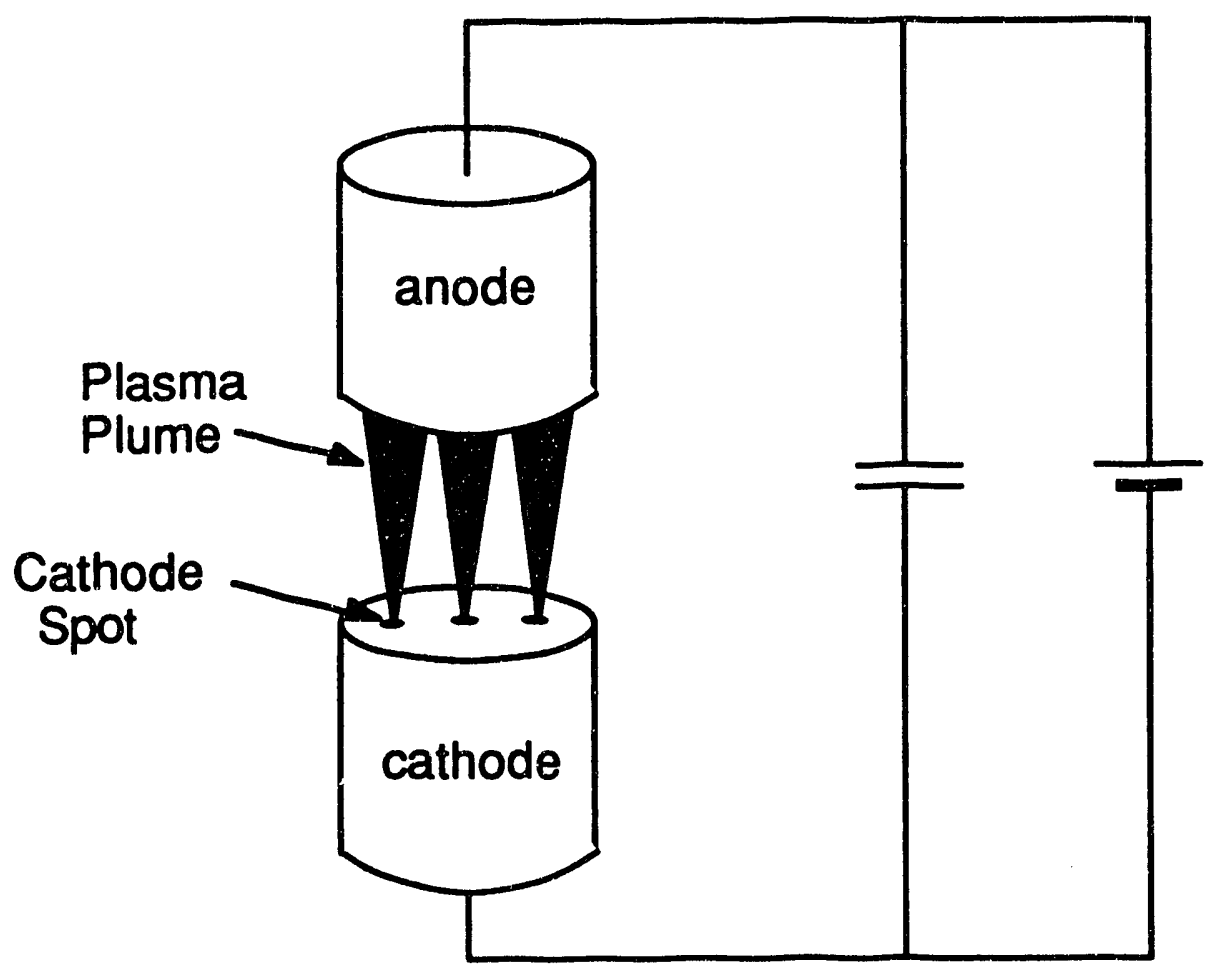

Figure 3.1 The multiple cathode-spot arcs (from ref. [14]). 
were proposed for the ionization of metal atoms in the plasma; step wise ionization by successive electron impact [16] and multiple ionization (the removal of several electrons in a single collision) [17].

\subsection{Pulsed Metal Plasma Deposition Source}

A photograph of the embodiment of the plasma gun that has been used in this work is shown in Figure 3.2. Figure 3.3 is a simplified schematic of the gun. The cathode is the material to be evaporated. A metal rod with a diameter of $0.3 \mathrm{~mm}$ was used as a cathode. $\mathrm{Pt}, \mathrm{Re}$ and $\mathrm{Al}$ cathodes have been used and they are easily interchangeable. Alumina is used for the insulating material and the trigger electrode and anode are made of stainless steel.

The plasma is generated from the solid metal cathode by means of a metal vapor discharge between the cathode and the anode as mentioned previously. The arc discharge is driven by a simple L-C circuit with an impedance of approximately $1 \mathrm{ohm}$ and a pulse duration in the range of 50 500 microseconds. The L-C line is charged up to several hundred volts with a small, isolated dc power supply. A high voltage (about $10 \mathrm{KV}$ ) pulse of several microseconds duration applied to a trigger electrode initiates a surface spark discharge between the central cathode and the coaxial trigger electrode. The spark plasma closes the anode-cathode circuit, allowing the main arc discharge to take place. Typically the source operates at a repetition rate of one pulse per several second to avoid any heating, but the source has been successfully operated at a pulse rate up to $20 \mathrm{~Hz}$. 


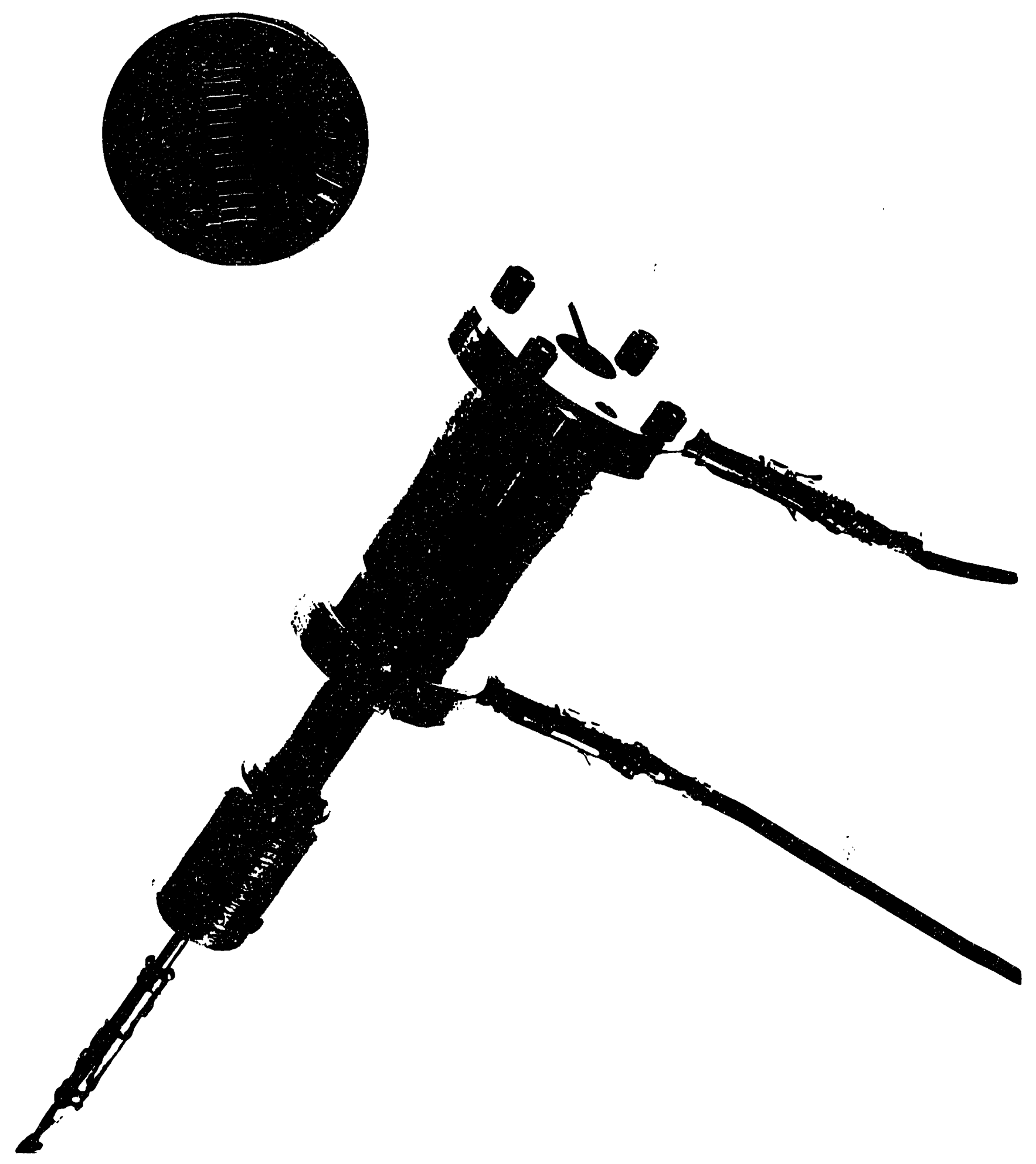

Figure 3.2 A photograph of a plasma deposition source. 


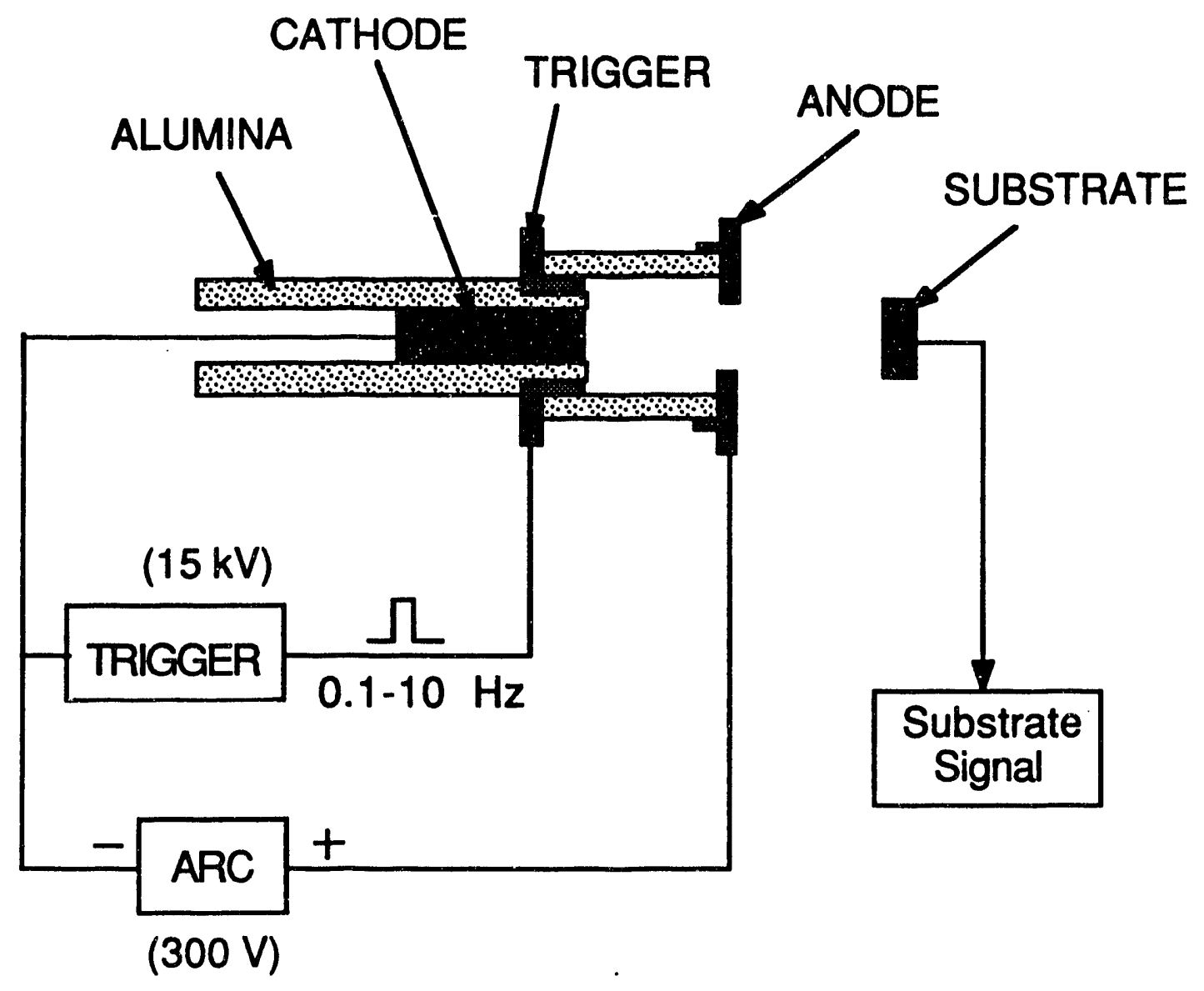

Figure 3.3 A schematic diagram of a plasma deposition source. 
The miniature pulsed metal plasma gun was located with its exit aperture some $1 \mathrm{~cm}$ from the substrate onto which deposition was to be formed. During the operation of a plasma gun, the base pressure increased from $1 \times 10^{-9}$ Torr up to $2 \times 10^{-8}$ Torr but the pressure subsided immediately after the completion of one plasma pulse. No degassing took place during deposition and the scattering of positive ions seems to be the reason for pressure increase.

By biasing the substrate negatively by several tens of volts the plasma ion current to the substrate can be measured and related the incremental film thickness. Figure 3.4 shows a set-up for a plasma current measurement. The change of substrate current was monitored by changing substrate bias, over a range of bias voltage adequate to indicate the ion saturation and electron saturation. Figure 3.5 shows the change of the Re plasma current collected by a Pt substrate as a function of the bias potential applied on the substrate. When the substrate was biased by $+30 \mathrm{~V}$, the electron current was saturated at $-13 \mathrm{~A}$. When the substrate was biased by $-60 \mathrm{v}$, most of electrons were repelled and the ion current increases up to a saturation value of about $0.3 \mathrm{~A}$.

Figure 3.6 shows a series of oscilloscope traces of the Re plasma ion current collected by a Pt substrate. When the target (substrate) was negatively biased by $50 \mathrm{~V}$, electrons were repelled and the positive ion flux could be traced (Figure $3.6(\mathrm{a})$ ). The residual electron current shows up as a very fast negative spike near $t=0$. The positive ion flux peaks at roughly $50 \mu s$ and decays to zero in about $200 \mu \mathrm{s}$ : the shape and duration of the plasma pulse are determined by the electronics used to drive the arc circuit, and can be varied 


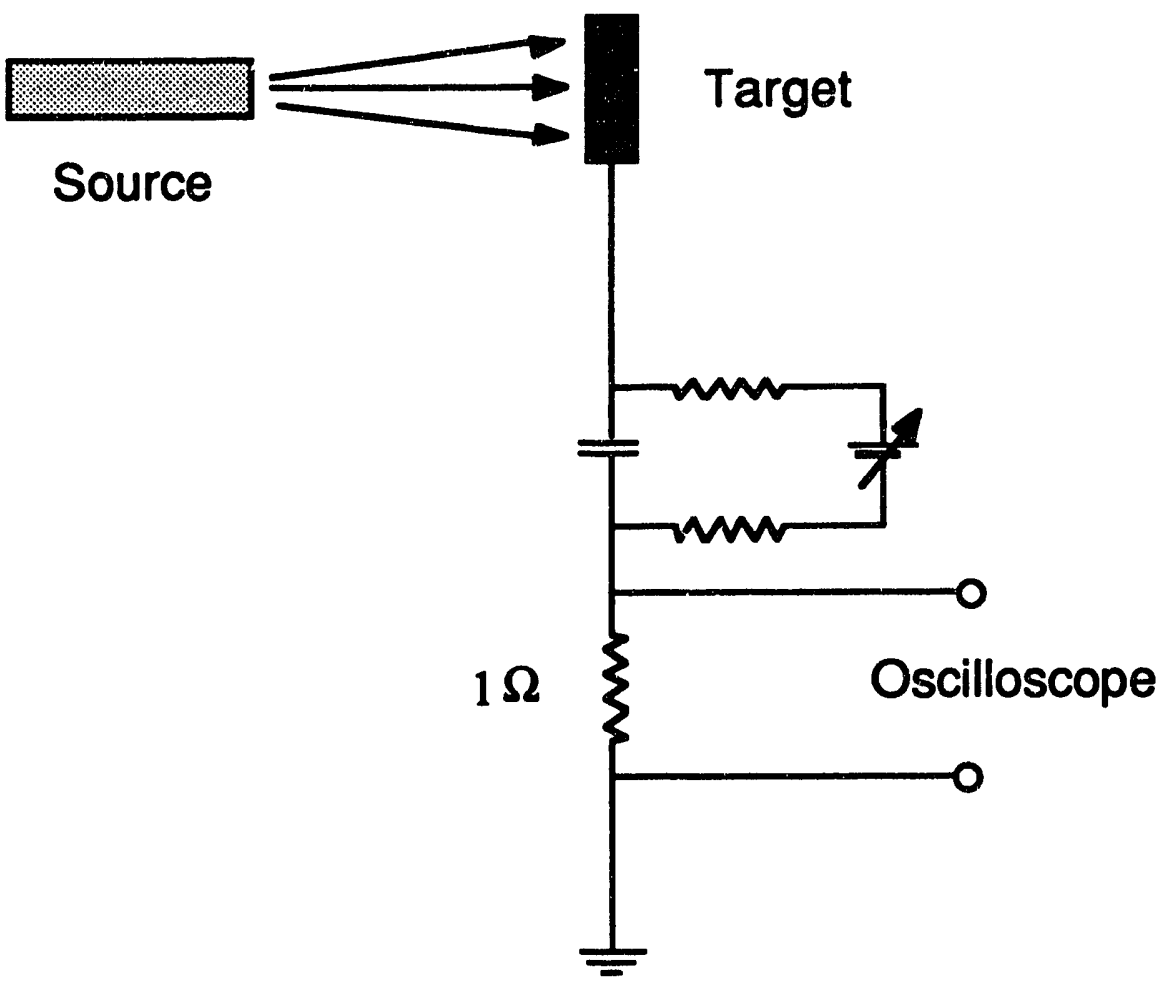

Figure 3.4 A set-up for a measurement of the plasma current collected by a substrate. 


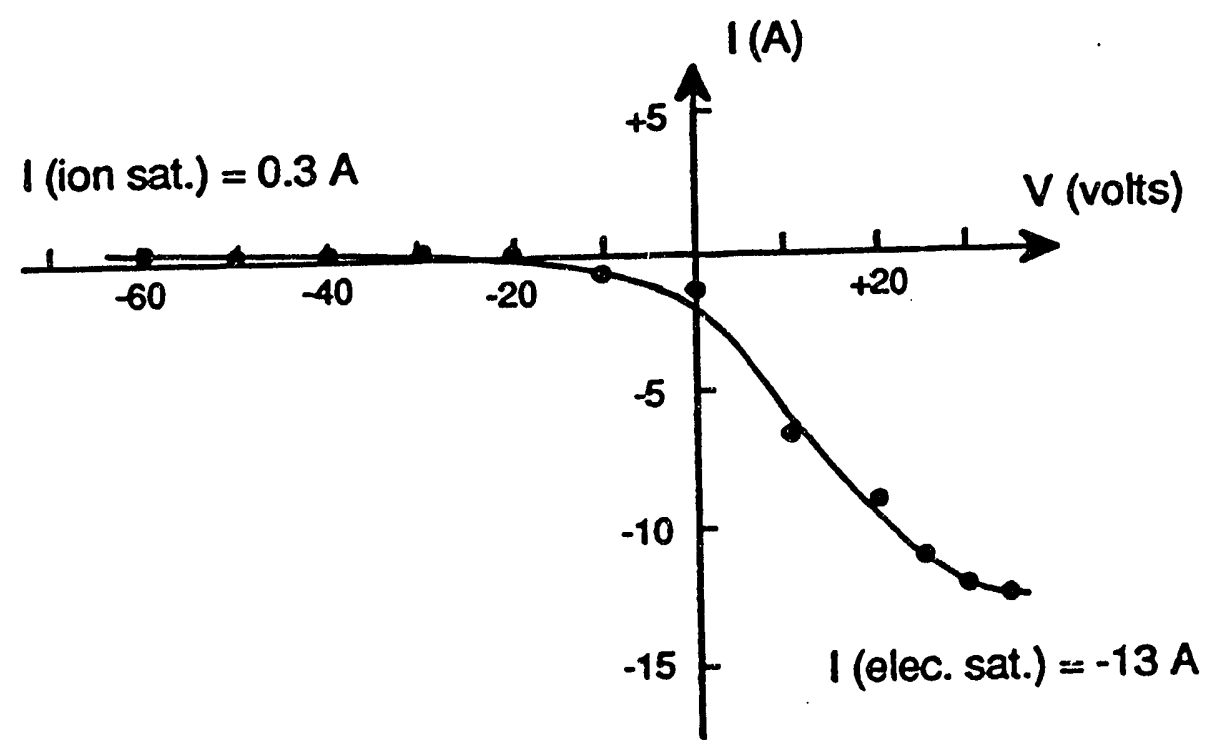

Figure 3.5 The change of the Re plasma current collected by a Pt substrate as a function of the bias potential on the substrate. 


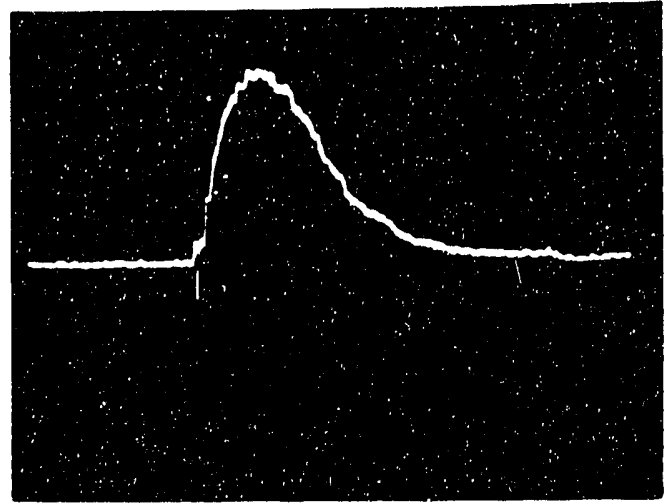

(a) $V_{\text {bias }}=-50 \mathrm{~V}$

$0.1 \mathrm{~A} / \mathrm{cm}$
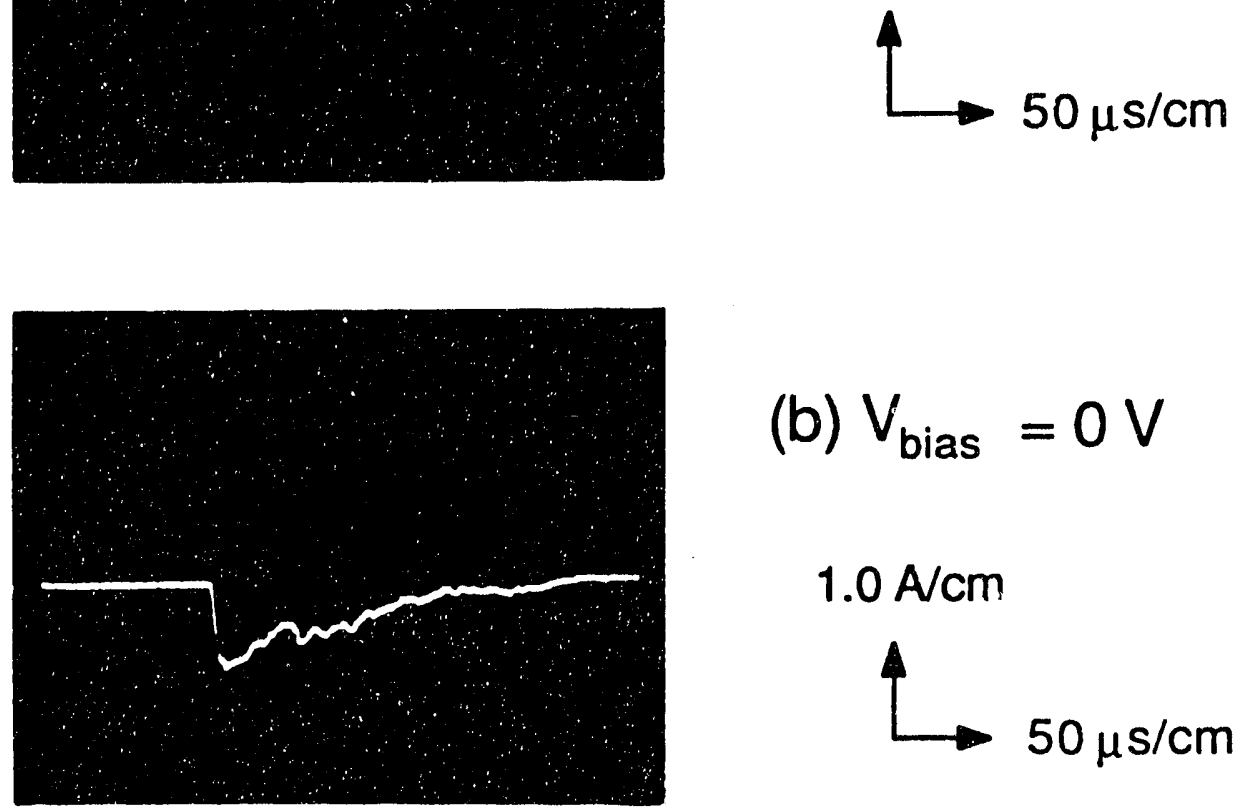

(b) $\mathrm{V}_{\text {bias }}=0 \mathrm{~V}$

\section{$1.0 \mathrm{~A} / \mathrm{cm}$}
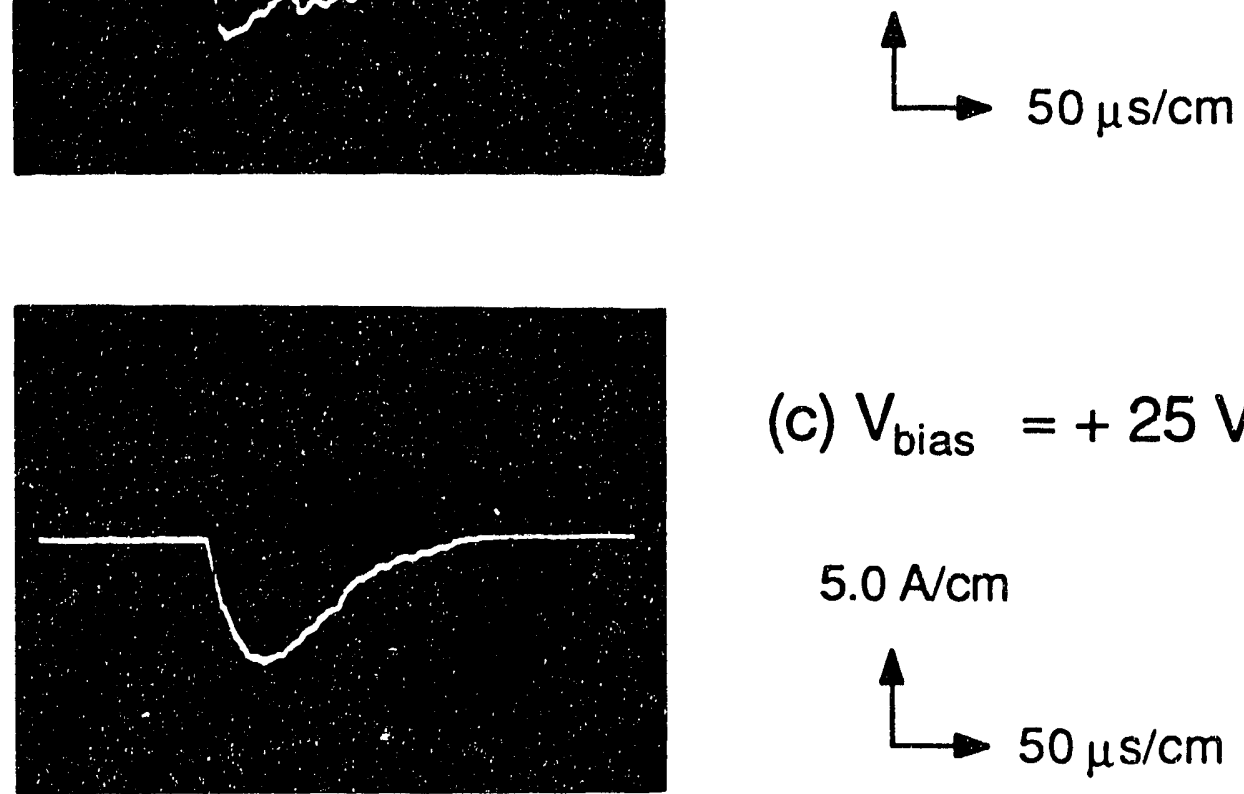

(c) $\mathrm{V}_{\text {bias }}=+25 \mathrm{~V}$

$5.0 \mathrm{~A} / \mathrm{cm}$

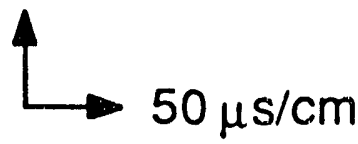

Figure 3.6 Oscillograms of Re plasma current collected by the $\mathrm{Pt}$ substrate. $V_{\text {bias }}$ is the potential applied to the substrate. 
over a wide range. When the target was not biased (Figure 3.6 (a)) or positively biased (Figure 3.6 (c), the electron flux was dominant.

The area of the positive ion (Re ion) flux peak in Figure $3.6(\mathrm{a})$ is about $2.5 \times 10^{-5}$ Asec which corresponds to the charge of $1.6 \times 10^{14}$ electrons. As we will discuss later, fourteen pulses of Re plasma form 1 monolayer of Re film on $0.5 \mathrm{~cm}^{2}$ of $\mathrm{Pt}(111)$ substrate. Fourteen pulses of Re plasma carry the charge of $2.2 \times 10^{15}$ electrons. If we assume the atomic density of the $\mathrm{Pt}(111)$ surface is $1.5 \times 10^{15}$ atoms $/ \mathrm{cm}^{2}$, then $7.5 \times 10^{14}$ Re ions form 1 monolayer of Re film on 0.5 $\mathrm{cm}^{2}$ of $\mathrm{Pt}$ substrate. Based on this argument, the average charge of Re ions can be estimated by dividing the charge of 14 shots of Re plasma by the number of atoms on the $\mathrm{Pt}(111)$ substrate surface; the value is +2.9 and it agrees with the charge state distribution of other heavy metal plasma ions analyzed using a time-of-flight mass spectrometer [12].

\subsection{Deposition of $\operatorname{Re}$ on $\mathrm{Pt}(111)$ and $\mathrm{Pt}$ on $\operatorname{Re}(0001)$}

Rhenium, a refractory metal with melting temperature of $3180^{\circ} \mathrm{C}$, was deposited on $\mathrm{Pt}(111)$ and the change of surface composition was monitored by AES. Figure 3.7 (a) shows the Auger spectrum of the clean Pt surface; the platinum peaks appear at 158, 168, 237 and $251 \mathrm{eV}$, but the 150 and $158 \mathrm{eV}$ peaks are not well-resolved by our Auger system. The change of the $\mathrm{Pt} 158 \mathrm{eV}$ peak intensity is plotted in Figure 3.8 as a function of the number of pulses of the Re plasma gun. This Re uptake curve shows breaks at about 14 and 28 pulses of Re plasma. These breaks imply filling of the first and second atomic 


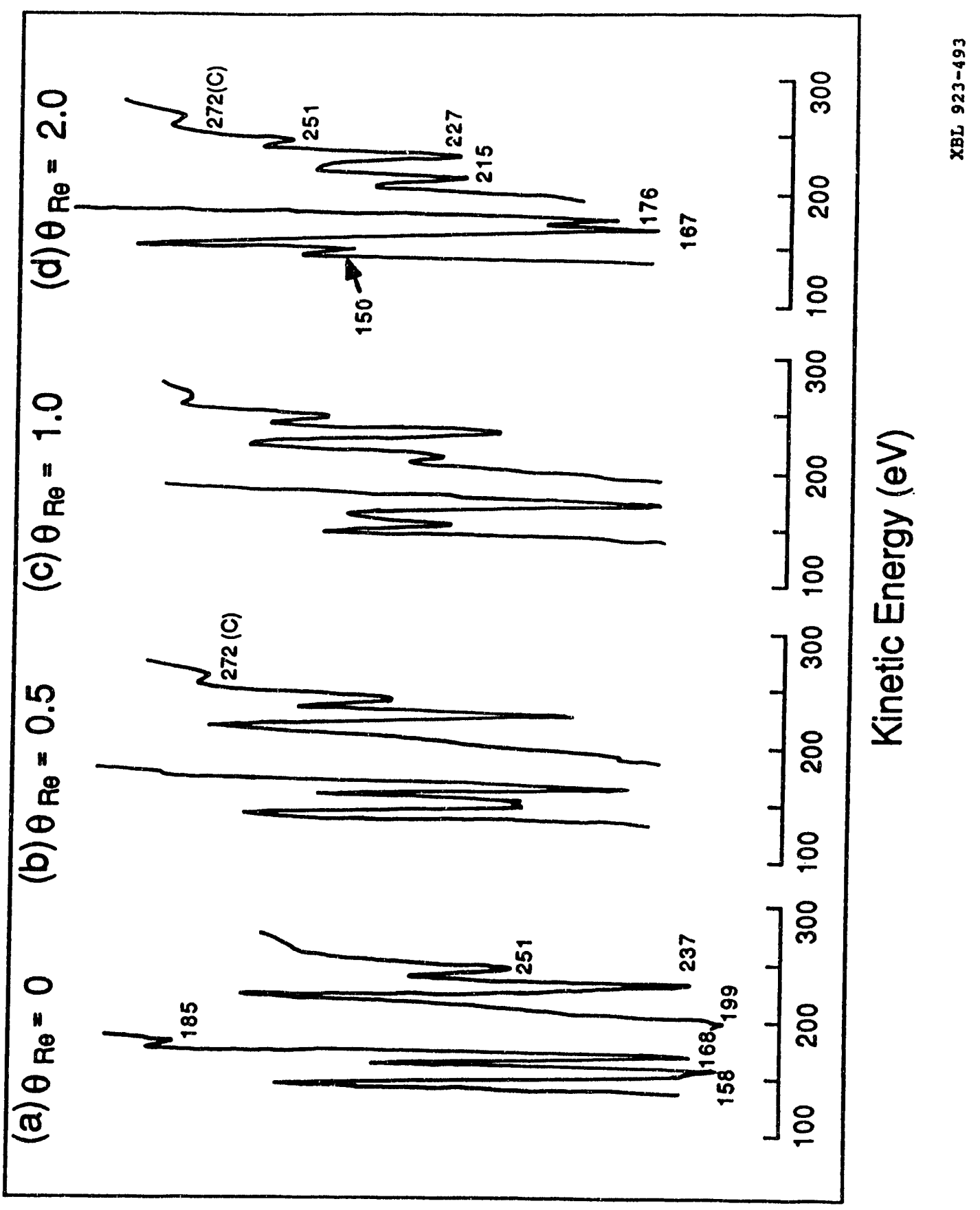

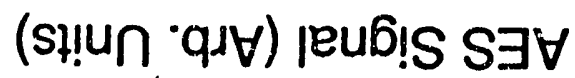

Figure 3.7 Representive AES spectra of the Pt surfaces covered by $\operatorname{Re}$ overlayers. (a) clean $\mathrm{Pt}$, (b) $0.5 \mathrm{ML}$ of $\mathrm{Re}$ on $\mathrm{Pt}$, (c) $1.0 \mathrm{ML}$ of $\mathrm{Re}$ on $\mathrm{Pt}$, (d) $2.0 \mathrm{ML}$ of Re on Pt. 
Chapter 3. PLASMA DEPOSITION SOURCE 63

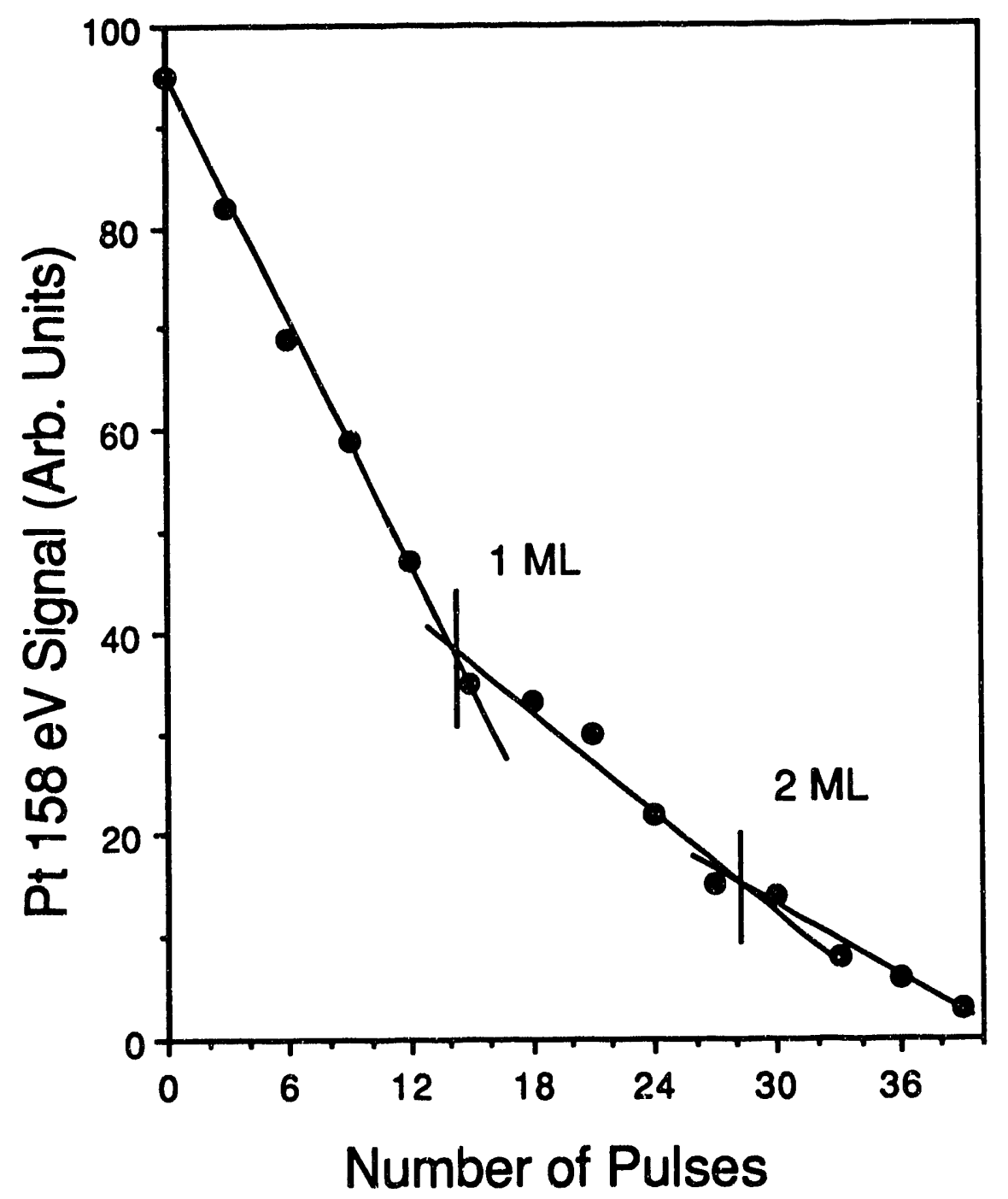

Figure 3.8 Variation of the intensity of the Pt $158 \mathrm{eV}$ Auger signal as a function of the number of pulses of Re plasma. Breaks on the line of best fit occurs at integral numbers of monolayers (complete filling of a monolayer by the plasma flux). 
layers of $\mathrm{Re}$ on $\mathrm{Pt}$, respectively. Similar results were obtained when $\mathrm{Re}$ was deposited on Pt using a resistively heated Re filament [18].

The amount of Re deposited per pulse was quite constant and the Re coverage of the Pt surface could be reproduced easily. Figure 3.7 shows representative Auger spectra of Pt-Re bimetallic surfaces covered by 0 (a), 0.5 (b), 1.0 (c) and 2.0 (d) monolayers of Re on the Pt substrate. The peak at $272 \mathrm{eV}$ is due to carbon contamination on the surface. The most probable source of the carbon impurities is from hydrocarbons deposited on the Re cathode of the vacuum arc plasma gun due to hydrocarbons leaked from the high pressure reactor of this UHV system. The hydrocarbon back ground in the hybrid reactor system is difficult to eliminate even after prolonged bake-out.

Deposited rhenium always forms a (1x1) surface structure on $\mathrm{Pt}(111)$. Figure 3.9 showa the LEED patterns of clean $\mathrm{Pt}(111)$ (a) and the $\mathrm{Pt}(111)$ surface covered by 7 monolayers of rhenium (b). Because interatomic distances of platinum $(d=2.76 \AA)$ and rhenium $(d=2.74 \AA)$ are very close, a $(1 \times 1)$ LEED pattern of clean $\mathrm{Pt}(111)$ and that of the $\mathrm{Pt}(111)$ surface with $7 \mathrm{ML}$ of Re are undistinguishable. Godbey and Somorjai found that thermally evaporated Re atoms form a hexagonal close packed crystal structure on the surface of $\mathrm{Pt}(111)$ [18] based on the LEED I-V experiment. However, in the case of plasma depositon, it was not clear whether deposited Re form a hexagonal close packed structure or face centered cubic structure on the surface of $\mathrm{Pt}(111)$.

We have also carried out the inverse deposition process of forming monolayer films of $\mathrm{Pt}$ on a Re substrate, and this showed a similar layer-bylayer growth mechanism as for the deposition of Re on Pt. Figure 7 shows typical Auger spectra of Pt-Re bimetallic surfaces made by depositing 0, 1.0, 2.0 


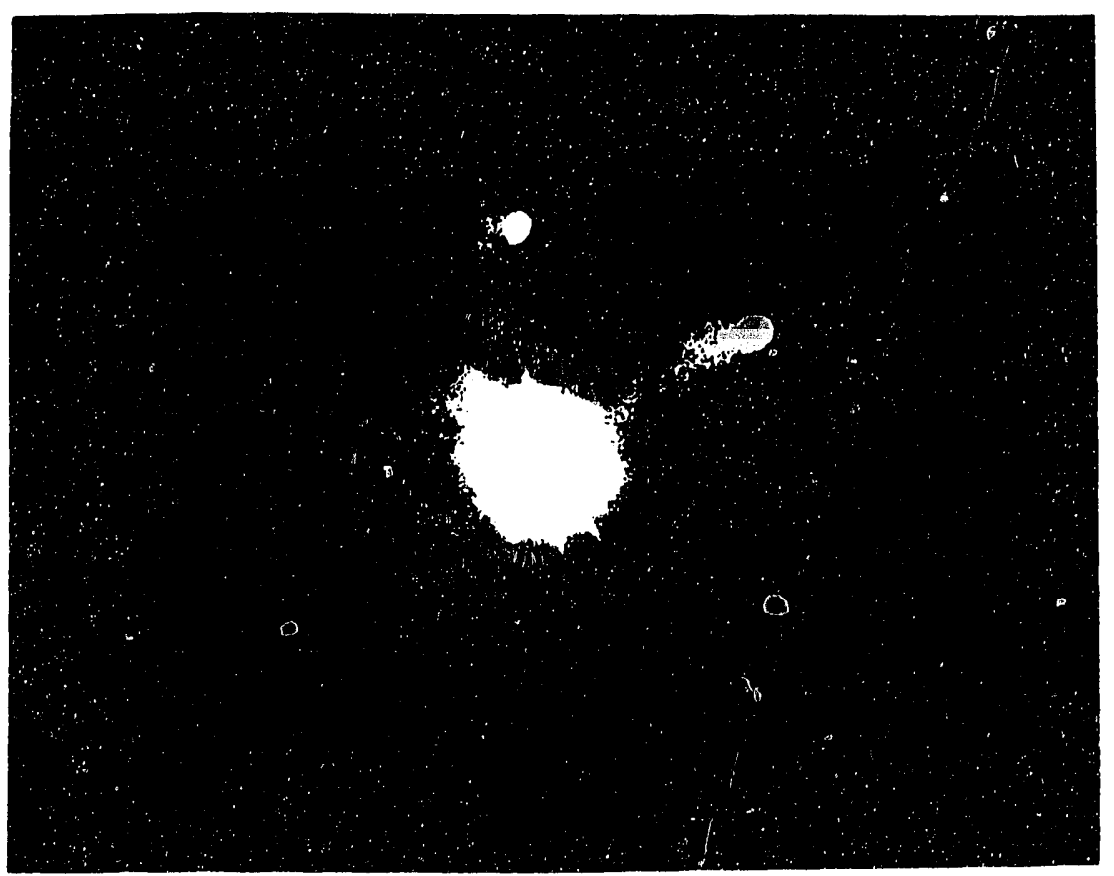

\section{(a) \\ Clean Pt(111)}

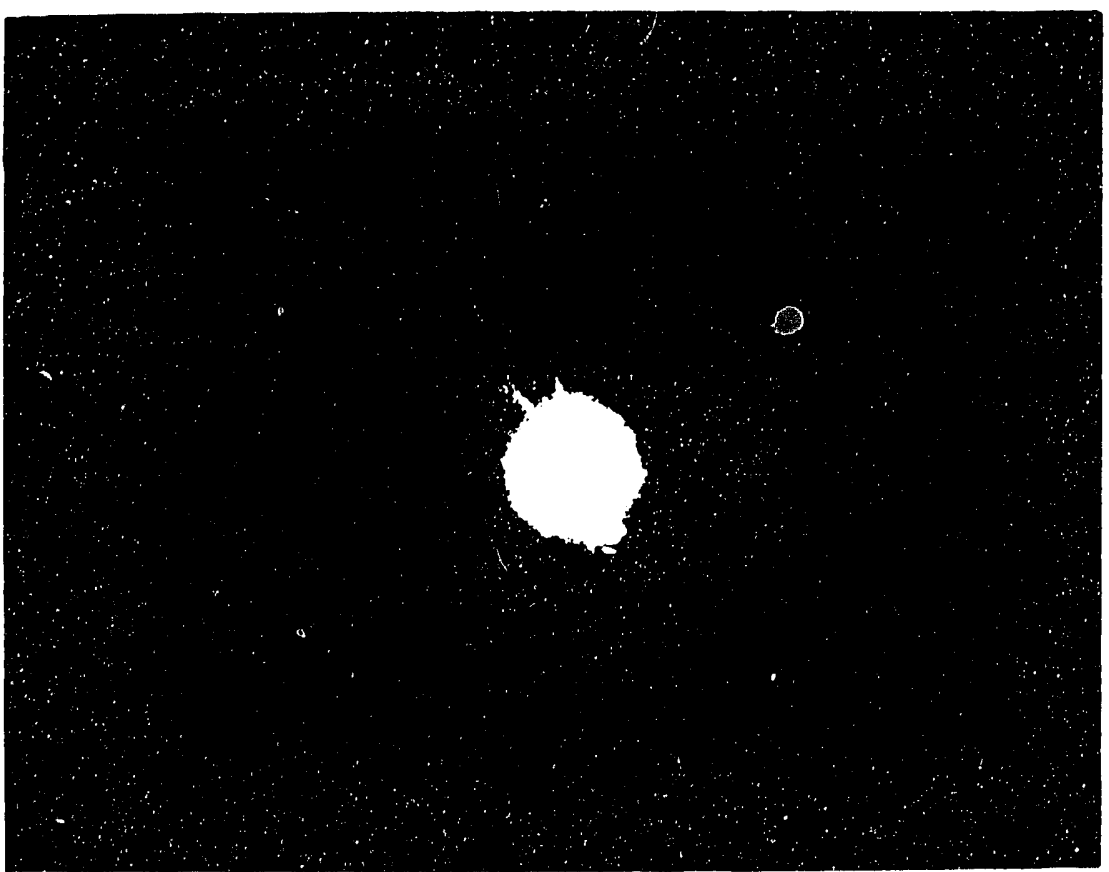

(b)

$7 \mathrm{ML}$ Re on $\operatorname{Pt}(111)$

3.9 LEED paterns of $\mathrm{Pt}(111)$ (a) and the $\mathrm{Pt}(111)$ surface covered by $7 \mathrm{ML}$ of $\mathrm{Re}$ (b). 


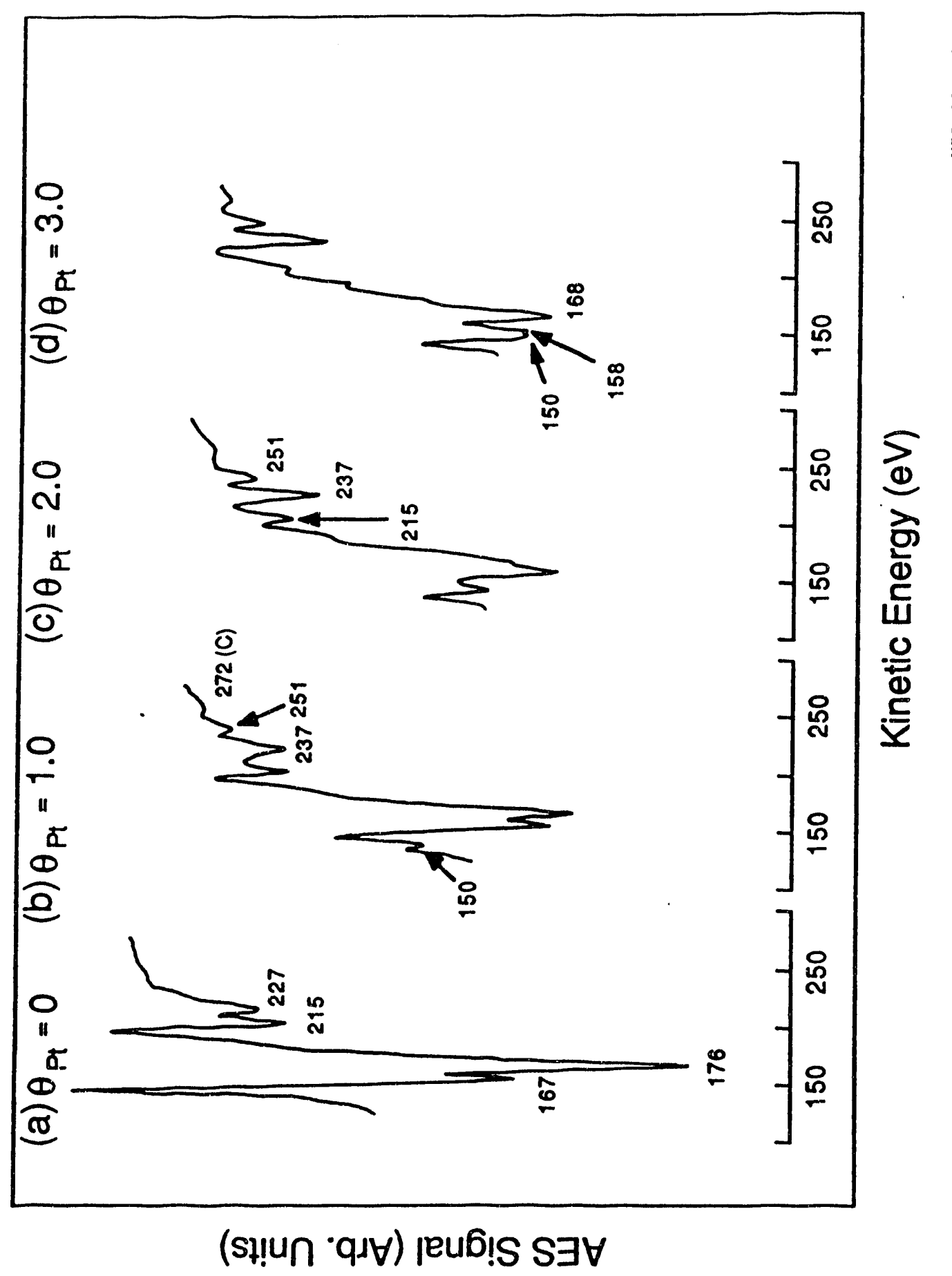

3.10 Representative AES spectra of the Re surfaces covered by Pt overlayers. (a) clean $\mathrm{Re}$, (b) 1.0 ML of Pt on $\mathrm{Re}$, (c) $2.0 \mathrm{ML}$ of Pt on $\mathrm{Re}$, (d) 3.0 ML of Pt on Re. 
and 3.0 monolayers of $\mathrm{Pt}$ onto the Re substrate. After deposition of 3 monolayers of $\mathrm{Pt}$ on the Re substrate, the Auger spectrum of this surface is very close to the Auger spectrum of clean $\mathrm{Pt}$.

\subsection{Summary}

Rhenium was deposited on $\mathrm{Pt}(111)$ and platinum on $\operatorname{Re}(0001)$ in UHV in submonolayer to thin film quantities using a pulsed metal vapor vacuum arc plasma gun technique. This means of fabrication of metal structures has several advantages over more conventional methods for the formation of thin films: (1) it is fundamentally a simple method and consequently fits in well with a research environment; (2) the deposition apparatus can be made extremely small, providing an avenue to locations and situations not normally accessible; (3) the method works for virtually all the solid metallic elements of the Periodic Table and the source is extremely effective for evaporating refractory metals; (4) film thickness can be controlled with great precision, down to 0.01 monolayer or less; (5) the method is very efficient and can work with a very small amount of 'feedstock' material, thus providing a feasible method for the fabrication of structures from expensive and exotic isotopes and materials. That the deposition plasma flux is pulsed and the timing of the plasma pulses can be controlled to the microsecond level provides a means for carrying out a range of novel processes, such as the formation of highly reactive films that could be immediately capped with a protective layer, the formation of unique nonequilibrium materials by using 
Chapter 3 . PLASMA DEPOSITION SOURCE 68

two or more plasma guns simultaneously, and the possibility of conducting some novel plasma chemistry experiments.

\section{References}

[1] K.K. Schuegraf, ed., "Handbook of Thin-Film Deposition Processes and Techniques", Noyes Publications, New Jersey (1988).

[2] K.J. Klabunde, Chem. Tech. 6 (1975) 624.

[3] E. Spiller, AIP Proc. 75 (1981) 125.

[4] K. Ploog and A. Fisher, Appl. Phys. 13 (1971) 111.

[5] D.E. Powers, S.G. Hansen, M.E. Guesic, A.C. Puiu, J.B. Hopkins, T.G. Dietz, M.A. Duncan, P.R. Langridge-Smith, and R.E. Camlley, J. Phys. Chem. 86 (1982) 2556.

[6] E.H. Parker, ed., "The Technology and Physics of Molecular Beam Epitaxy", Plenum Press, New York (1985).

[7] D.M. Sanders, J. Vac. Sci. Tech. A7 (1989) 2339.

[8] R.L. Boxman, S. Goldsmith, S. Shalev, H. Yaloz and N. Brosh, Thin Solid Films 139 (1985) 41.

[9] C. Bergman, in "Ion Plating and Implantation", edited by R. F. Hochman, American Society of Metals, USA, 1986. (Proceedings of the ASM Conference on Applications of Ion Plating and Implantation to Materials, June 3-5, 1985, Atlanta, GA). 
[10] X. Godechot, M.B. Salmeron, D.F. Ogletree, J.E. Galbin, R.A. MacGill, M.R. Dickinson, K.M. Yu and I.G. Brown, Mat. Res. Soc. Symp. Proc. 190 (1991) 95.

[11] I.G. Brown, J.E. Galvin, B.F. Gavin and R.A. MacGill, Rev. Sci. Instrum. 57 (1986) 1069.

[12] I.G. Brown, B. Feinberg and J.E. Galvin, J. Appl. Phys. 63 (1988) 4889.

[13] J.M. Lafferty, ed., "Vacuum Arcs -Theory and Application", Wiley, New York (1980).

[14] P. Malkin, J. Phys. D: Appl. Phys. 22 (1989) 1005.

[15] H.C. Miller, IEEE Trans. Electr. Insul. 26 (1991) 949.

[16] B.L. Schram, Physica 32 (1966) 197.

[17] A. Muller, Phys. Lett 113A (1986) 415.

[18] D.J. Godbey and G.A. Somorjai, Surface Sci. 202 (1988) 204. 


\section{CHAPTER 4}

\section{Conversion of Hydrocarbons over the Pt/Re/S Model Catalyst}

\subsection{Introduction}

The development of the Pt-Re bimetallic reforming catalyst in the late sixties [1] was one of the breakthroughs in the history of transition metal catalyst development. The addition of the second metal, rhenium, to platinum/alumina system greatly enhances the performance of the reforming catalyst. Figure 4.1 clearly shows the advantage of the Pt-Re bimetallic catalyst over $\mathrm{Pt}$ monometallic catalyst. Figure 4.1 (a) shows the average catalyst temperature as a function of hours on stream required to maintain a 100-octane product for the $\mathrm{Pt}$ and Pt-Re catalyst. The catalyst temperature should be increased continuously to maintain the quality of the product because the catalyst deactivates. It is called the fouling rate. The fouling rate of the Pt-Re catalyst is much lower than that of the Pt catalyst. The operation at lower catalyst temperature is an obvious advantage. The higher reaction temperature induces the hydrocracking reactions which have higher activation energies. Figure 4.1 (b) shows the yield of $\mathrm{C}_{5}+$ liquid product during reforming with each of the two catalyst as a function of the 
(a)

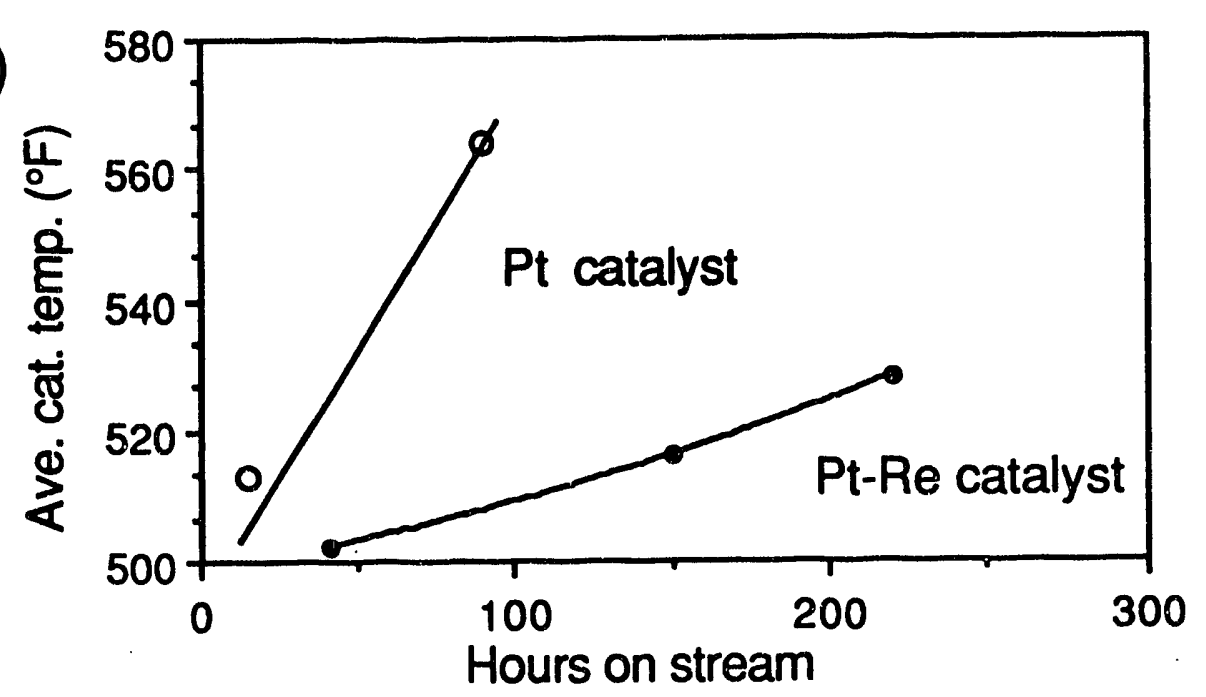

(b)

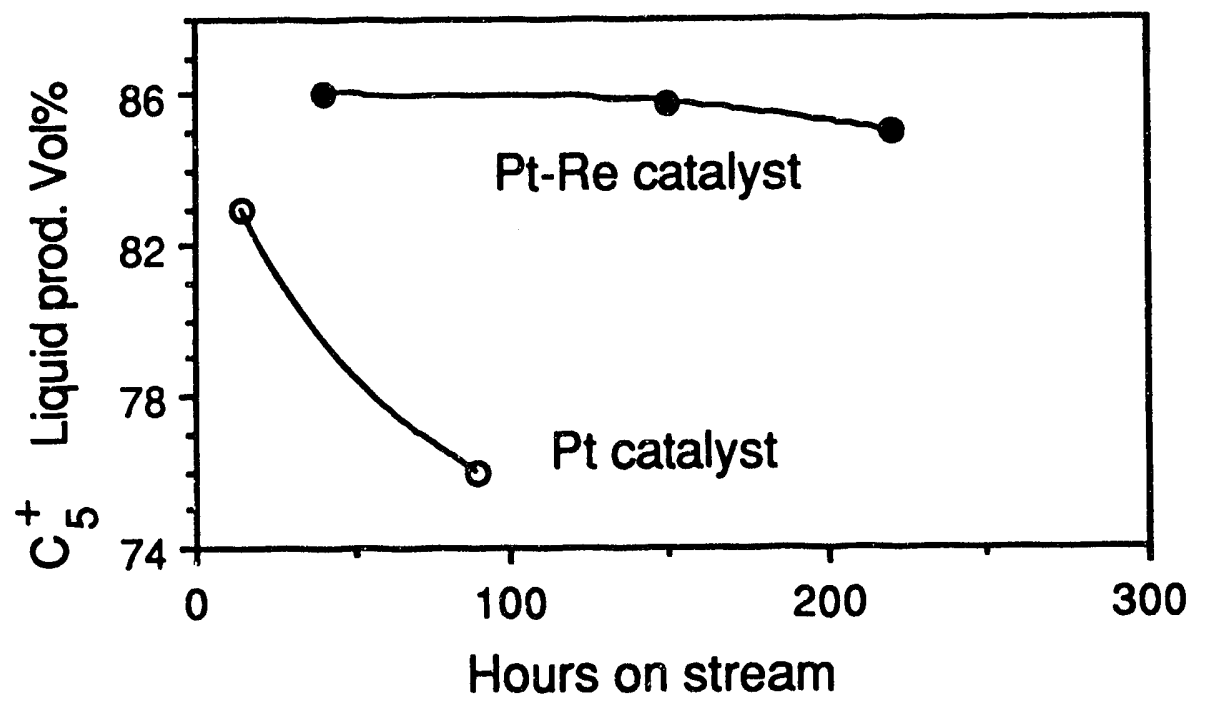

Figure 4.1 Comparison of $\mathrm{Pt}$ and $\mathrm{Pt}-\mathrm{Re}$ catalysts (from ref. [1]) in reforming. (a) The average catalyst temperature required to maintain a 100-octane product. (b) The yield of $\mathrm{C}_{5}+$ liquid product. 
time on-stream. The Pt-Re catalyst maintains high yield, but the yield from the $\mathrm{Pt}$ catalyst decreases rapidly because of the operation at the higher temperature. Higher hydrocracking rate not only decreases the yield of the liquid product but accerarates deactivation of the catalyst due to the formation of the coke layer on the catalyst surface.

The reason for the enhanced catalytic performance of $\mathrm{Pt}-\mathrm{Re}$ over $\mathrm{Pt}$ has not been fully understood. The proposed mechanisms for the enhanced performance are summarized in Chapter 1. In general, "ensemble effect" and "ligand effect" have been introduced to explain the changes in catalytic activity and selectivity of bimetallic or multimetallic catalysts [2].

The ensemble effect is based on the assumption that many adsorption complexes require more than one surface atom for the formation of surface chemical bonds. If the alloy of two metals provides ideal adsorption sites for reactents or reaction intermediates of a particular reaction, the selectivity for that particular reaction would be increased.

The ligand effect stems from the observation in organometallic chemistry and homogeneous catalysis. The nature and strength of the metalligand bond is influenced by the other species bonded to the central metal atom. It is commonly observed in homogeneous catalysis [3] but there is not much experimental evidence in heterogeneous catalysis.

In the actual reforming reactions, the Pt-Re bimetallic catalyst is complicated with sulfur, chlorine, alumina and carbon deposit. That makes it very difficult to study and determine the role of $\mathrm{Re}$ in the Pt-Re catalyst. Sulfur is used to suppress the initial hydrocracking activity of the catalyst and the Pt-Re catalyst shows its unique property when it is sulfided. Carbon 
deposit poisons the catalyst but it suppresses hydrocracking activity of the catalyst like sulfur [1]. Alumina is used to disperse and support metal components, but alumina also has its own catalytic activity because of its acidic property [4]. Chlorine is used to control the acidity of the alumina support.

In this chapter, the results of hydrocarbon conversion over model PtRe catalysts have been presented. In this model catalyst system, acidic part of the reforming catalyst was excluded and only the metal part of the catalyst was studied. The change of product distribution due to the interaction between two metals, $\mathrm{Pt}$ and $\mathrm{Re}$, and the interaction between metal and sulfur has been studied. The effect of sulfur on the decomposition of hydrocarbons on the metal surfaces has been also studied to understand the role of sulfur in the catalytic process.

The Pt-Re bimetallic model catalyst surfaces were prepared either by depositing $\operatorname{Re}$ on $\operatorname{Pt}(111)$ or by depositing $\mathrm{Pt}$ on $\operatorname{Re}(0001)$. The plasma deposition source, which is described in Chapter 3, was used to deposit metals. Sulfided catalysts were prepared by depositing atomic sulfur on the catalyst surface in UHV using a solid state electrochemical cell described in Chapter 2. The process of catalyst preparation is shown schematically in Figure 4.2. 

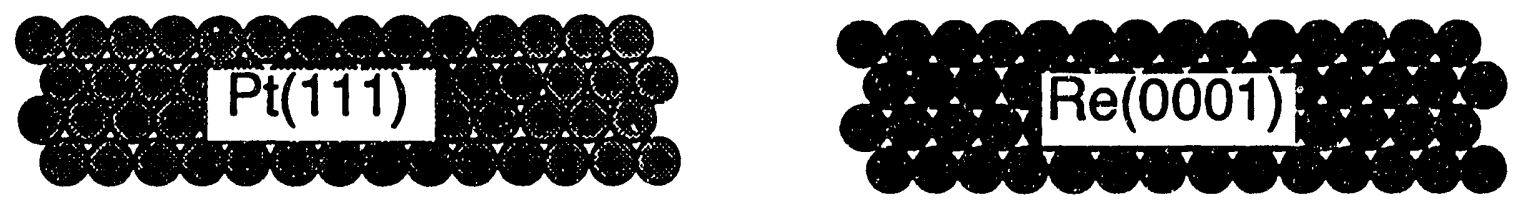

Re

Deposition of Second metal
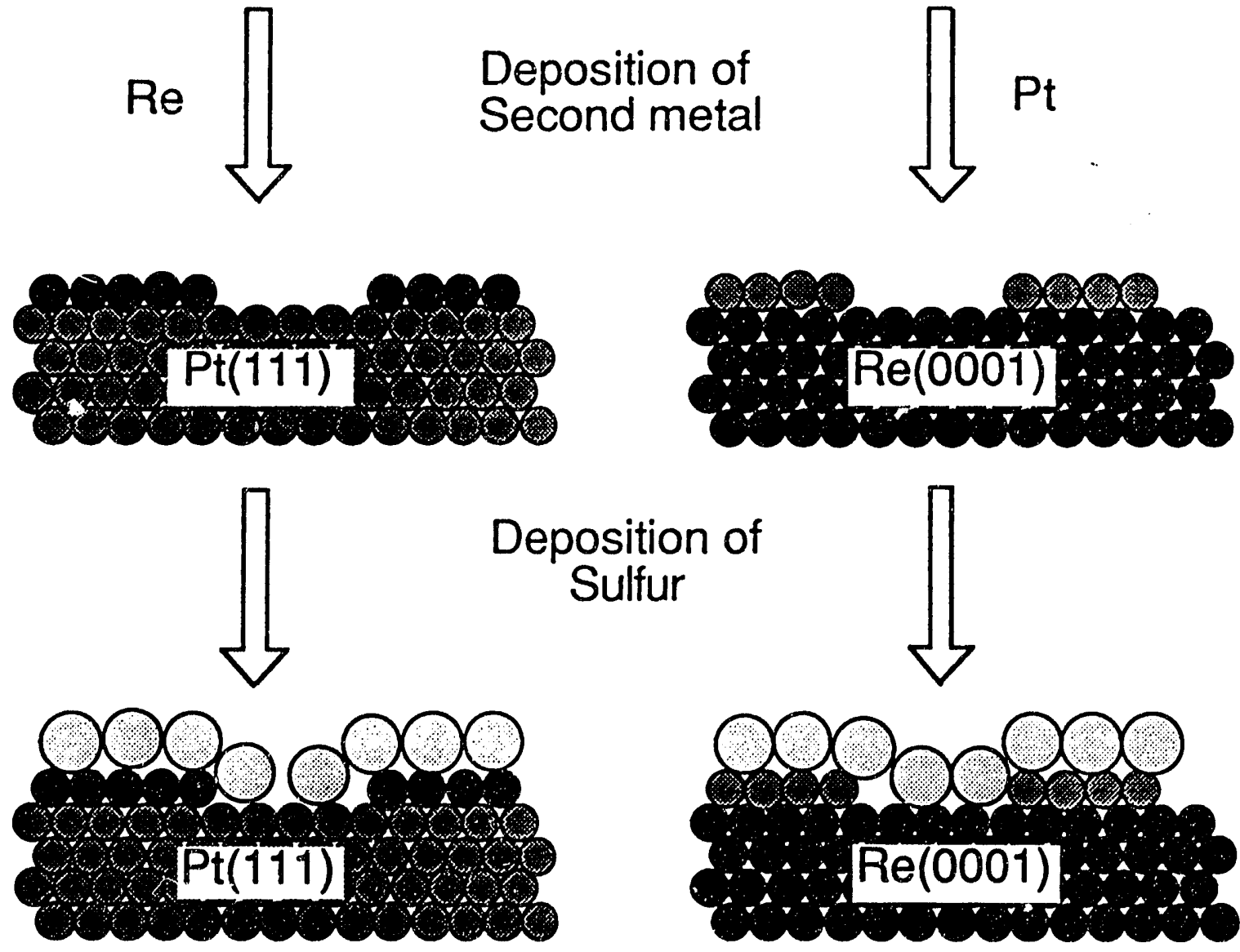

Sulfur

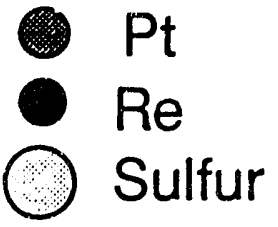

Figure 4.2 Preparation of the Pt-Re bemetallic model catalyst surfaces. 


\subsection{Conversion of Hydrocarbons over $\mathrm{Pt} / \mathrm{Re} / \mathrm{S}$}

\subsubsection{Conversion of $\mathrm{n}$-hexane over $\mathrm{Pt}(111) / \mathrm{Re}$ and $\mathrm{Pt}(111) / \mathrm{Re} / \mathrm{S}$}

Conversion of $n$-hexane was performed over $\mathrm{Pt}(111)$ using 20 Torr of $n$ hexane and 200 Torr of hydrogen. The reaction temperature was $300^{\circ} \mathrm{C}$ and the reaction was generally continued for two hours. After two hours of reaction on $\mathrm{Pt}(111)$, total conversion uras about $1 \%$ and the products were composed of methylcyclopentane (cyclization), $C_{1}-C_{5}$ hydrocarbons (hydrogenolysis), 2- and 3-methylpentane (isomerization), a small amount of benzene (dehydrocyclization), and olefins (dehydrogenation). The effect of $\operatorname{Re}$ coverage on $\mathrm{Pt}(111)$ on the reactivity and selectivity of $n$-hexane conversion was determined. The presence of $\operatorname{Re}$ on $\mathrm{Pt}(111)$ increased hydrogenolysis activity enormously (Figure 4.3). The initial turnover frequency for hydrogenolysis increased from $0.038 \mathrm{molecules} / \mathrm{sec} / \mathrm{site}$ to 0.87 molecules/sec/site when the $\mathrm{Pt}(111)$ surface was covered by 1 monolayer (ML) of Re. Cyclization activity over Pt decreased as Re coverage increased. Isomerizaion and dehydrocyclization activities were too low to be compared meaningfully.

The single crystal catalysts used in this experiment were deactivated very quickly in the reaction condition used. After two hours of reaction, the catalyst surfaces were heavily deposited with carbon. The amount of carbon left on the surface after the reaction was estimated based on AES spectra. Figure 4.4 shows the amount of carbon left on the surface after the reaction

over the Pt catalysts with different Re coverage. The peak-to-peak heights of Pt 273 peak from the Pt-Re surfaces were calibrated to compensate the 
attenuation by coadsorbed Re. Using ${ }^{14} \mathrm{C}$-radiotracer technique, Davis showed that the $\mathrm{C}_{273} / \mathrm{Pt}_{237}$ AES peak-to-peak height ratio was about 1.5 when the $\mathrm{Pt}(111)$ surface was covered by $1 \mathrm{ML}$ of carbon [5]. Carbon left on the catalyst surface was roughly proportional to the activity of hydrogenolysis of the catalyst.

The effect of sulfur on the catalysis of Pt-Re was studied by sulfiding the catalysts before the reaction. Initial sulfiding changed the selectivity of the catalysts. The most significant change was a decrease in hydrogenolysis activity and an increase in cyclization activity (Figure 4.5). By sulfiding, hydrogenolysis activity over the $\mathrm{Pt}(111)$ surface covered by $1 \mathrm{ML}$ of $\mathrm{Re}$ dropped from 0.87 to 0.11 molecules $/ \mathrm{sec} / \mathrm{site}$, and cyclization activity increased from 0.17 to 0.4 molecules / $/ \mathrm{sec} / \mathrm{site}$. When the Pt-Re bimetallic surfaces were sulfided, maximum rates for hydrogenolysis and cyclization were observed when the Pt surface was covered by $0.5 \mathrm{ML}$ of Re and $1 \mathrm{ML}$ of Re, respectively. Figure 4.6 shows the difference between sulfided and unsulfided Pt-Re catalysts toward cyclization of $n$-hexane to methylcyclopentane. In the case of unsulfided catalysts, the addition of Re on $\mathrm{Pt}(111)$ decreased cyclization activity. However, sulfiding of the catalyst increased the cyclization activity and the maximum activity was observed when the surface was covered by $1 \mathrm{ML}$ of Re. When the Pt surface was covered by $1 \mathrm{ML}$ of $\mathrm{Re}$, the sulfided catalyst was twice as reactive as the unsulficied catalyst. "able 1 summarizes the initial turn-over rates for the conversion of $\mathrm{n}$-hexane on clean $\mathrm{Pt}(111), \mathrm{Pt}(111)$ with $1 \mathrm{ML}$ of $\mathrm{Re}$, and sulfided $\mathrm{Pt}(111)$ with $1 \mathrm{ML}$ of $\mathrm{Re}$. 


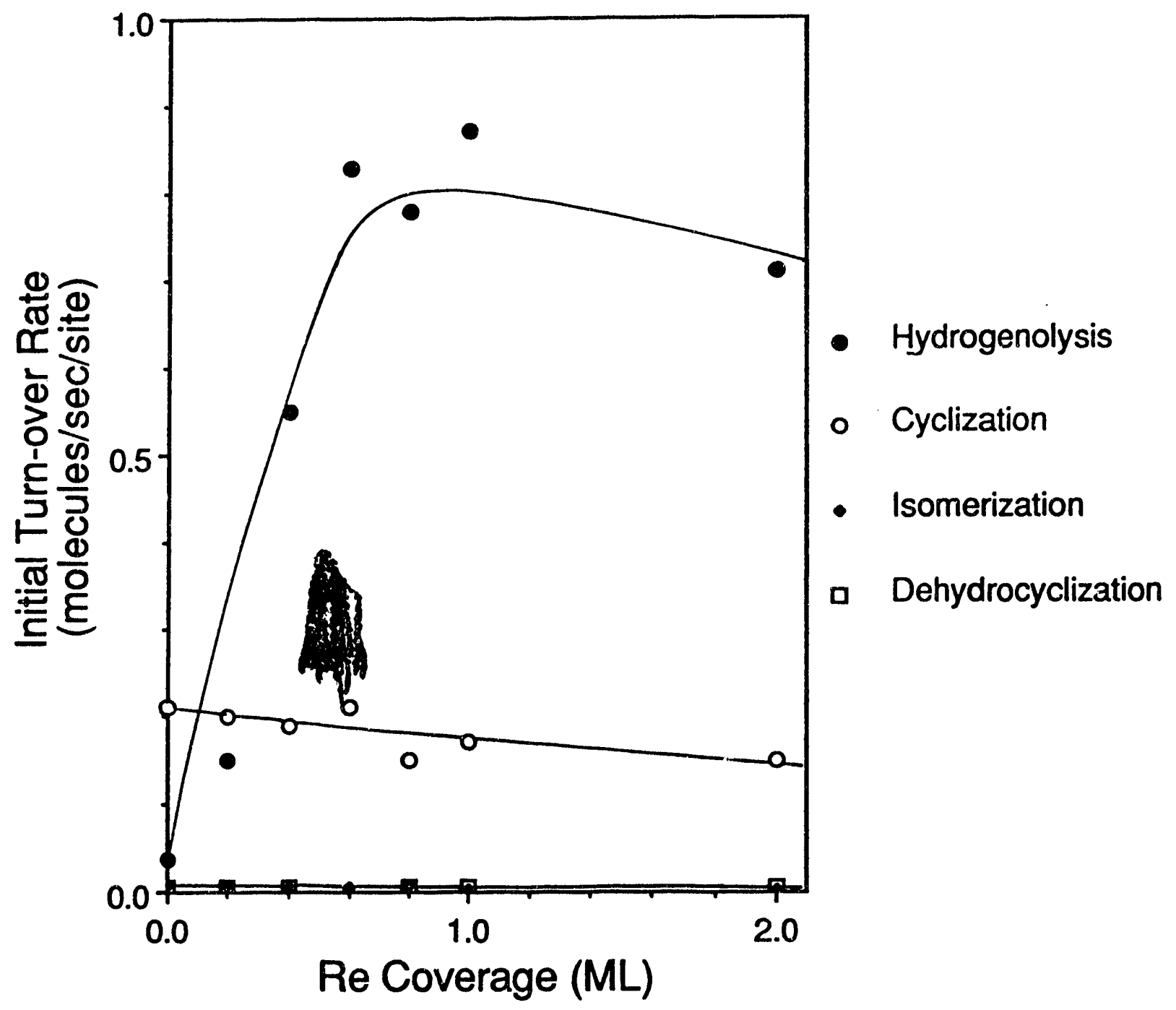

Figure 4.3 Rate of $n$-hexane conversion on the Re-modified $\mathrm{Pt}(111)$ surfaces. Reaction conditions: $\mathrm{T}=300^{\circ} \mathrm{C}, \mathrm{P}_{\mathrm{n} \text {-hexane }}=20 \mathrm{Torr}$, and $\mathrm{P}_{\mathrm{H}_{2}}=200$ Torr. 
Chapter 4. Pt-Re-S System

78

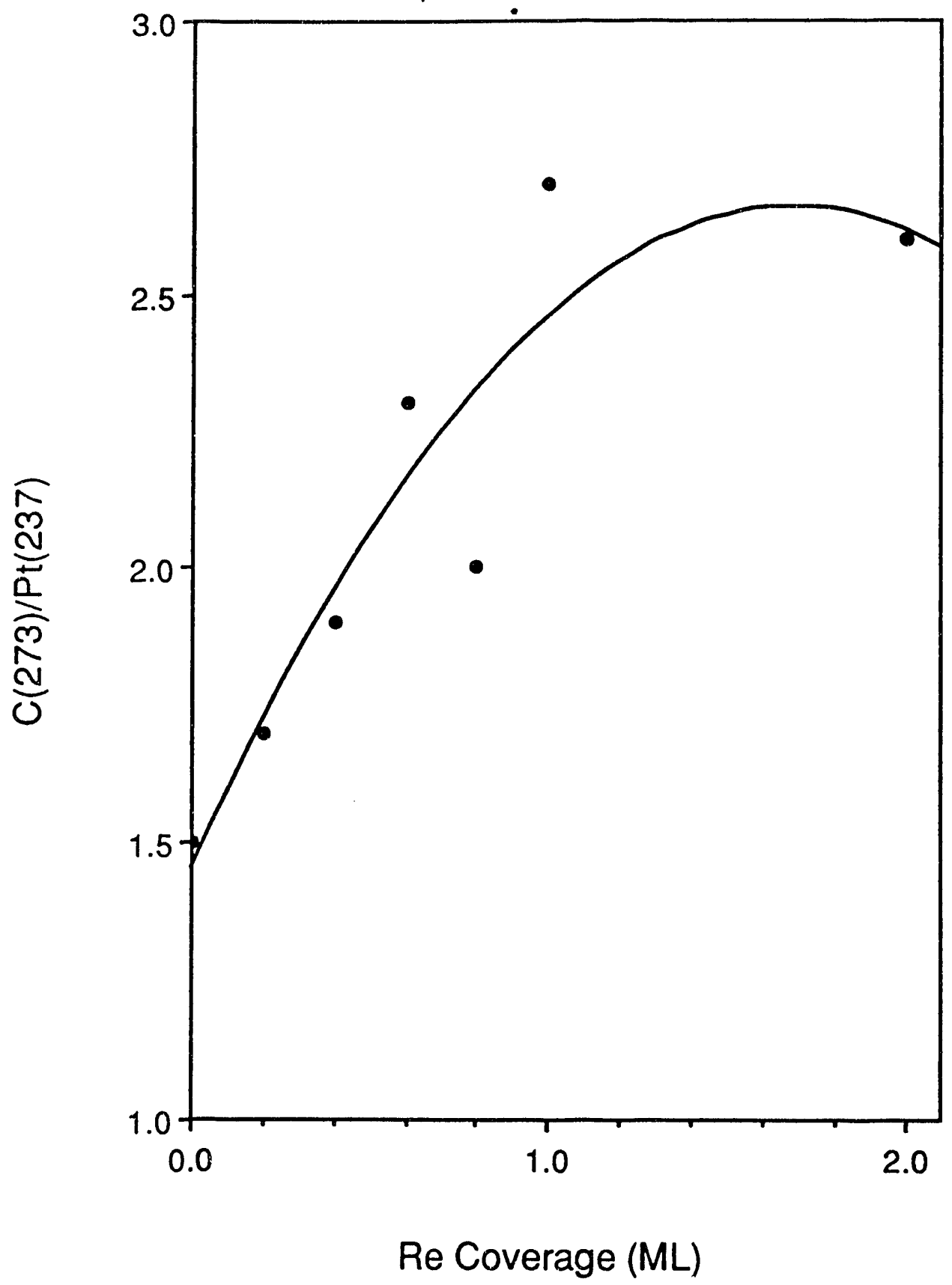

Figure 4.4 Carbon left of the Pt-Re catalyst surface after 2 hours of $n$-hexane reaction. Reaction conditions: $\mathrm{T}=300^{\circ} \mathrm{C}$, n -hexane $=20$ Torr, and $\mathrm{P}_{\mathrm{H}_{2}}=200$ Torr. 


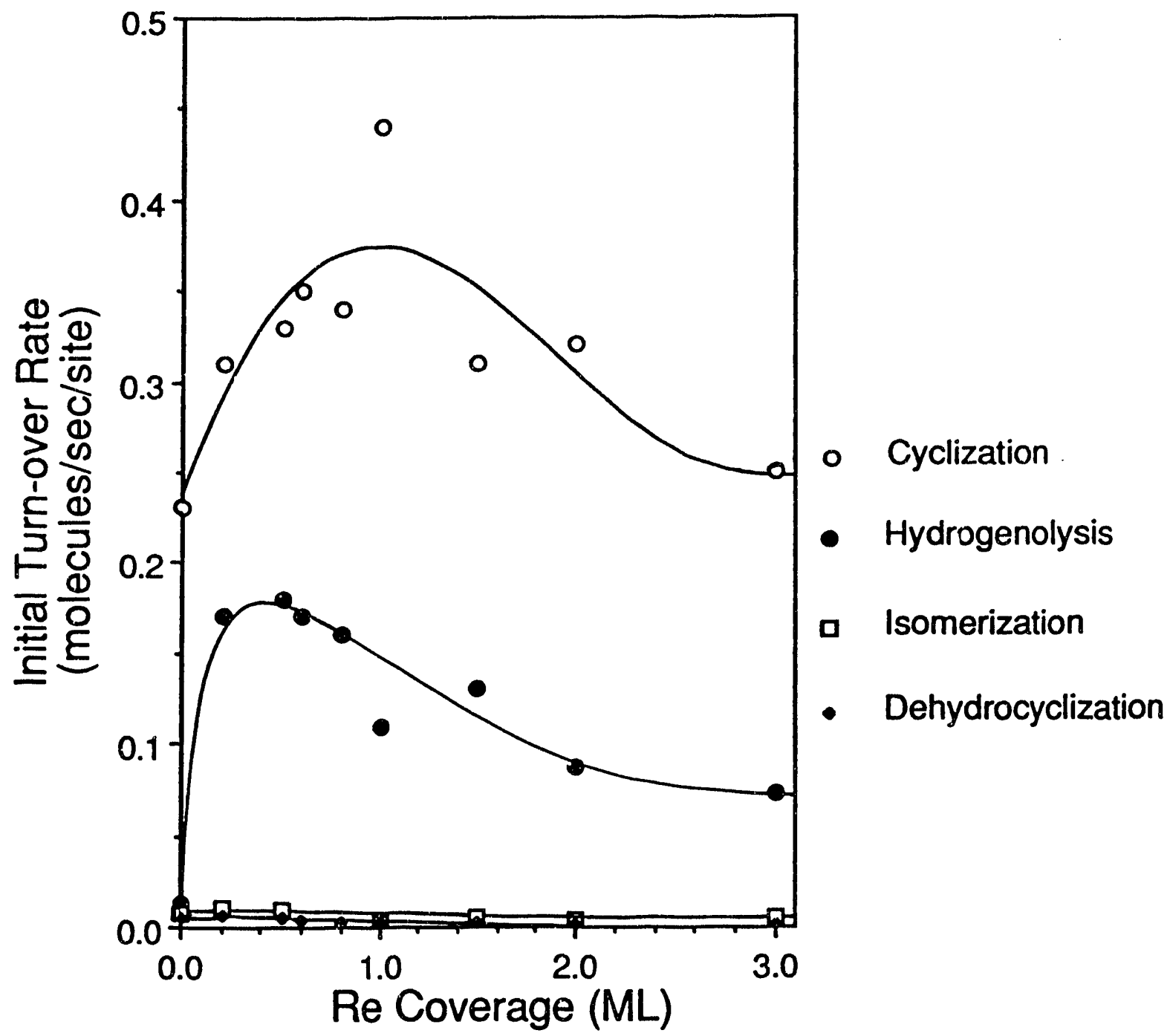

Figure 4.5 Rate of $n$-hexane conversion on the Re-modified $\mathrm{Pt}(111)$ surfaces which are presulfided. The catalysts were sulfided by depositing saturation amount of sulfur. Reaction conditions: $\mathrm{T}=300^{\circ} \mathrm{C}, \mathrm{P}_{\mathrm{n} \text {-hexane }}=20 \mathrm{Torr}$, and $\mathrm{P}_{\mathrm{H}_{2}}=$ 200 Torr. 
Chapter 4. Pt-Re-S System 80

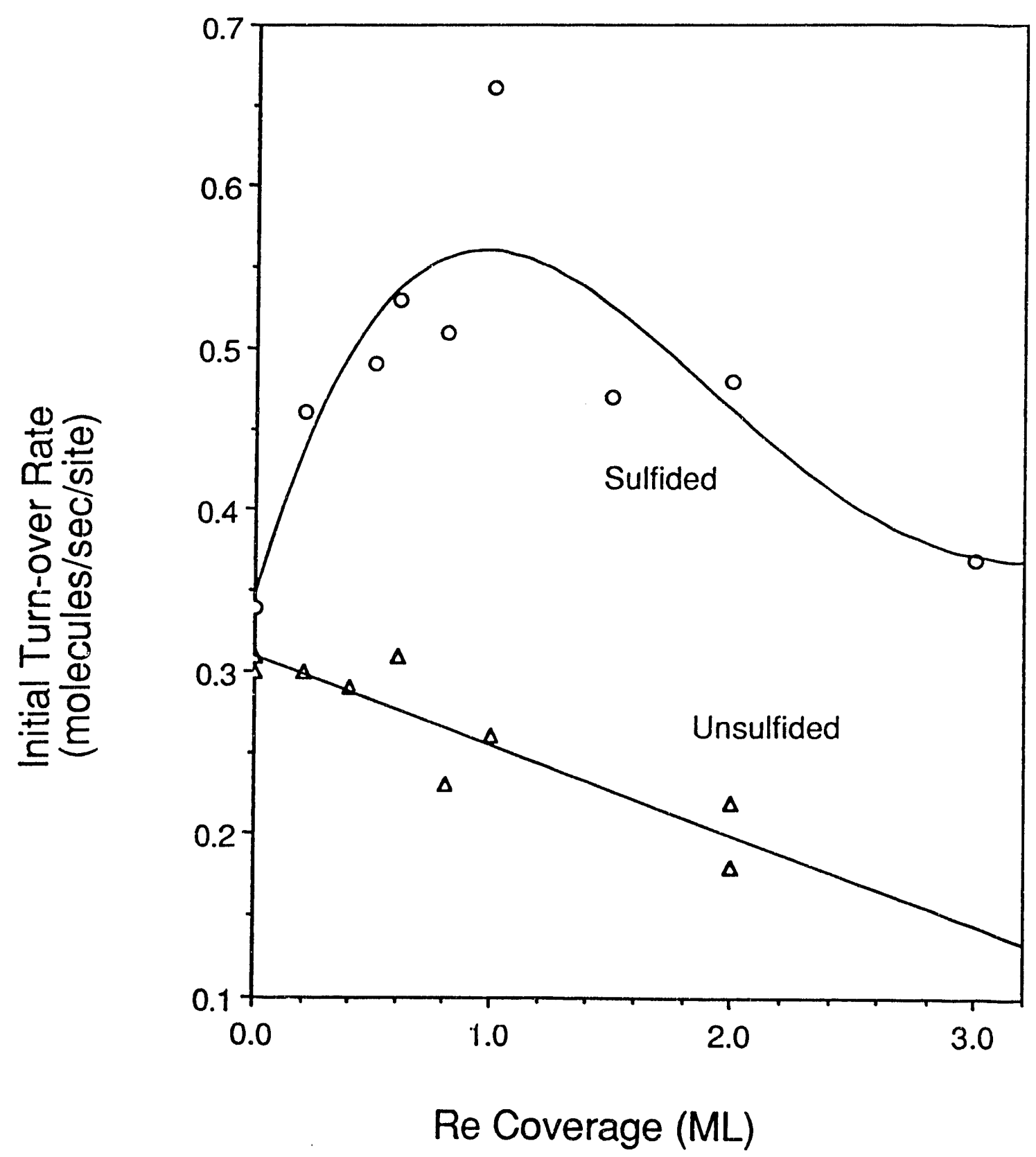

Figure 4.6 Cyclization $c$ ? $n$-hexane on sulfided and unsulfided $\operatorname{Re} / \mathrm{Pt}(111)$ surfaces. Reaction conditions: $\mathrm{T}=300^{\circ} \mathrm{C}, \mathrm{P}_{\mathrm{n} \text {-hexane }}=20 \mathrm{Torr}$, and $\mathrm{P}_{\mathrm{H}_{2}}=200 \mathrm{Torr}$. 
Chapter 4. Pt-Re-S System

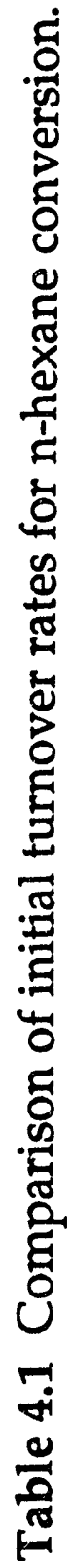

\begin{tabular}{|c|c|c|c|c|}
\hline 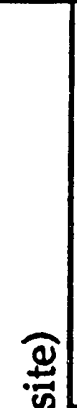 & 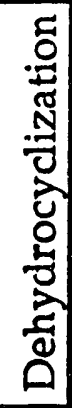 & 范 & 苂 & రి \\
\hline 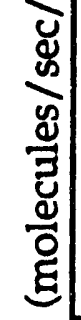 & 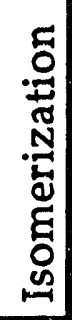 & oे & $\begin{array}{l}0 \\
0 \\
0\end{array}$ & రి \\
\hline 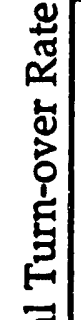 & 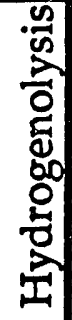 & $\begin{array}{l}\infty \\
0 \\
0\end{array}$ & $\stackrel{\infty}{0}$ & 궁 \\
\hline 되 & 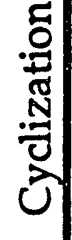 & $\stackrel{\check{0}}{0}$ & $\stackrel{\overrightarrow{0}}{0}$ & $\mathbb{Z}$ \\
\hline & 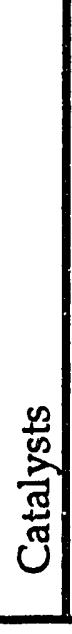 & 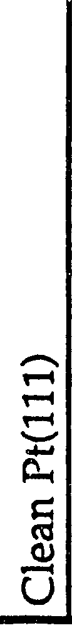 & 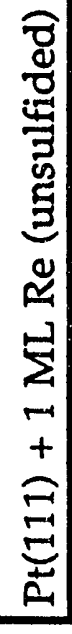 & 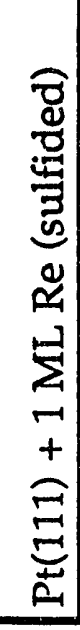 \\
\hline
\end{tabular}


The hydrogenolysis of hydrocarbons, in the range of $\mathrm{C}_{2}-\mathrm{C}_{8}$, over Pt-Re bimetallic catalysts has been studied extensively [6-8]. Because of lower activation energy of hydrogenolysis over the Re catalysts [9], the Pt-Re catalysts show high hydrogenolysis activity. It has been generally found that the Pt-Re bimetallic catalysts show higher hydrogenolysis activity than the physical mixture of $\mathrm{Pt}$ and Re [10]. It is well known that sulfur selectively poisons the hydrogenolysis activity of hydrocarbon conversion catalysts [7]. The model catalysts used in this work also show that the addition of Re on $\mathrm{Pt}(111)$ increases hydrogenolysis and coadsorbed sulfur selectively suppresses the hydrogenolysis of $n$-hexane (Figures 4.4 and 4.5). However, it is a quite unusual result that co-adsorbed sulfur enhances the activity of cyclization of $n$-hexane over Pt-Re catalysts (Figure 6). This result shows that sulfur not only change the selectivity of the catalyst by selective poisoning but enhances the reactivity. One possible explanation stems from the competition between the two different reactions, hydrogenolysis and cyclization. Over sulfided catalysts, adsorbed hydrocarbon species have a greater probability to form cyclic molecules because hydrogenolysis activity is suppressed. This argument is especially applicable to the case of the conversion of n-hexane over the Pt-Re catalysts, on which hydrogenolysis is a dominant reaction.

The selective formation of methylcyclopentane over benzene is an important result. Since the sulfided Pt-Re system on alumina is wellrecognized for its superior aromatization (dehydrocyclization) activity, the model Pt-Re-S system of this work is clearly different from that used in the petroleum refining technology. Either the unique preparation of the catalysts is responsible for the enhanced selectivity for methyl cyclopentane formation 
or the requirement of the presence of alumina is implicated for ring enlargement of the five-membered cyclic molecules to six-membered rings followed by dehydrogenation to benzene.

As the results of hydrocarbon conversion over Pt-Re show, the reactivity of the bimetallic catalyst is greater than the linear combination of the reactivities of the two components, $\mathrm{Pt}$ and Re. The Pt-Re-S catalysts show the maximum reactivity when the Pt surface is covered by $1.0 \mathrm{ML}$ of Re for cyclization of $\mathbf{n}$-hexane toward methylcyclopentane. There is the possibility that the effective surface area of Pt is increased by deposition of Re. However, titration by CO TPD showed that the effective area for $\mathrm{CO}$ adsorption decreased as Re coverage increased (Figure 4.7). It is not unusual that the reactivity of the bimetallic catalyst is more than the linear combination of the activity of the two components. Hydrogenolysis of ethane over Pt-Re bimetallic catalysts showed the highest activity when the Pt surface was covered by $1 \mathrm{ML}$ of $\mathrm{Re}$ [8] and hydrogenation of $\mathrm{CO}_{2}$ to methane on $\mathrm{Rh}$ showed the highest activity when the Rh surface was covered by $0.5 \mathrm{ML}$ of titania $\left(\mathrm{TiO}_{x}\right)$ [11]. 


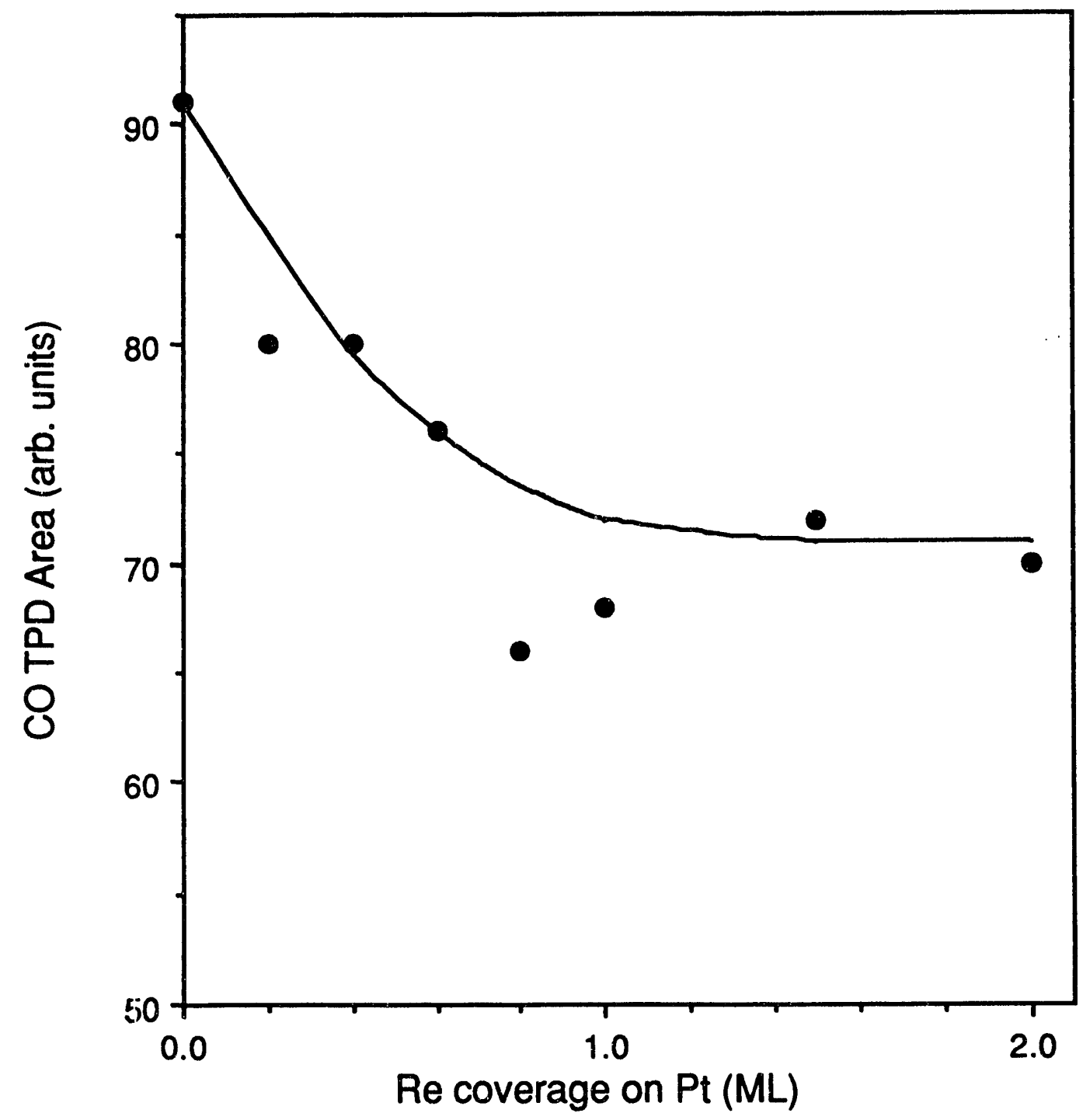

Figure 4.7 Change of $\mathrm{CO}$ adsorption area of the Re-covered $\mathrm{Pt}(111)$ surfaces. $\mathrm{CO}$ adsorption area is the peak area of the CO TPD spectrum. 


\subsubsection{Conversion of $\mathrm{n}-\mathrm{Hexane}$ over $\operatorname{Re}(0001) / \mathrm{Pt}$ and $\operatorname{Re}(0001) / \mathrm{Pt} / \mathrm{S}$}

Conversion of $n$-hexane was performed over Pt-covered Re(0001). Reaction conditions were the same as the conditions for the reaction over Re-covered $\mathrm{Pt}(111) ; 20$ Torr of $\mathrm{n}$-hexane and 200 Torr of $\mathrm{H}_{2}$ reacted at $300^{\circ} \mathrm{C}$. Figure 4.8 shows the change of the conversion rate of n-hexane as a functionof $\mathrm{Pt}$ coverage on $\operatorname{Re}(0001)$. As the $\mathrm{Pt}$ coverage increased, cyclization activity increased. When the $\mathrm{Pt}$ coverage was $2.0 \mathrm{ML}$, the initial turnover frequency was $0.24 \mathrm{molecules} / \mathrm{sec} / \mathrm{site}$. This value is very close to the turnover frequency over clean $\mathrm{Pt}(111)$ at the same reaction conditions. Hydrogenolysis showed interesting results. Addition of less active $\mathrm{Pt}$ increased hydrogenolysis activity an the maximum activity was obtained when the $\mathrm{Re}(0001)$ surface was cove fed by about $0.5 \mathrm{ML}$ of $\mathrm{Pt}$. Isomerization and clehydrocyclization activity were lower than hydrogenolysis and cyclization activities by one order of magnitude.

The effect of sulfur on Pt-covered Re was investigated by depositing saturation amount of sulfur on the catalyst surfaces before the reaction. Addition of sulfur suppressed hydrogenolysis activity and increased cyclization activity slightly (Figure 4.9). 


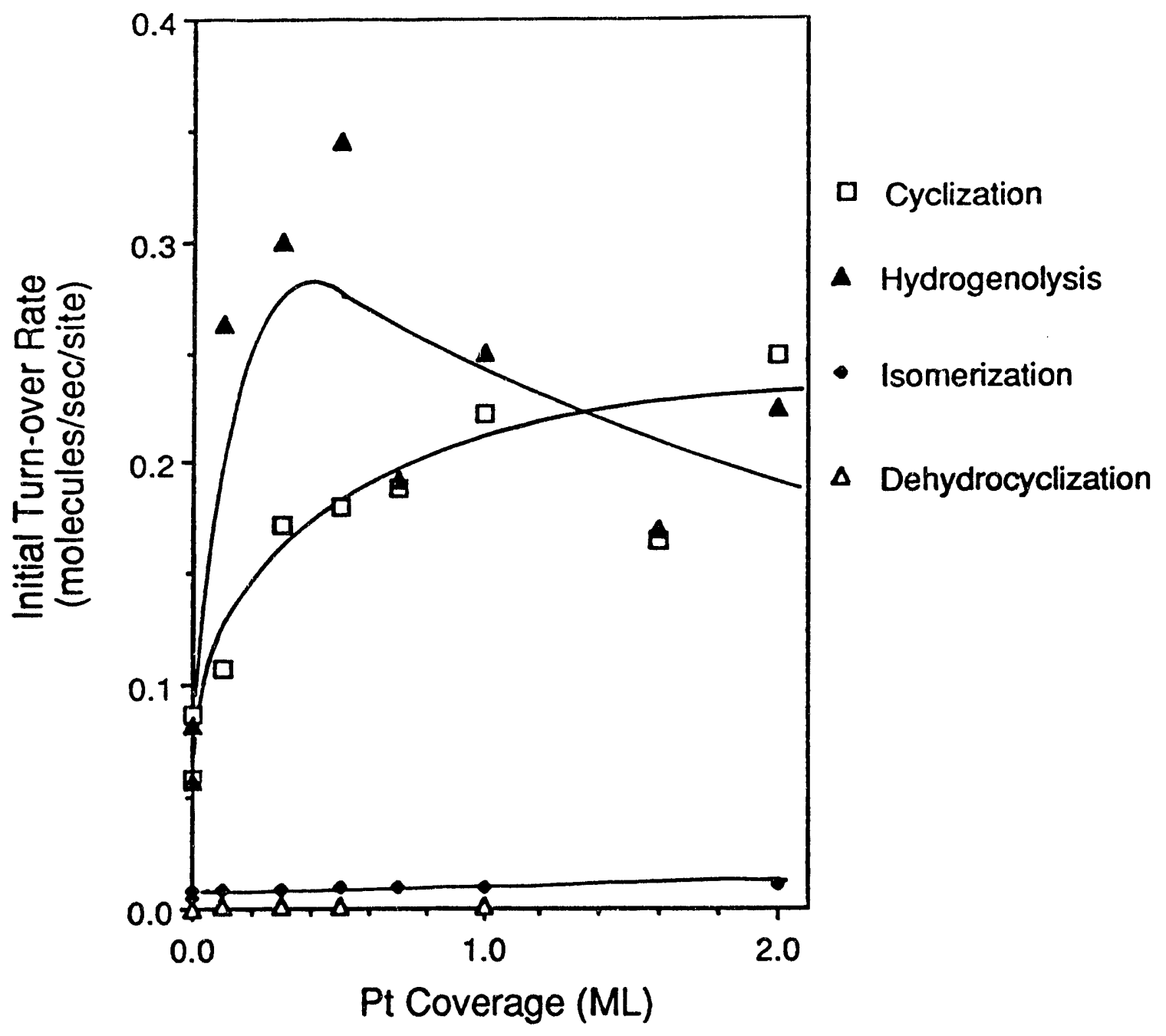

Figure 4.8 Rate of $n$-hexane conversion on the Pt-modified $\operatorname{Re}(0001)$ surfaces. Reaction conditions: $\mathrm{T}=300^{\circ} \mathrm{C}, \mathrm{P}_{\mathrm{n} \text {-hexane }}=20 \mathrm{Torr}$, and $\mathrm{P}_{\mathrm{H}_{2}}=200$ Torr. 


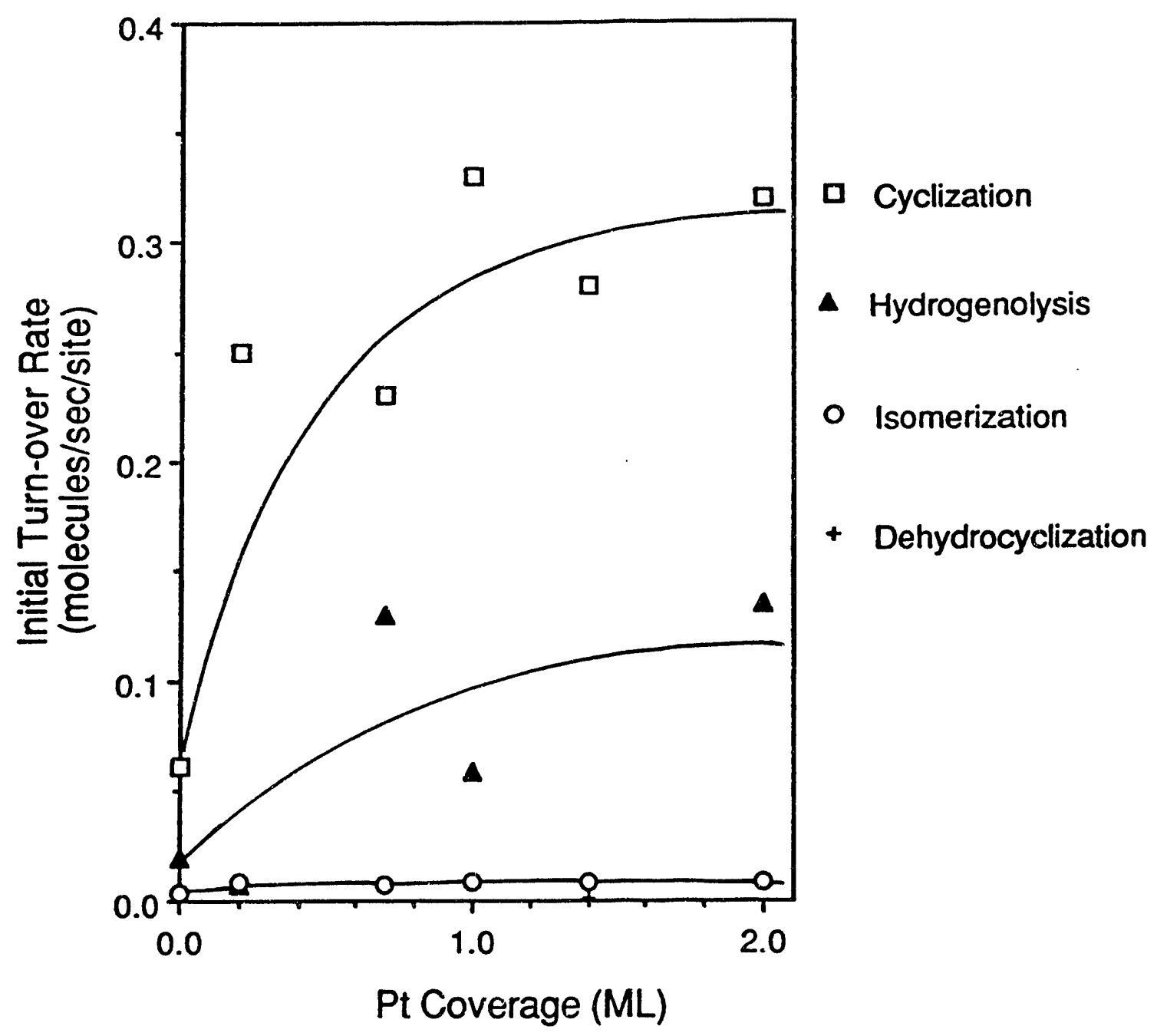

Figure 4.9 Rate of $n$-hexane conversion on the Pt-modified $\operatorname{Re}(0001)$ surfaces which are presulfided. The catalysts were sulfided by depositing saturation amount of sulfur. Reaction conditions: $\mathrm{T}=300^{\circ} \mathrm{C}, \mathrm{P}_{\text {n-hexane }}=20 \mathrm{Torr}$, and $\mathrm{P}_{\mathrm{H}_{2}}=$ 200 Torr. 


\subsubsection{Conversion of Cyclohexane over $\mathrm{Pt}(111) / \mathrm{Re}$ and $\mathrm{Pt}(111) / \mathrm{Re} / \mathrm{S}$}

Conversion of cyclohexane over the Pt-Re catalysts was performed under the same reaction conditions for $n$-hexane conversion; $P_{\text {cyclohexana }}=20 \mathrm{Torr}$, $P_{\text {hydrogen }}=200$ Torr, and Temperature $=300^{\circ} \mathrm{C}$. After 2 hours of reaction over the clean $\mathrm{Pt}(111)$ surface, total conversion was $23 \%$ with $99.99 \%$ of product being benzene. The addition of $\operatorname{Re}$ to the $\mathrm{Pt}(111)$ surface decreased dehydrogenation activity and slightly increased hydrogenolysis activity (Fig. 4.10). However, hydrogenolysis products formed only $10 \%$ of the total product even after the $\mathrm{Pt}$ surface was covered by $1.5 \mathrm{ML}$ of Re. Sulfiding of the Pt-Re catalysts suppressed hydrogenolysis and increased dehydrogenation rates of cyclohexane to benzene. The maximum rate of dehydrogenation was obtained when the Pt surface was covered by approximately $0.5 \mathrm{ML}$ of $\operatorname{Re}$ and was sulfided. Table 4.2 summarizes the initial turn-over rates for the conversion of cyclohexane on clean $\mathrm{Pt}(111), \mathrm{Pt}(111)$ with $0.4 \mathrm{ML}$ of $\mathrm{Re}$, and sulfided Pt(111) with 0.4 ML of Re.

The conversion of cyclohexane to benzene on Pt-Re catalysts, where hydrogenolysis is insignificant, shows enhancement of the dehydrogenation activity by sulfur (Figure 4.10). The activity enhancement can be explained by reduced hydrogen coverage over the sulfided surfaces. The presence of coadsorbed sulfur reduces the hydrogen coverage over the catalyst. Then the cyclohexane-benzene equilibrium is shifted in the direction of benzene. The result is the increased dehydrogenation rate of cyclohexane on sulfided surfaces of Pt-Re. 


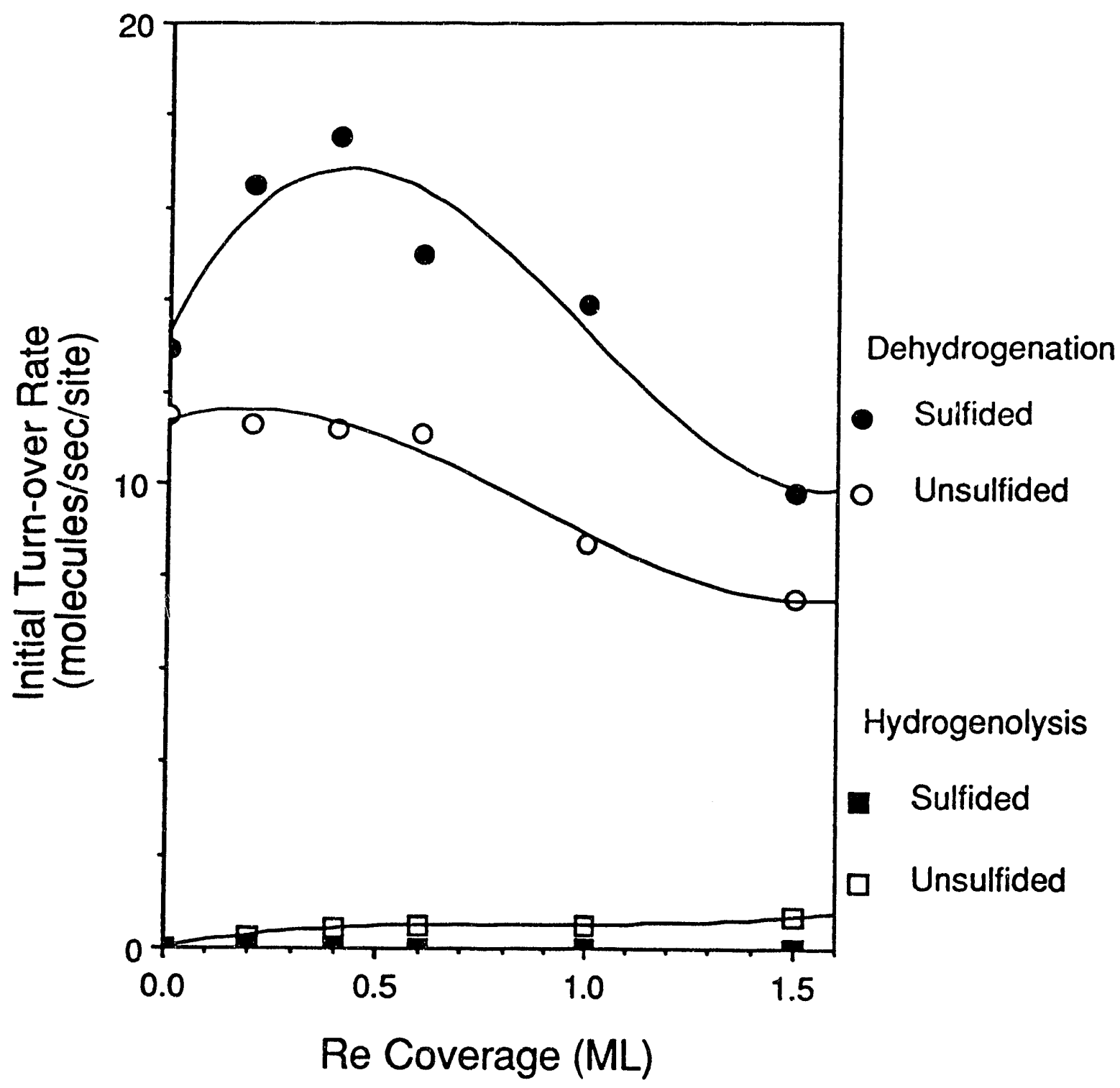

Figure 4.10 Rate of cyclohexane conversion of sulfided and unsulfided $\mathrm{Pt}(111)$ as a function of Re coverage. The catalysts were sulfided by depositing saturation amount of sulfur. Reaction conditions: $\mathrm{T}=300^{\circ} \mathrm{C}, \mathrm{P}_{\text {cyclohexane }}=20$ Torr, and $\mathrm{P}_{\mathrm{H}_{2}}=200$ Torr. 
Chapter 4. Pt-Re-S System 90

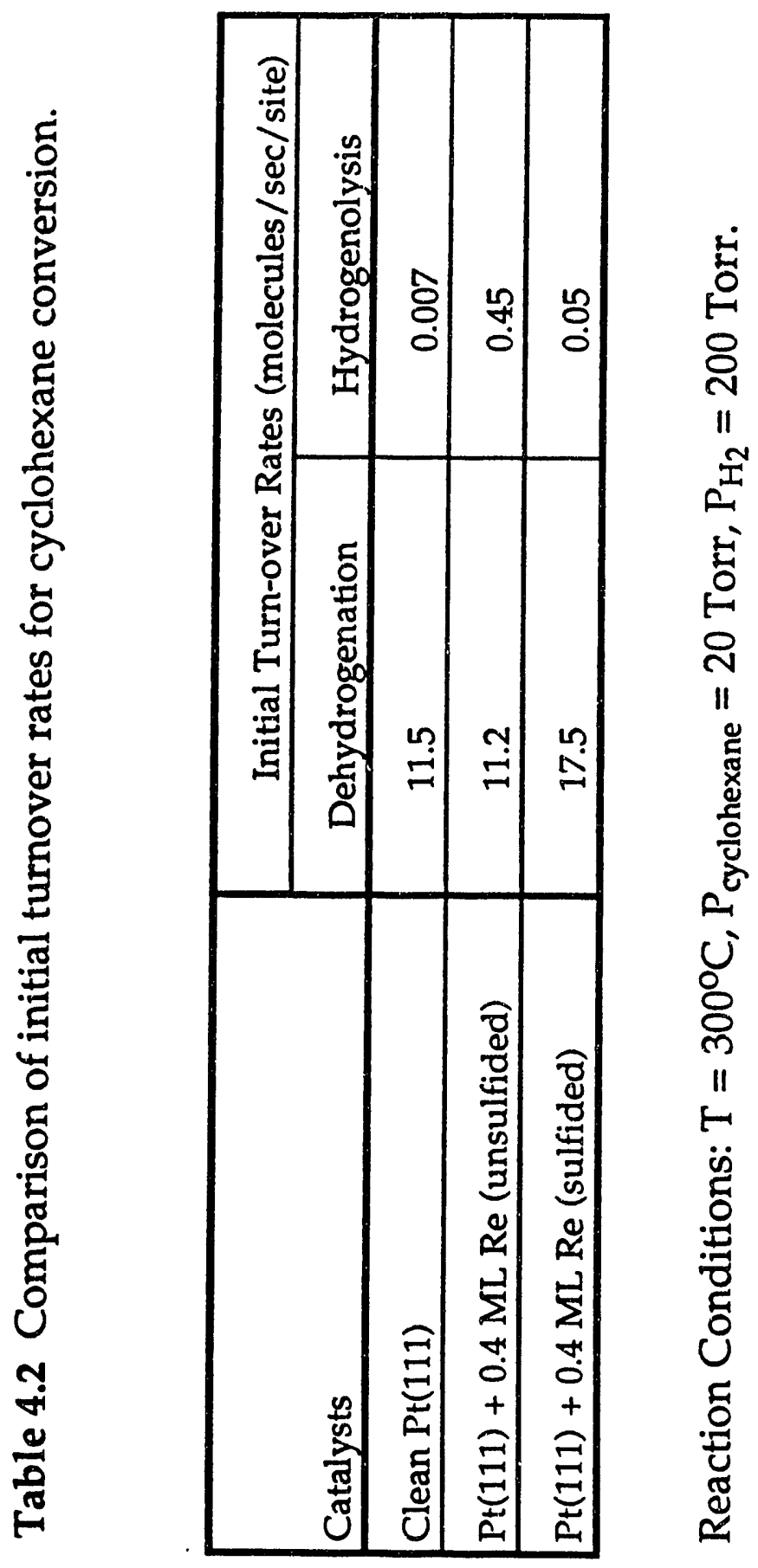




\subsubsection{Conversion of Methylcyclopentane over Pt-Covered Re(0001)}

Conversion of methylcyclopentane was performed over the Pt-covered $\operatorname{Re}(0001)$ surfaces. Twenty Torr of methylcyclopentane and 200 Torr of hydrogen reacted at $300^{\circ} \mathrm{C}$. The reaction products were composed of 1methylcyclopentene, $C_{1}-C_{5}$ hydrocarbons, ring opening products, and olefins. Ring opening products include n-hexane, 2-methylpentane and 3methylpentane. Olefins were mainly c-2-hexene and c-3-hexene. The initial turnover rates for the each component of the product are given in Table 4.3. The effect of $\mathrm{Pt}$ on $\operatorname{Re}(0001)$ on the reactivity and selectivity of methylcyclopentane was determined. The presence of $\mathrm{Pt}$ on $\operatorname{Re}(0001)$ increased dehydrogenation activities (formation of 1-methylcyclopentene and other olefins). When the $\operatorname{Re}(0001)$ surface was covered by $1 \mathrm{ML}$ of $\mathrm{Pt}$, the initial turnover frequency for 1-methylcyclopentene formation was increased from 0.071 to $0.41 \mathrm{molecules} / \mathrm{sec} / \mathrm{site}$ (Figure 4.11). Table 4.3 summarizes the change of selectivity and reactivity of methylcyclopentane conversion over the Pt-covered $\operatorname{Re}(0001)$ surfaces. 


\section{Methylcyclopentane Conversion over} Pt-Covered $\operatorname{Re}(0001)$

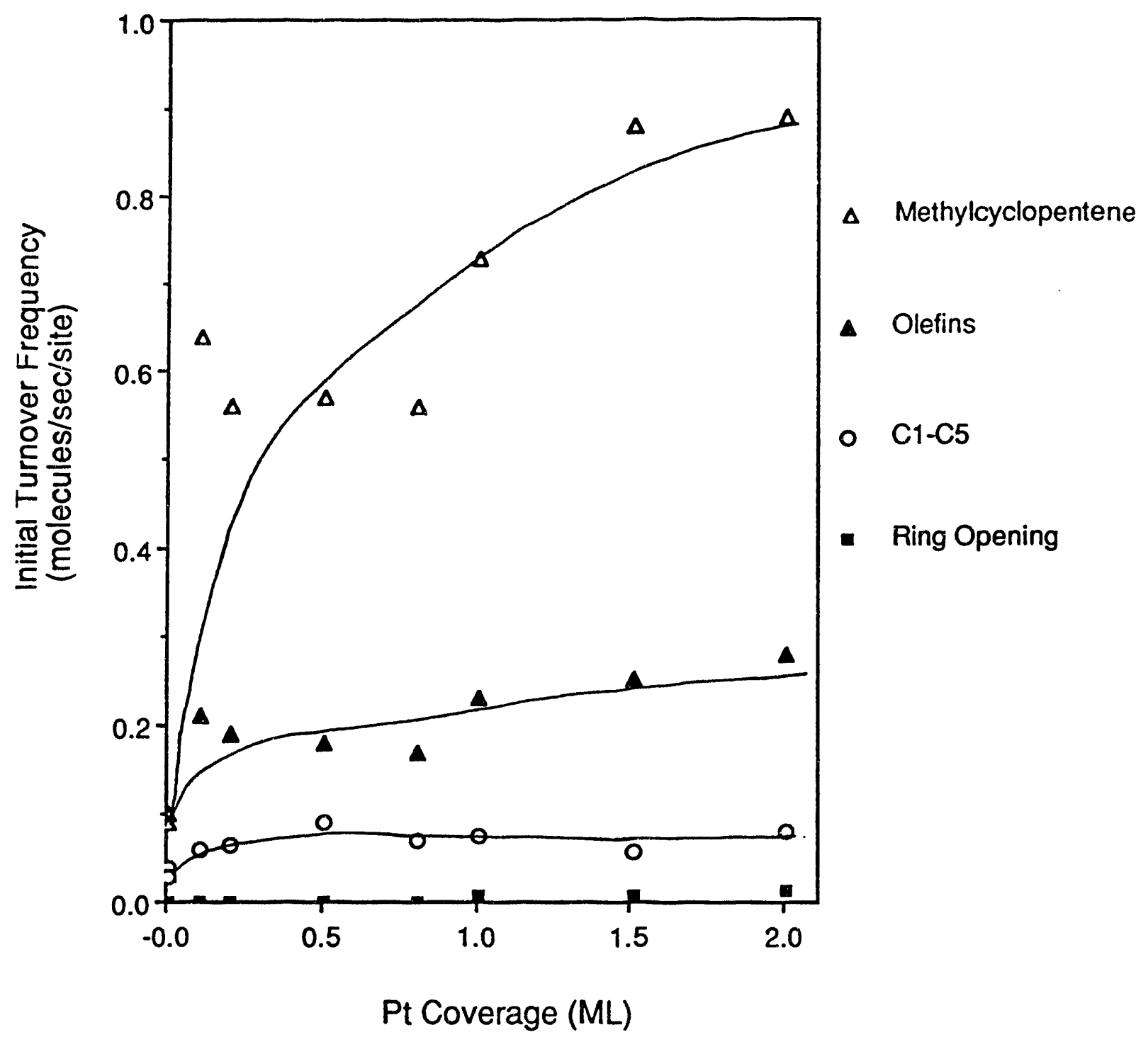

Figure 4.11 Rate of methylcyclopentane conversion over Pt-modified $\operatorname{Re}(0001)$. Reaction conditions: $\mathrm{T}=300^{\circ} \mathrm{C}, \mathrm{P}_{\text {methylcyclopentane }}=20 \mathrm{Torr}$, and $\mathrm{P}_{\mathrm{H}_{2}}=$ 200 Torr. 
Chapter 4. Pt-Re-S System 93

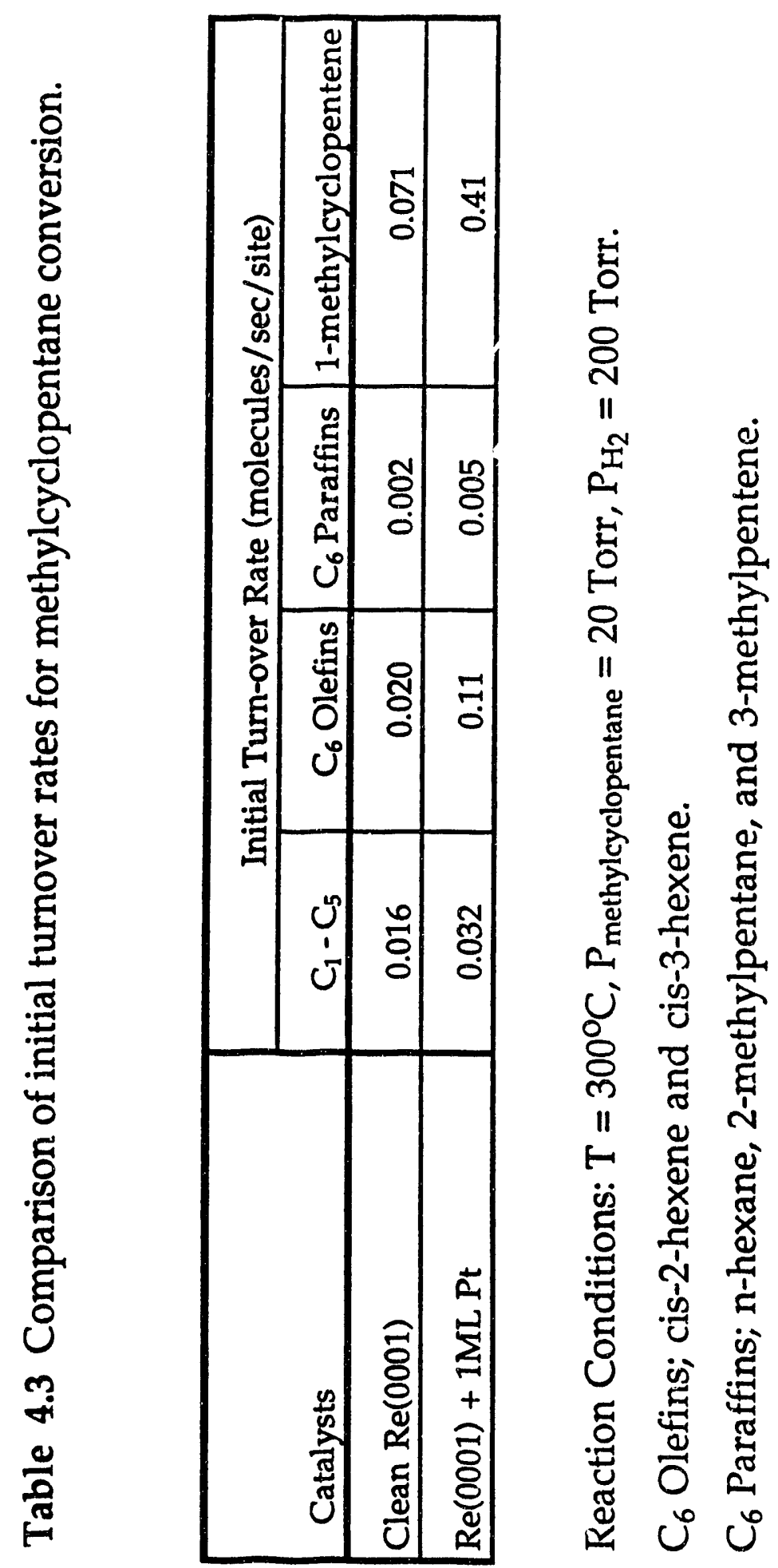




\subsection{Decomposition of Hydrocarbons over the $\mathrm{Pt} / \mathrm{Re} / \mathrm{S}$ surfaces}

\subsection{1 $\mathrm{H}_{\mathbf{2}}$ TPD form sulfur-covered $\mathrm{Pt}(111)$ surfaces}

Temperature programmed desorption of hydrogen from the sulfur-covered $\mathrm{Pt}(111)$ surfaces was studied. Figure 4.12 shows representative TPD spectra of $\mathrm{H}_{2}$ from, the $\mathrm{Pt}(111)$ surfaces with different sulfur coverage. Hydrogen exposure was $1 \mathrm{~L}$ and the adsorption temperature ivas $100 \mathrm{~K}$. The sample was heated after the exposure at a rate of $25 \mathrm{~K} / \mathrm{sec}$.

A TPD spectrum of hydrogen from clean $\mathrm{Pt}(111)$ showed maximum desorption peak at $330 \mathrm{~K}\left(\mathrm{~T}_{\max }\right)$. Assuming first order desorption, the heat of adsorption of hydrogen from clean $\mathrm{Pt}(111)$ is $19 \mathrm{kcal} / \mathrm{mole}$. With the addition of sulfur on $\mathrm{Pt}(111)$, the desorption temperature shifted to the lower temperature. The shift of $T_{\max }$ can be explained by the increase of effective hydrogen coverage. Because of the repulsive interaction between sulfur and hydrogen atoms on the surface, the effective hydrogen coverage increases, resulting in the shift of $T_{\max }$ to the lower temperature.

When the $\mathrm{Pt}(111)$ surface was covered by $0.33 \mathrm{ML}$ of sulfur, no hydrogen adsorption was observed. It is ivell known that sulfur blocks the adsorption sites on metal surfaces and poisons the transition metal catalysts. The poisoning by sulfur has been explained by local steric effects and long range electronic effects [12]. The $\mathrm{Pt}(111)$ surface covered by $0.33 \mathrm{ML}$ of sulfur formed a $(\sqrt{3} \times \sqrt{3}) \mathrm{R} 30^{\circ}$ structure. $\mathrm{A}(\sqrt{3} \times \sqrt{3}) \mathrm{R} 30^{\circ} \mathrm{S}-\mathrm{Pt}(111)$ structure is shown schematically in Figure 4.13. The radius of a Pt atom is $1.38 \AA$ corresponding to a $2.77 \AA \mathrm{Pt}-\mathrm{Pt}$ lattice spacing. The shaded circle represents sulfur adatom 
whose van der Waals radius is $1.85 \AA$ for atomic sulfur [13]. The $\mathrm{H}_{2}$ TPD result implies that each of the sulfur atom adsorbed on three-fold hollow site of $\mathrm{Pt}(111)$ blocks more than three neighboring three-fold sites. Because the radius of adsorbed sultur is much shorter than that of atomic sulfur [14], it seems that adsorbed sulfur not only physically blocks adsorption sites but has a long range interaction. George and coworkers showed, using the hydrogen surface diffusion measurements, that a sulfur atom adsorbed on the threefold site of Ru(0001) blocks as many as ten neighboring three-fold sites [15].

Temperature programmed desorption of $n$-hexane was also studied on the sulfur/Pt(111) system (Figure 4.14). The expose of $n$-hexane was $1 \mathrm{~L}$ and the adsorption temperature was $100 \mathrm{~K}$. Heating rate was $45 \mathrm{~K} / \mathrm{s}$. Temperature programmed desorption of $\mathrm{n}$-hexane produced a single desorption peak centered at $225 \mathrm{~K}$. This peak corresponds to the desorption of molecularly or reversibly adsorbed $\mathrm{n}$-hexane and the heat of adsorption is $12.5 \mathrm{kcal} / \mathrm{mole}$ assuming the first order desorption. As the sulfur coverage increased, $n$ hexane desorption peak split and finally high temperature peak disappeared when the sulfur coverage reached $0.33 \mathrm{ML}$. At $0.33 \mathrm{ML}$, the desorption peak centered at $178 \mathrm{~K}$ and the heat of adsorption was $9.8 \mathrm{kcal} / \mathrm{mole}$. This energy is close to the molecular sublimation energy $(7.6 \mathrm{kcal} / \mathrm{mole})$ and there seems to be no interaction between adsorbed n-hexane and platinum. 


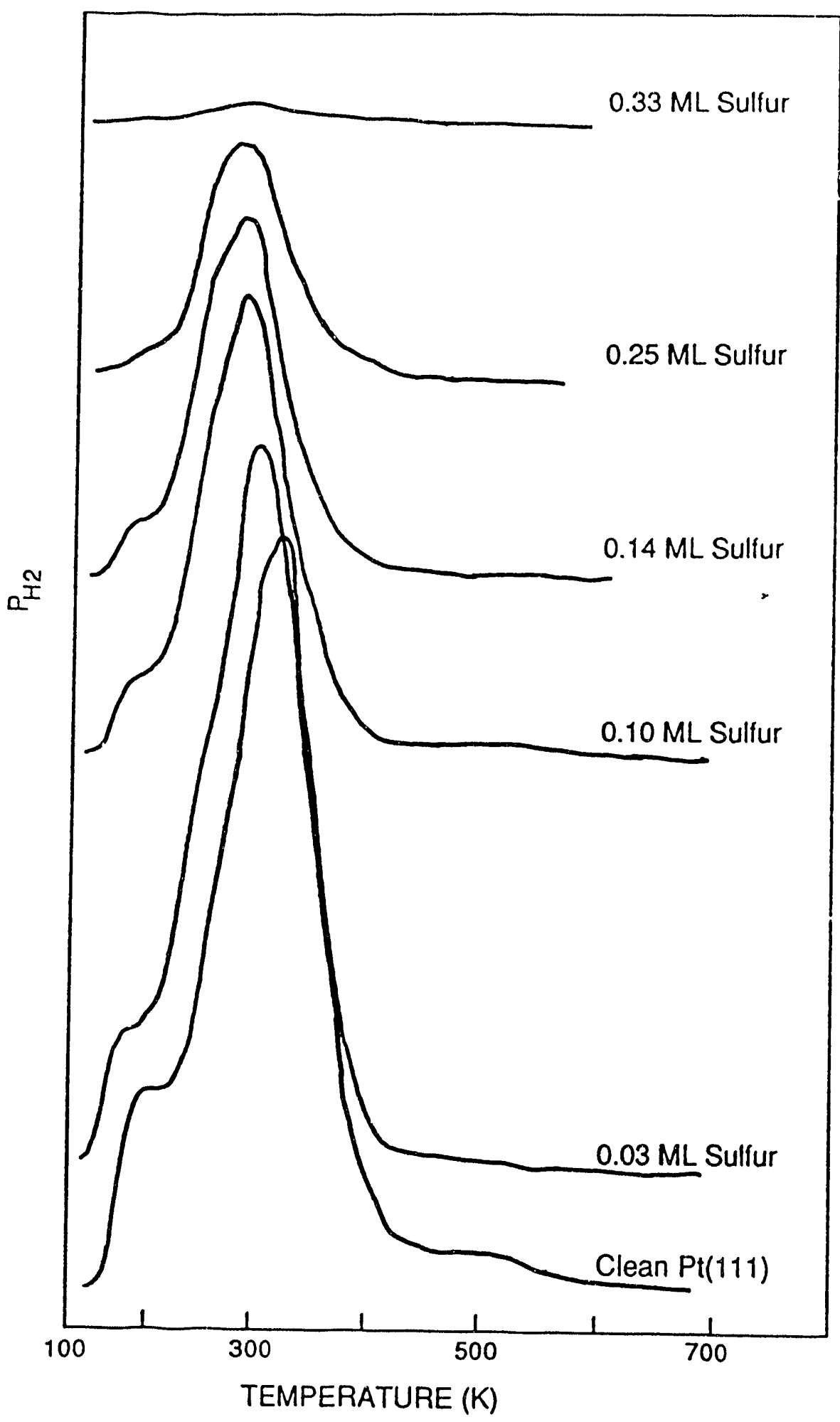

Figiure 4.12 Hydrogen TPD spectra from sulfur-modified $\mathrm{Pt}(111)$. The adsorption temperature was $100 \mathrm{~K}$ and $\mathrm{H}_{2}$ exposure was $1 \mathrm{~L}$ and. The heating rate was $25 \mathrm{~K} / \mathrm{sec}$. 


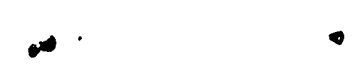

Chapter 4. Pt-Re-S System 97

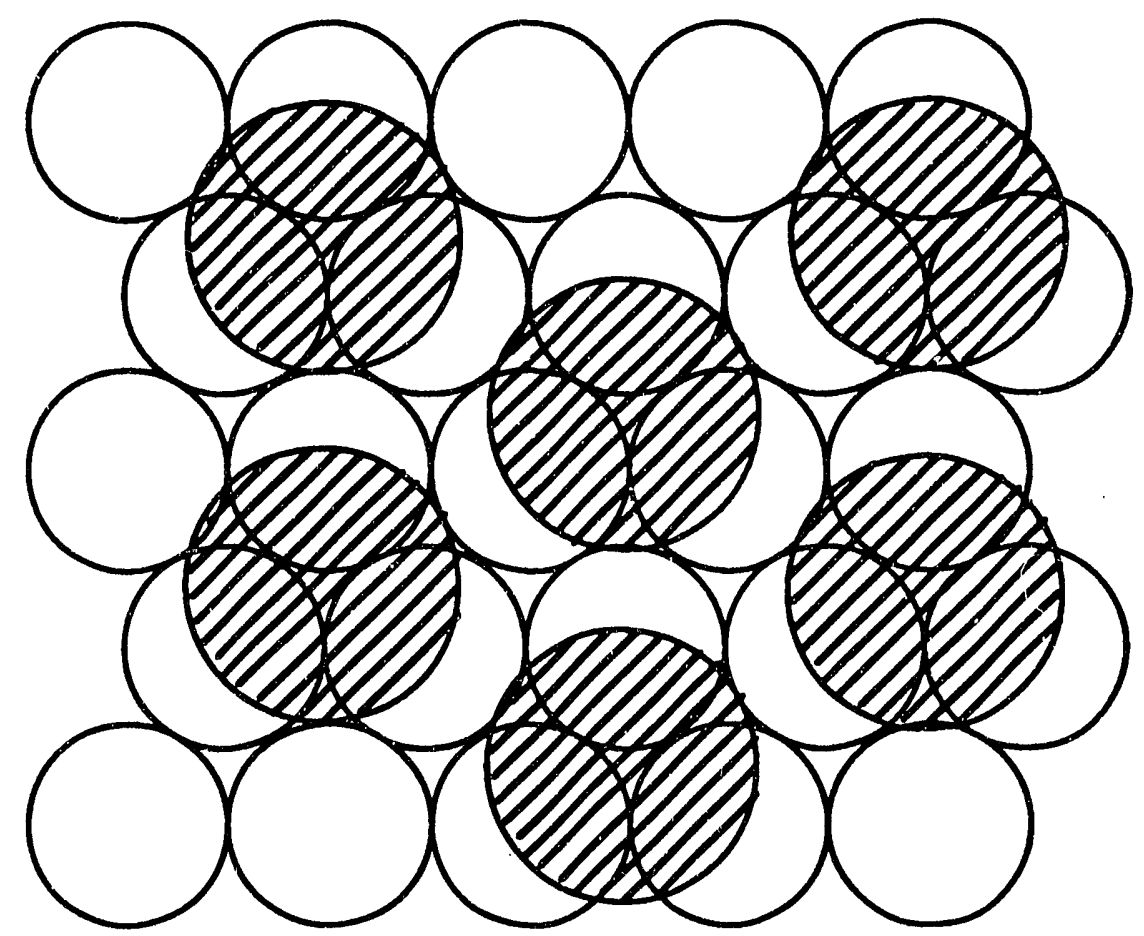

Figure 4.13 Schematic diagram of sulfur adatoms on $\mathrm{Pt}(111)$ showing a $(\sqrt{3} \times \sqrt{3}) \mathrm{R} 30^{\circ}$ structure. The radius of a $\mathrm{Pt}$ atom is $1.38 \AA$ abd that of a sulfur atom is $1.85 \AA$. 


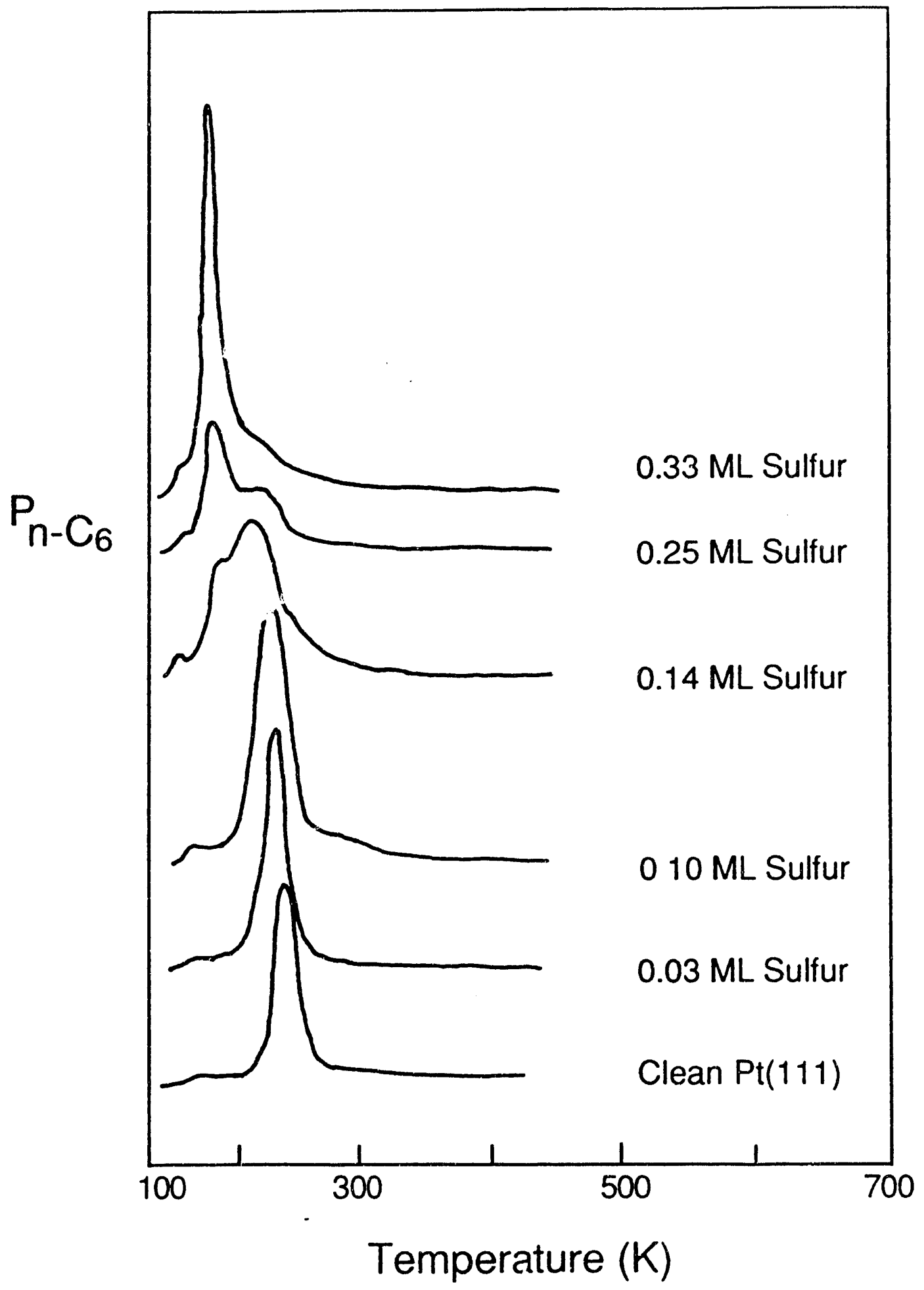

Figure 4.14 Normal hexane TPD spectra from sulfur-modified $\mathrm{Pt}(111)$. The $n$ hexane exposure was $1 \mathrm{~L}$ and the adsorption temperature was $100 \mathrm{~K}$. The heating rate was $45 \mathrm{~K} / \mathrm{sec}$. 


\subsubsection{Decomposition of hydrocarbons on sulfur covered $\mathrm{Pt}(111)$}

Figure 4.15 shows the $\mathrm{H}_{2}$ TPD spectra corresponding to the decomposition of $n$-hexane adsorbed on sulfur-modified $\mathrm{Pt}(111)$ at $100 \mathrm{~K}$. When the surface is clean, most of the hydrogen comes off around $360 \mathrm{~K}$ (peak A) and small amount of hydrogen comes off around $560 \mathrm{~K}$ (peak C). Salmeron and Somorjai [16] suggested that the peak A corresponds to the decomposition pathway

$$
\left(\mathrm{C}_{6} \mathrm{H}_{14}\right)_{\text {ads }} \longrightarrow\left(\mathrm{C}_{\mathrm{n}} \mathrm{H}\right)_{\text {ads }}+\times \mathrm{H}_{2} \text {, where } \mathrm{n}=1 \text { to } 6
$$

and peak $\mathrm{C}$ corresponds to the complete dehydrogenation to form a graphitic carbon layer

$$
\left(\mathrm{C}_{\mathrm{n}} \mathrm{H}\right)_{\mathrm{ads}} \longrightarrow \mathrm{nC}_{\mathrm{ads}}+1 / 2 \mathrm{H}_{2}
$$

The deposition of sulfur on the surface of $\mathrm{Pt}(111)$ changed $\mathrm{T}_{\max }$ 's of $\mathrm{H}_{2}$ desorption from $n$-hexane decomf , ition. The shift of $T_{\max }(A)$ to the lower temperature can be explained by the same argument used to explain the shift of $\mathrm{T}_{\max }$ of $\mathrm{H}_{2}$ TPD. The reason for the shift of $\mathrm{T}_{\max }(\mathrm{C})$ to the higher temperature is not clear. One possible explanation is the difficulty of the migration of the hydrocarbon species which are highly dehydrogenated on the Pt surface. Surface sulfur atoms seem to keep the small hydrocarbon species from forming the graphitic carbon island, resulting in the increase of the decomposition temperature. 
The presence of the coadsorbed sulfur changes the deromposition pathway of $n$-hexane on $\mathrm{Pt}(111)$. As the sulfur coverage increases, new $\mathrm{H}_{2}$ desorption peak appears around $450 \mathrm{~K}$ (peak B). This peak shows that some $\mathrm{C}-\mathrm{H}$ bond breaking takes place through a different pathway. It is believed that a different intermediate species is formed because of the blocking by the coadsorbed sulfur atoms. It's not clear what this intermediate species is. From the relative peak area of the peaks A, B and C, it can be deduced that $n$ hexane is decomposed on the $\mathrm{Pt}(111)$ surface with $0.2 \mathrm{ML}$ of sulfur as follows;

$$
\left(\mathrm{C}_{6} \mathrm{H}_{12}\right)_{\mathrm{ads}} \stackrel{360 \mathrm{~K}}{\longrightarrow}\left(\mathrm{C}_{6} \mathrm{H}_{8}\right)_{\mathrm{ads}} \stackrel{450 \mathrm{~K}}{\longrightarrow}\left(\mathrm{C}_{6} \mathrm{H}_{3} \stackrel{550 \mathrm{~K}}{\longrightarrow} \mathrm{C}_{n}\right. \text { (polymeric carbon). }
$$

Figure 4.16 (a) and (b) show the $\mathrm{H}_{2}$ TPD spectra corresponding to the decomposition of methylcyclopentane and cyclohexane, respectively. These spectra show similar decomposition pattern. Both of them have intermediate desorption peaks which can be seen from the decomposition of $n$-hexane on the sulfur-covered Pt surfaces.

Figure 4.17 shows the change of the $\mathrm{H}_{2}$ TPD spectra corresponding to the decomposition of methylcyclopentane on the Pt-covered $\operatorname{Re}(0001)$ surfaces. On the clean $\operatorname{Re}(0001)$ surface, adsorbed methylcyclopentane produces two hydrogen desorption peaks at $300 \mathrm{~K}$ and $500 \mathrm{~K}$. Addition of $\mathrm{Pt}$ on Re changes the decomposition pattern of methylcyclopentane completely. Over the Pt-covered $\operatorname{Re}(0001)$ surfaces methylcyclopentane is thermally decomposed more easily than over the clean $\operatorname{Re}(0001)$ surface. When the $\operatorname{Re}$ surface is covered by $1 \mathrm{ML}$ of $\mathrm{Pt}$, thermal decomposition of methylcyclopentane produces three $\mathrm{H}_{2}$ desorption peaks. About $50 \%$ of 
hydrogen comes off at $250 \mathrm{~K}, 20 \%$ of hydrogen comes of at $400 \mathrm{~K}$, and $30 \%$ of hydrogen at $600 \mathrm{~K}$. Compared with thermal decomposition of methylcyclopentan'; on clean $\operatorname{Re}(0001)$, methylcyclopentane loses hydrogen much easily on the Pt-covered Re surfaces. This result agrees well with the increased dehydrognation rate of methylcyclopentane over the Pt-covered Re surfaces as shown in section 4.2.4 


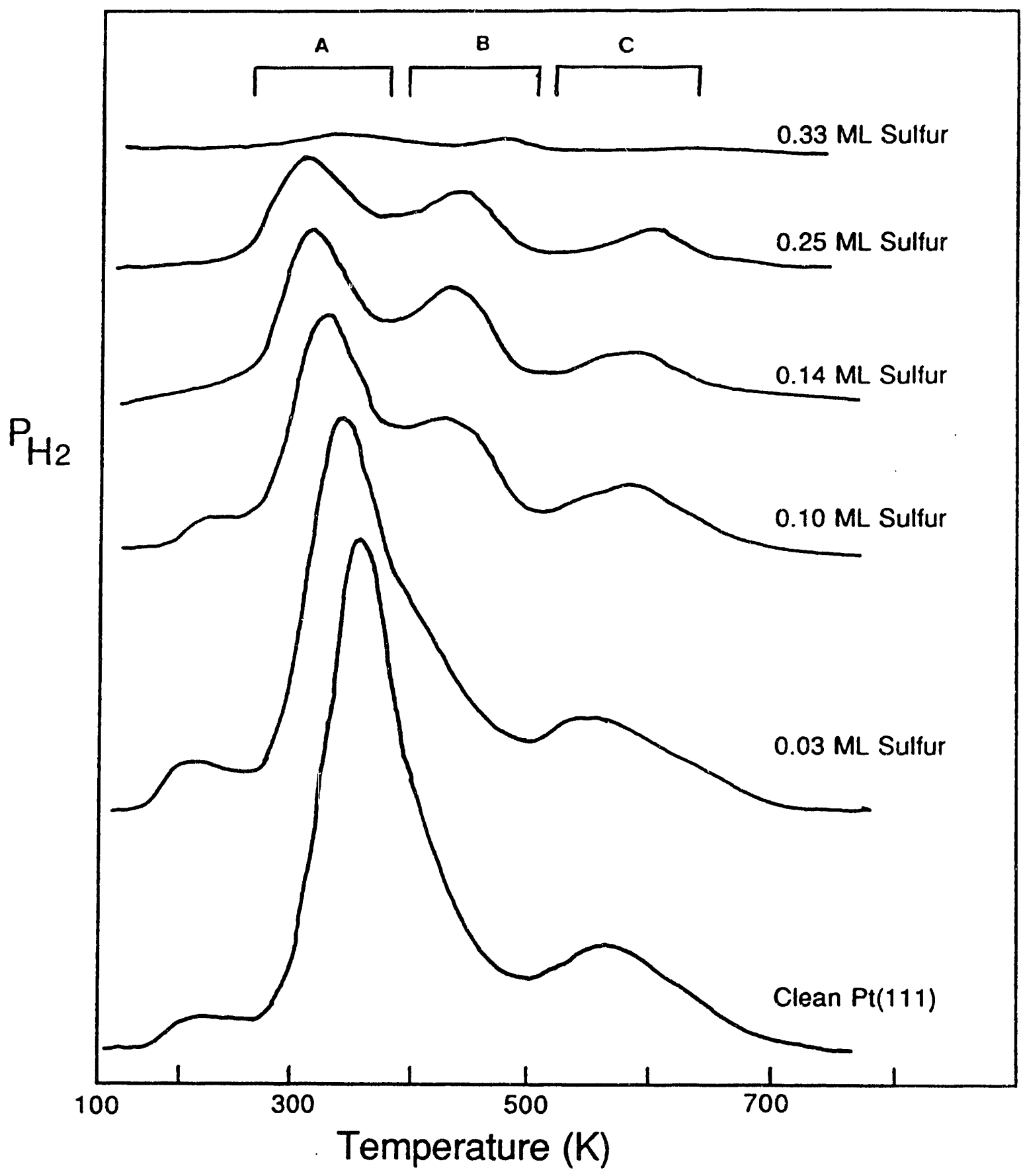

Figure 4.15 Hydrogen TPD spectra corresponding to the decomposition of $n$ hexane 
(a)

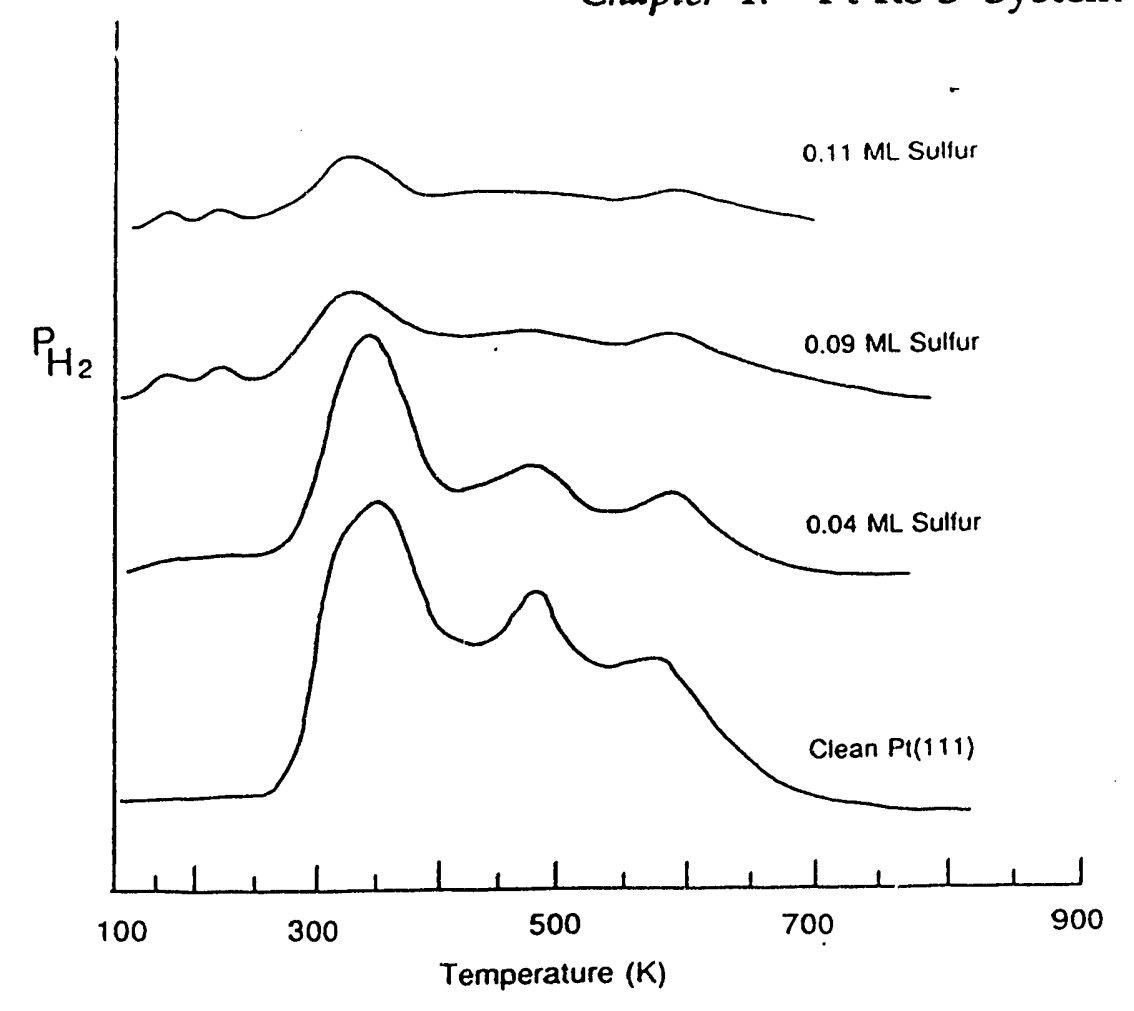

(b)

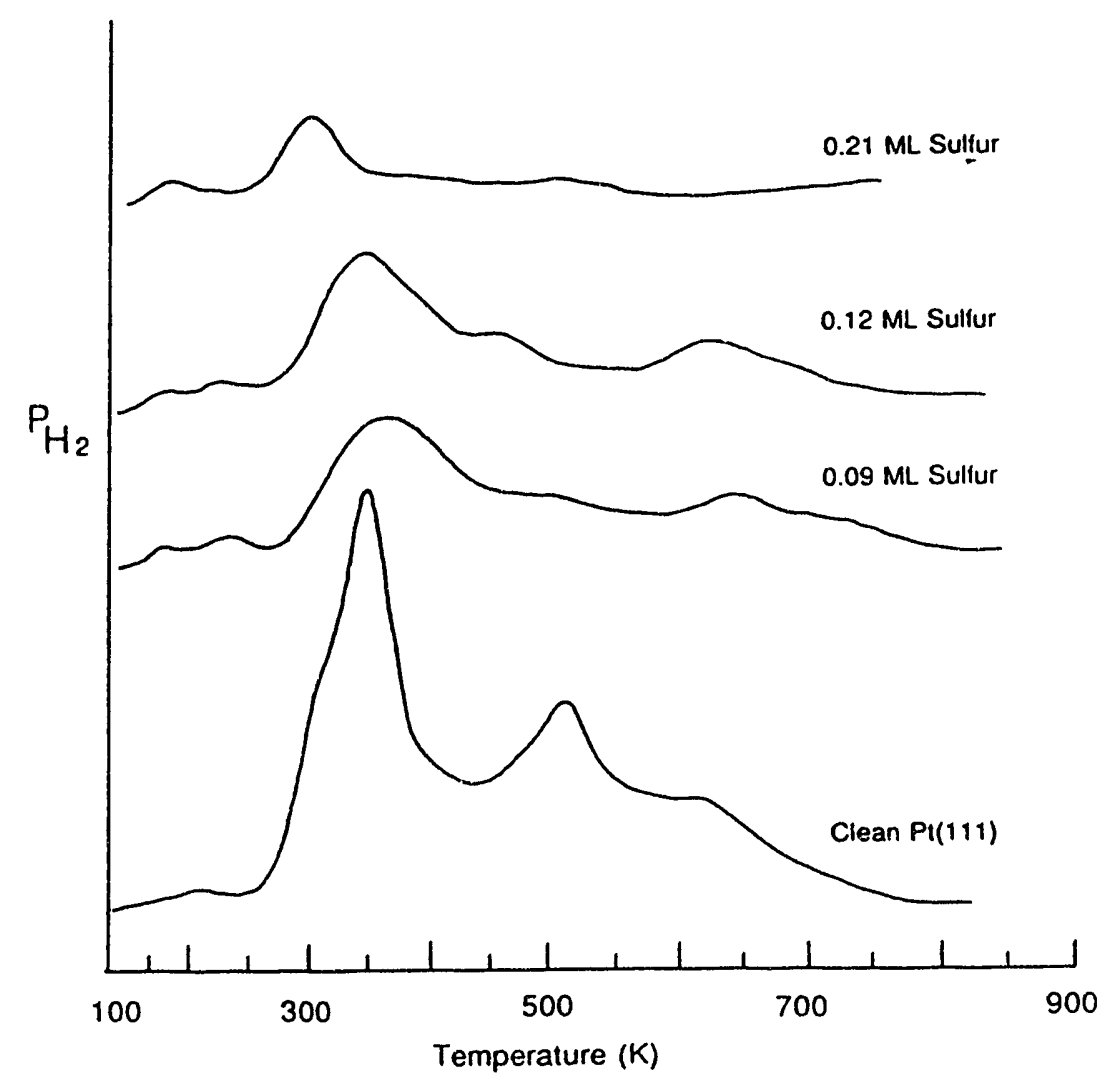

Figure 4.16 Hydrogen TPD spectra corresponding to the decomposition of cyclic compounds. (a) Methylcyclopentane, (b) cyclohexane. 
Chapter 4. Pt-Re-S System 104

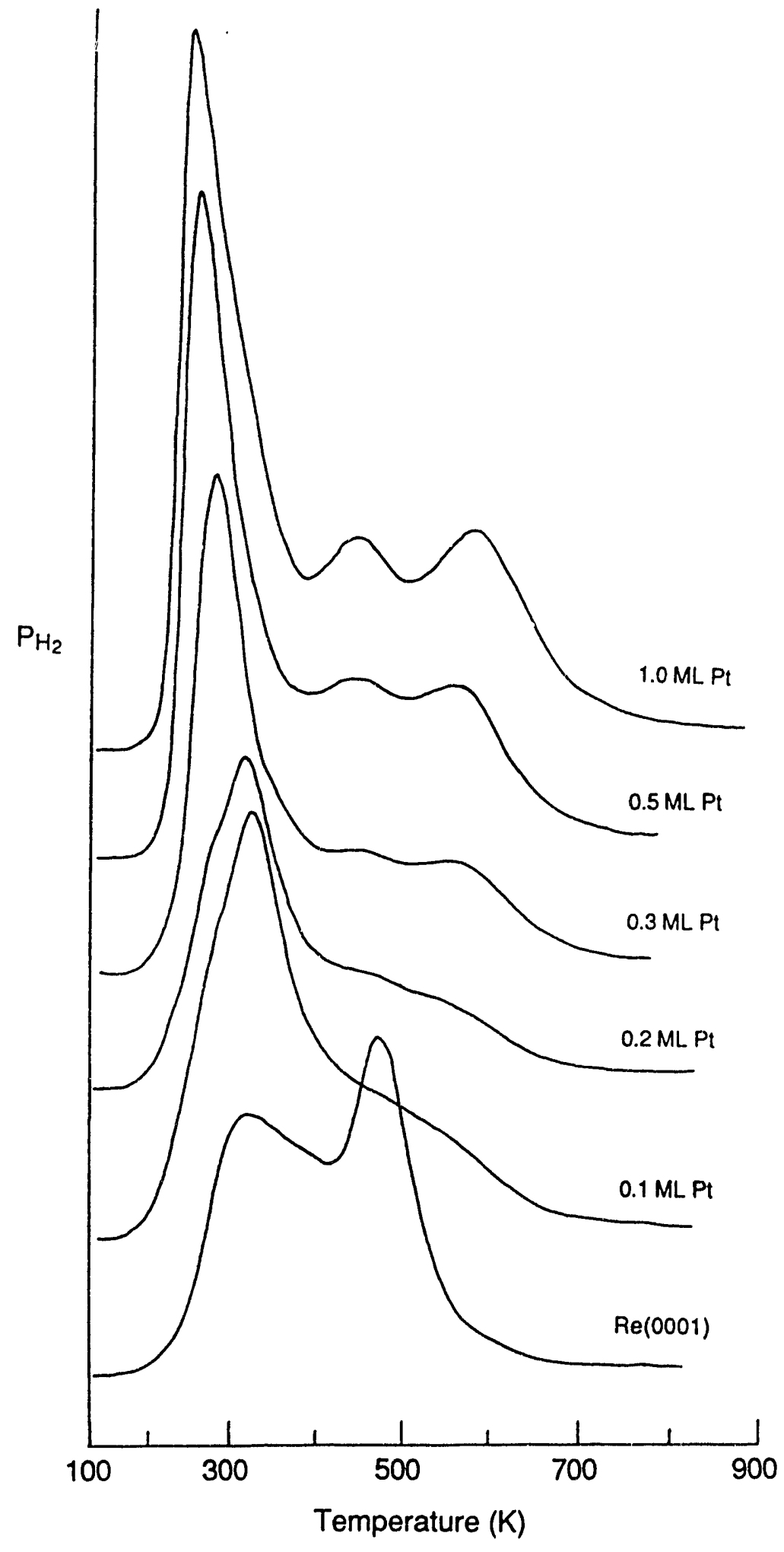

Figure 4.17 Hydrogen TPD spectra corresponding to the deccomposition of methylcyclopentane on Pt-modified $\operatorname{Re}(0001)$. 


\subsection{Desorption of Sulfur form Pt/Re surfaces}

The removal of sulfur from $\mathrm{Pt}(111)$ in high pressure of hydorgen and $n$ hexane was studied. During the reaction of hydrocarbons over the sulfurcovered single crystal catalysts, the amount of predeposited sulfur was decreased significantly. This experiment was performed to understand the mechanism of sulfur desorption in high pressure of hydrogen and hydrocarbon.

Surface Pt-S bonds are fairly strong. Thermal desorption of sulfur from $\mathrm{Pt}(111)$ was studied by Hayak and coworkers [17]. Sulfur overlayer forms a stable $(\sqrt{3} \times \sqrt{3}) \mathrm{R} 30^{\circ}$ structure in the temperature range of $400-700^{\circ} \mathrm{C}$ and a $(2 \times 2)$ structure in the $700-1000^{\circ} \mathrm{C}$. The desorption energy of sulfur from $\mathrm{Pt}(100)$ was estimated to be $106-112 \mathrm{kcal} / \mathrm{mole}$ [18].

For the sulfur desorption experiment in high pressure of hydrogen and hydrocarbon, saturation amount of sulfur was deposited on $\mathrm{Pt}(111)$ and annealed at $600^{\circ} \mathrm{C}$ to form a $(\sqrt{3} \times \sqrt{3}) \mathrm{R} 30^{\circ}$ structure. The sulfur coverage of the $(\sqrt{3} \times \sqrt{3})$ R30 $30^{\circ}$ structure was estimated to be $5 \times 10^{14}$ atoms $/ \mathrm{cm}^{2}(0.33 \mathrm{ML})$. The sulfur-covered platinum sample was placed in the high pressure cell and was heated to the desired temperature in 200 Torr of $\mathrm{H}_{2}$ and 20 Torr of $n$-hexane. The change of sulfur coverage was monitored by AES.

Figure 4.18 shows the removal of sulfur from $\mathrm{Pt}(111)$ in 200 Torr of $\mathrm{H}_{2}$ and 20 Torr of $n$-hexane. Desorption of sulfur took place when the temperature was higher than $500 \mathrm{~K}$. When the desorption temperature was $650 \mathrm{~K}$, the sulfur coverage decreased by half in one minute. It is believed adsorbed sulfur is desorbed in a form of $\mathrm{H}_{2} \mathrm{~S}$. Figure 4.19 shows the activation 
energy plots for the process of sulfur removal in hydrogen and hydrocarbon. The activation energy of sulfur desorption from $\mathrm{Pt}(111)$ in 200 Torr of $\mathrm{H}_{2}$ and 20 Torr of $n$-hexane was $12.4 \mathrm{kcal} / \mathrm{mole}$. Without $n$-hexane, desorption rate decreased slightly but the activation energy was almost the same (12.1 $\mathrm{kcal} / \mathrm{mole})$. It seems that the presence of $n$-hexane does not change the sulfur desorption mechanism but provides additional hydrogen or acts as a hydrogen transfer agent to make desorption easier. This result is different from the sulfur removal from Mo(100) studied by Gellman and Somorjai [19]. In that case, sulfur removal rate was increased by 30 times when 1 Torr of thiophene was added into 780 Torr of $\mathrm{H}_{2}$.

In the pressure range of $10-200$ Torr, the positive hydrogen partial pressure dependence for sulfur removal rate was the order of 0.46 . 
Chapter 4. Pt-Re-S System 107

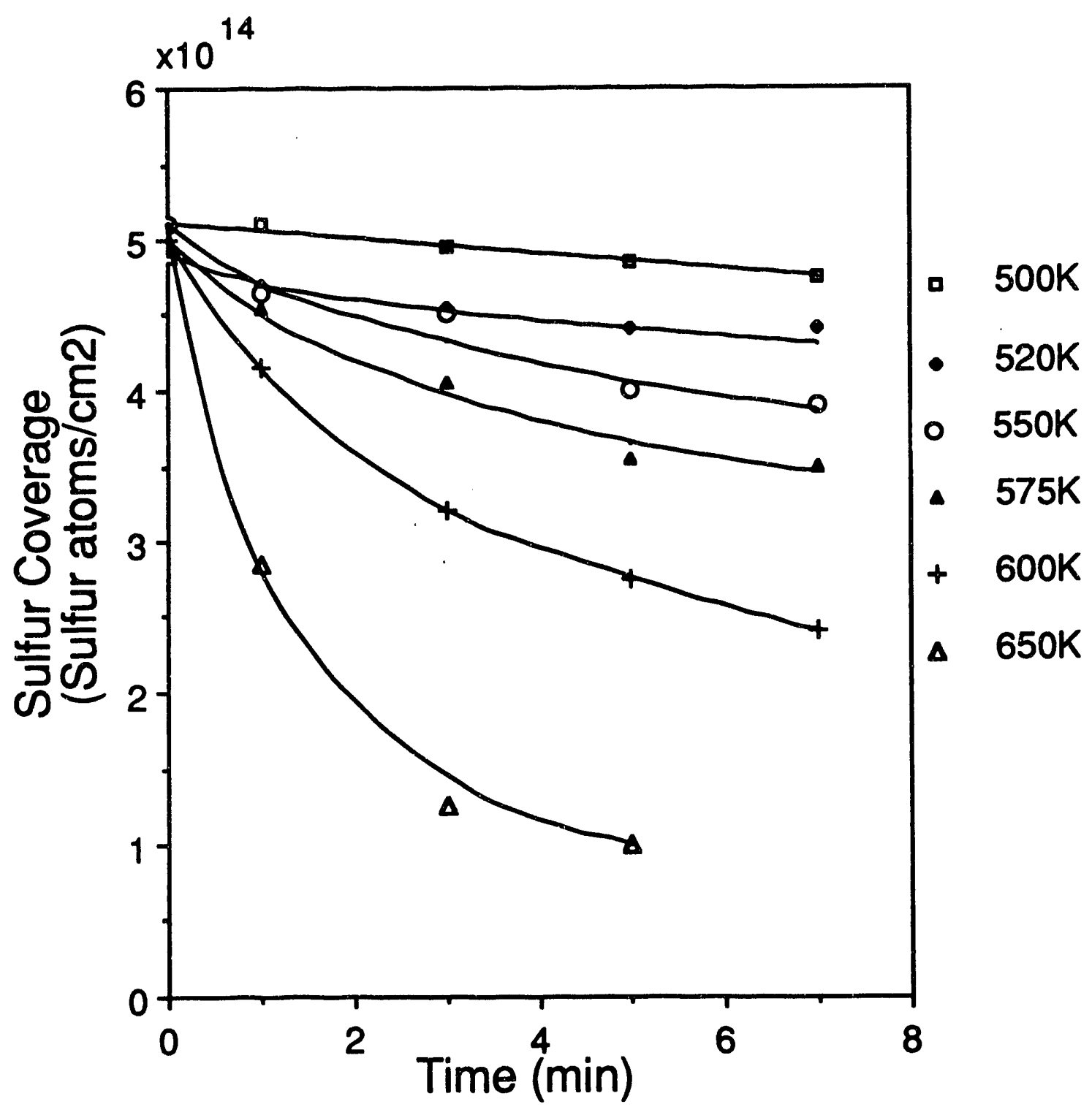

Figure 4.18 The removal of sulfur from $\mathrm{Pt}(111)$ in 200 Torr of $\mathrm{H}_{2}$ and 20 Torr of $n$-hexane at various temperatures. The initial sulfur coverage on the $\mathrm{Pt}$ surface was $0.33 \mathrm{ML}\left(5 \times 10^{14}\right.$ sulfur atoms $\left./ \mathrm{cm}^{2}\right)$. 
Chapter 4. Pt-Re-S System 108

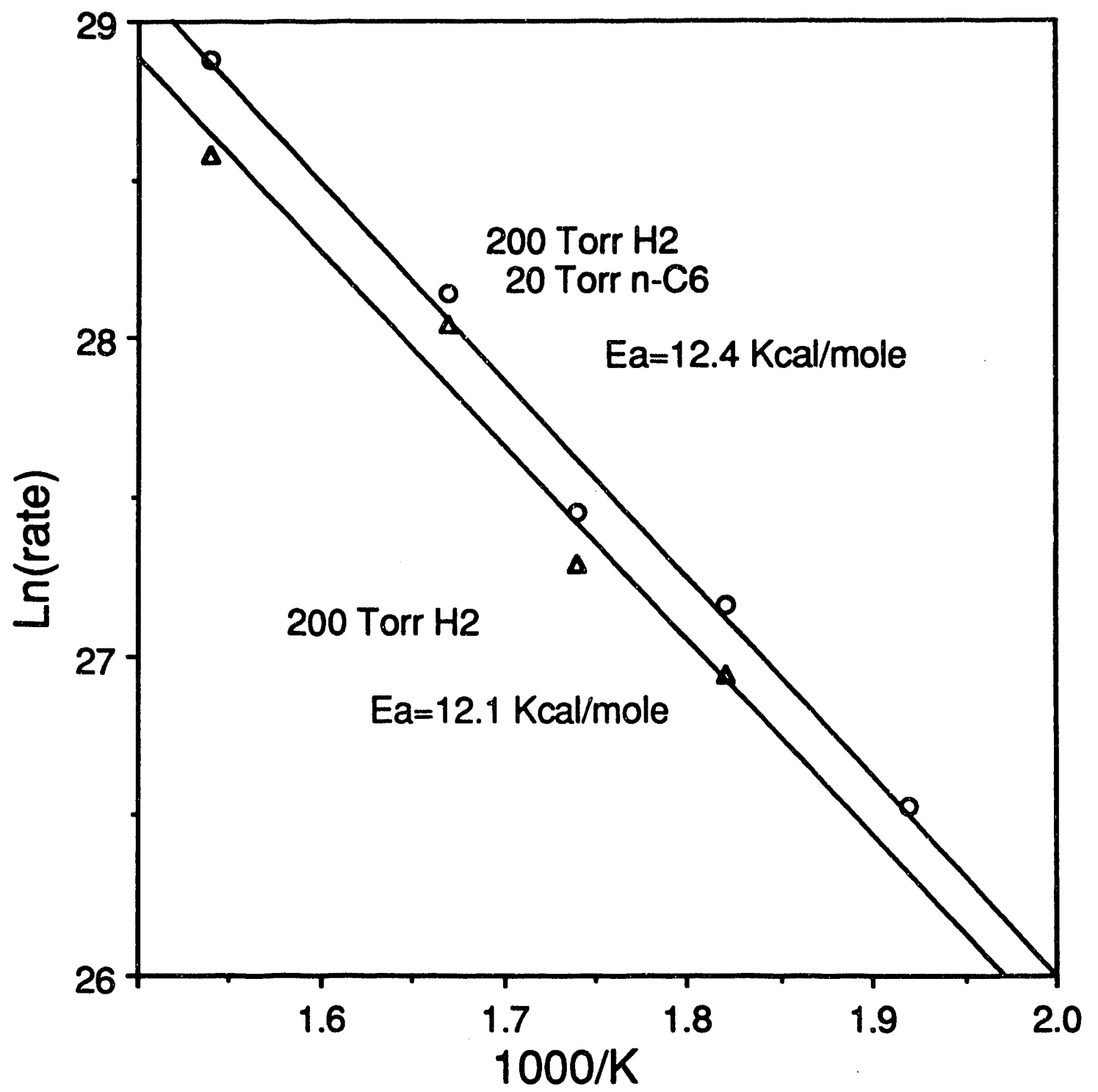

Figure 4.19 The activation energy plots for the process of sulfur removal in hydrogen and $n$-hexane. 


\subsection{Summary}

The conversion of $n$-hexane has been performed over both $\mathrm{Pt}$-covered $\operatorname{Re}(0001)$ and Re-covered $\mathrm{Pt}(111)$. The platinum-rhenium bimetallic surfaces showed higher hydrogenolysis activity than $\mathrm{Pt}$ or Re surfaces. The platinum surface covered by $1 \mathrm{ML}$ of rhenium was 20 times as active as the clean platinum surface for hydrogenolysis of $n$-hexane. The rhenium surface covered by $0.5 \mathrm{ML}$ of platinum was also 5 time as active as the clean rhenium surface for the same reaction. These are quite interesting results because the addition of less reactive platinum to the more reactive rhenium catalyst surface increased reactivity of the catalyst. These results show the typical synergistic effect of the bimetallic or alloy catalysts.

The electronic interaction between $\mathrm{Pt}$ and Re seems to be responsible for the synergistic increase of the hydrogenolysis activity of the Pt-Re bimetallic catalysts. The Pt-Re model catalysts were prepared by depositing either $\operatorname{Re}$ on $\mathrm{Pt}(111)$ or $\mathrm{Pt}$ on $\operatorname{Re}(0001)$. Low-energy electron diffraction results showed that deposited $\mathrm{Re}$ and $\mathrm{Pt}$ form (1x1) surface structures on the $\mathrm{Pt}(111)$ and $\operatorname{Re}(0001)$ surface, respectively. That implies that deposited metal atoms form islands on the substrate surface instead of being dispersed as single atoms. It was also found that deposited Re grows layer by layer on $\mathrm{Pt}(111)$ and $\mathrm{Pt}$ on $\operatorname{Re}(0001)$ (Chapter 3). So, when the $\mathrm{Pt}(111)$ surface is covered by more that $1 \mathrm{ML}$ of $\mathrm{Re}$, the substrate adsorption sites are completely blocked by the adlayer of deposited Re. These Pt-Re surfaces were used as model catalysts without any further treatment and no surface disorder was observed in the reaction conditions. 
In this particular catalyst system, the ensemble size effect cannot explain the enhanced hydorgenolysis activity of the Pt-Re catalysts. Deposition of $\mathrm{Re}$ on $\mathrm{Pt}$ (or $\mathrm{Pt}$ on $\mathrm{Re}$ ) does not produce the new Pt-Re mixed ensembles which might promote the reaction. Electronic interactions between $\mathrm{Pt}$ and $\mathrm{Re}$ seems to be responsible for the enhanced hydrogenolysis activity over the bimetallic surfaces. It is not well known how strong the electronic interaction between $\mathrm{Pt}$ and $\mathrm{Re}$ is on the catalyst surface, and how it changes the catalytic reactivity. Platinum is known to catalyze the reduction of rhenium oxide by hydrogen [20]. Somorjai and coworkers found that $\mathrm{Pt}$ catalyzed the reduction of Re which was evaporated on the Pt surface [21].

It is well known that the catalytic activity of most transition metal catalysts is drastically reduced by the presence of sulfur-containing compounds [12]. Adsorbed sulfur on the metal surface blocks active sites of the catalyst by forming a strong metal sulfur bond. The most significant effect of sulfur on the Pt-Re model catalyst used in this work was decrease in hydrogenolysis activity. Sulfur is well known to selectively poison the hydrogenolysis activity of transition metal catalysts. The mechanism of selective poisoning has been explained by the blocking of large metal ensembles. It is generally accepted that larger ensembles are required for hydrogenolysis than for other metal-catalyzed reactions even though some controversial results have been reported $[22,23]$. So hydrogenolysis seems to be more affected by adsorbed sulfur than other reactions. The result of this work suggest that adsorbed sulfur not only blocks the adsorption sites but changes the decomposition mechanism as Figure 4.15 shows. Because of coadsorbed sulfur, $n$-haxane cannot adsorb flat on the sulfur-covered 
platinum surface and some carbons of $n$-hexane are not accessible to surface platinum atoms, resulting in sequential decomposition. However, sulfur does not change the decomposition mechanism of methylcyclopentane and cyclohexane (Figure 4.16). This result implies that methylcyclopentane and cyclohexane are not adsorbed flat on the platinum surface and coadsorbed sulfur does not affect the decomposition mechanism of them.

The increase of the cyclization rate of $n$-hexane over sulfided Pt-Re catalysts is a surprising result. It is well known that sulfur changes the selectivity of the catalyst by selective poisoning, but the increase of the absolute rate is quite unusual. There are quite a few examples of the enhancement of the reactivity by sulfur. Shum and coworkers reported that the sulfided $\mathrm{PtRe} / \mathrm{Al}_{2} \mathrm{O}_{3}$ catalyst was more active than the unsulfided catalyst [7]. It was also found that pre-adsorbed sulfur on the $\mathrm{Rh} / \mathrm{SiO}_{2}$ enhanced the hydrogenation of carbon monoxide [24]. In the catalysis by $\mathrm{Pt}-\mathrm{Re}$, the role of coadsorbed sulfur is essential as this thesis work shows and the electronic interactions between platinum and rhenium, and metal and sulfur seem to be responsible for the enhanced performance of the bimetallic catalyst.

As the results of this chapter show, sulfided Pt-Re is a better catalyst than $\mathrm{Pt}$ or $\mathrm{Re}$ for cyclization of $\mathrm{n}$-hexane to methylcyclopentane and dehydrogenation of cyclohexane to benzene. However, this catalyst is not effective for dehydrocyclization of n-hexane to benzene. The sulfided Pt-Re single crystal catalyst is not active for ring enlargement of methylcyclopentane to cyclohexane or benzene, either. Because one of the major reactions of the alumina-supported reforming catalyst is dehydrocyclization of $n$-paraffins to aromatic compounds, the model Pt-Re catalyst used in this work is different 
from the alumina-supported industrial catalyst. The function of acidic alumina seems to be responsible for ring enlargement of the five-membered cyclic molecules to six membered ring followed by dehydrogenation to aromatic compounds. The role of the acidic alumina support of the reforming catalyst is discussed in Chapter 5.

\section{References}

[1] H.E. Kluksdahl, US Patent 3,415,787 (1968).

[2] W.M.H. Sachtler, J. Mol. Catal. 25 (1984) 1.

[3] F.A. Cotton and G. Wilkinson, "Advanced Inorganic Chemistry", John Wiley and Sons, New York (1980).

[4] K. Taaanabe, M. Misono, Y. Ono, and H. Hattori, "New Solid Acids and Bases", Elsevier, Amsterdam (1989).

[5] S.M. Davis, Ph.D. Thesis, University of California, Berkeley, CA (1981).

[6] C. Betizeau, G. Leclercq, R. Maurel, C. Bolivar, H. Charcosset, R. Frety, and L. Tournayan, J. Catal. 45 (1976) 179.

[7] V.K. Shum, J.B. Butt, and W.M.H. Sachtler, J. Catal. 96 (1985) 371.

[8] D.J. Godbey, F. Garin, and G.A. Somorjai, J. Catal. 117 (1989) 144.

[9] J.H. Sinfelt, Catal. Rev. 3 (1970) 175.

[10] C.R. Apesteguia and J. Barbier, J. Catal. 78 (1982) 352.

[11] K.J. Williams, A.B. Boffa, J. Lahtinen, M. Salmeron, A.T. Bell, and G.A. Somorjai, Catal. Lett. 5 (1991) 385. 
[12] J. Oudar, Catal. Rev. -Sci. Eng. 22 (1980) 171.

[13] L. Pauling, "The Nature of the Chemical Bond", 3rd ed., Cornell University Press, Ithaca (1960).

[14] K. Hayek, H. Glassl, A. Gutmann, and H. Leonhard, Surf. Sci. 175 (1986) 457.

[15] J.R. Brand, A.A. Deckert, and S.M. George, Surf. Sci. 194 (1988) 457.

[16] M. Salmeron and G.A. Somorjai, J. Phys. Chem. 86 (1982) 341.

[17] W. Heegemann, K.H. Meister, E. Bechtold, and K. Hayek, Surf. Sci. 49 (1975) 161.

[18] H. Gutleben and E. Bechtold, Surf. Sci. 191 (1987) 157.

[19] A.J. Gellman, Ph.D. Thesis, University of California, Berkeley, CA.

[20] C. Bolivar, H. Charcosset, R. Frety, M. Primet, L. Tournayon, C. Betozeau, G. Leclerq, and R. Maurel, J. Catal. 39 (1975) 249.

[21] W.T. Tysoe, F. Zaera, and G. A. Somorjai, Surf. Sci. 200 (1988) 1.

[22] V. Ponec, Adv. Catal. 32 (1983) 149.

[23] J.H. sinfelt, "Bimetallic Catalysts: Discoveries, Concepts, and Applications", Wiley, New York (1983).

[24] B.J. Braudreth and D. Winstanley, J. Catal. 129 (1991) 540. 


\section{Conversion of 1-Butene over Planar Pt/AIOx Model Catalysts}

\subsection{Introduction}

Reforming catalysts are generally made by dispersing metal ( $\mathrm{Pt}$ or $\mathrm{Pt} / \mathrm{Re}$ ) on the high surface area support, $\gamma$-alumina [1]. The surface of the alumina support has the acidic property. The acidic property of the alumina surface has been demonstrated by titration with basic molecules, color change of acidbase indicators, and the ability to catalyze the acid-catalyzed reactions [2]. Because of the catalytic property of the alumina support, the supported reforming catalyst has been termed as the dual functional, bifunctional, or multifunctional catalyst [3]. Even though bifunctional process of the reforming reaction was proposed in the early 1950's as summarized in Figure 1.4, quite a few experimental results have shown the bifunctionality of the reforming precess. Weisz's experiment is a classical example of bifunctionality of the $\mathrm{Pt} /$ alumina catalyst [4]. As Table 5.1 shows, neither a platinum/silica catalyst or a silica-alumina catalyst is not active toward isomerization of $n$-hexane, but a mechanical mixture of the two catalysts is 
Table 5.1 Hexane isomerization on mechanical catalyst mixtures (from ref. [4]).

Catalyst charge to reactor

$10 \mathrm{~cm} 3$ of platinum/silica

$10 \mathrm{~cm} 3$ of silica-alumina

Mixture of $10 \mathrm{~cm} 3$ of each above
Wt\% conversion to isohexanes

0.9

0.3

6.8

quite active for the same reaction. Recently, Sachtler and coworkers [5] showed that the conversion of methylcyclopentane over Pd/Y-zeolite mostly produced ring-opening products, such as n-hexane, and 2- and 3-methylpentanes when zeolite did not carry any acidic protons. However, when zeolite was portonated, main products from the same reaction were benzene and cyclohexane.

The catalytic property of alumina greatly depends on the crystal structure. "Alumina" is frequently used in the generic identification of any of the several crystalline forms of aluminum oxides $\left(\mathrm{Al}_{2} \mathrm{O}_{3}\right)$, aluminum trihydroxides $\left[\mathrm{Al}(\mathrm{OH})_{3}\right]$, and aluminum oxyhydroxides [AlO(OH)] [6]. Generally, various forms of alumina can be transferred from aluminum trihydroxides and the structure of a specific alumina depends to a large extent on the state of hydration [7]. Figure 5.1 shows decomposition sequence of aluminum hydroxides [8]. Gibbsite and bayerite are common crystalline forms of $\mathrm{Al}(\mathrm{OH})_{3}$. Complete dehydration of $\mathrm{Al}(\mathrm{OH})_{3}$ produces $\alpha-\mathrm{Al}_{2} \mathrm{O}_{3}$. In $\alpha$ $\mathrm{Al}_{2} \mathrm{O}_{3}$, the oxide ions from a hexagonal colse-packed array and the aluminum ions are distributed symmetrically among the octahedral interstices. It has 


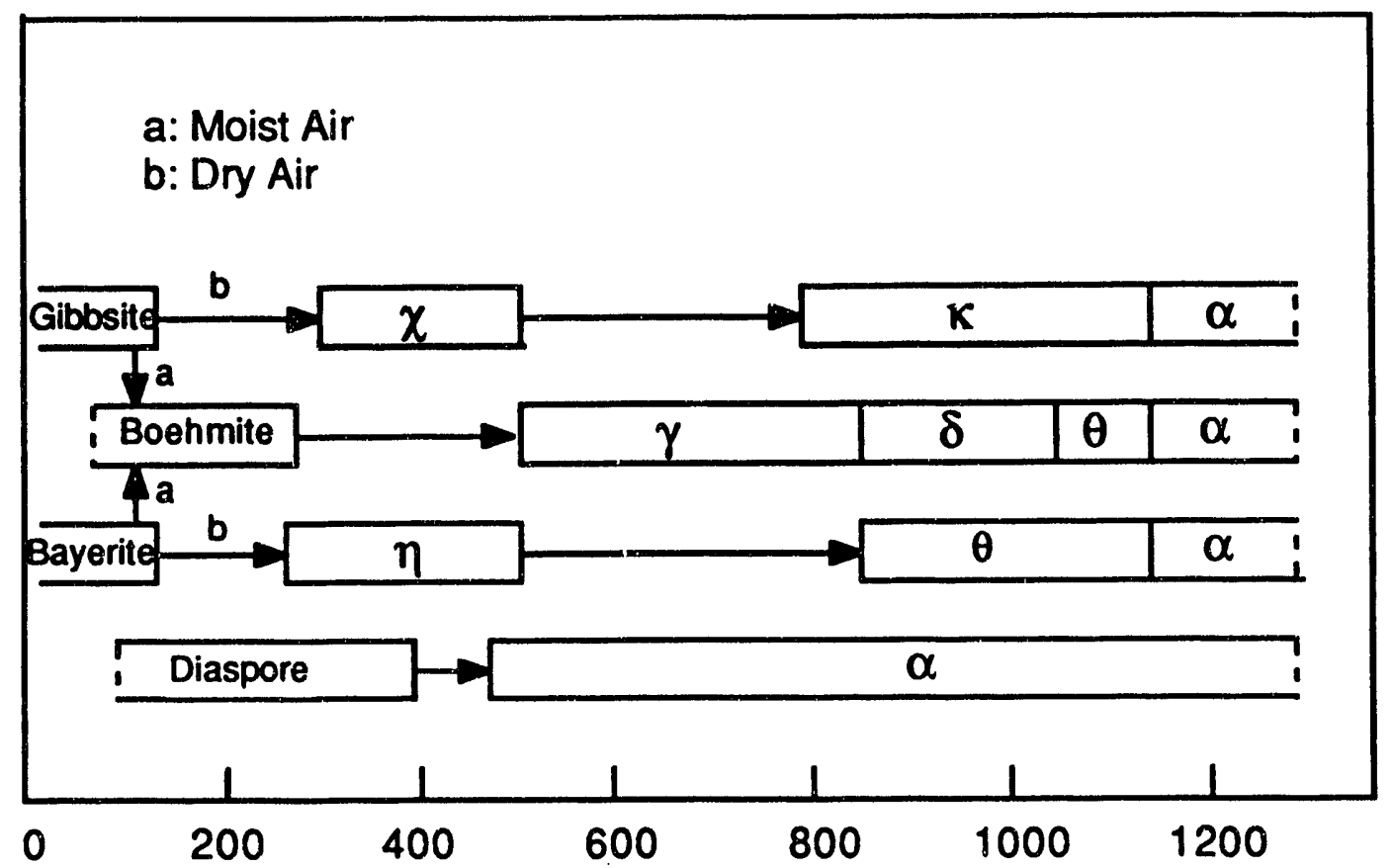

Figure 5.1 Decomposition sequence of aluminum hydrocides (from ref. [8]).

low surface area (about $30 \mathrm{~m}^{2} / \mathrm{g}$ ) and resistant to hydration and attack by acids. Depending on the degree of hydration, alumina forms several transition structures; $\delta-, \theta-, \chi-, \eta-, \gamma$, and $\mathrm{k}-\mathrm{Al}_{2} \mathrm{O}_{3}$. Among them, $\gamma-\mathrm{Al}_{2} \mathrm{O}_{3}$ is catalytically most important. $\gamma-\mathrm{Al}_{2} \mathrm{O}_{3}$ has a defect spinal structure. The unit cell consists of 32 oxygens with $21 \frac{2}{3}$ aluminums and $2 \frac{2}{3}$ cation vacancies distributed between the tetrahedral and octahedral sites [9]. $\gamma-\mathrm{Al}_{2} \mathrm{O}_{3}$ has high surface area $\left(150-300 \mathrm{~m}^{2} / \mathrm{g}\right)$ and readily takes up water and dissolves in acids.

The catalytic activity of alumina not only depends on its structure but its acidity. A linear relationship was found between the logarithm of the rate of 2-butanol dehydration over alumina and the acid strength represented by the heat of pyridin adsorption on alumina [10]. It was also found that the activity of propylene polymerization over $\mathrm{SiO}_{2} / \mathrm{Al}_{2} \mathrm{O}_{3}$ catalysts is proportional 
to the amount of acid of the catalyst [11]. The acidic property of alumina is closely related to the degree of hydration [7] and the acidity can be greatly enhanced by the treatment with halogen-containing molecules [12,13]. The super acid of alumina was also produced by the treatment with $\mathrm{SbF}_{5}$ [14].

The use of planar alumina as models for alumina-based catalysts is gaining more attention [7]. The advantage of using planar alumina is that uniform film of aluminum oxide can be produced and modern surface science techniques can be use to characterize the aluminum oxide surfaces. Aluminum oxide films have been prepared by direct oxidation of aluminum foils and single crystals [15-17] or by oxidizing deposited aluminum on the second metal such as $\mathrm{Pt}$ or $\mathrm{Ru}[18,19]$. The thickness of the oxide film can be controlled from several monolayers to $1000 \AA$ and various planar aluminum oxides have been prepared and studied.

In this chapter, the conversion of 1-butene over $\mathrm{Pt} / \mathrm{AlO}_{x}$ catalysts has been presented. Isomerization of 1-butene over alumina is the classical example of an acid-catalyzed reaction which takes place on alumina [20]. This chapter discusses the change of the activity and selectivity of the alumina catalyst with the addition of platinum. The model $\mathrm{Pt} / \mathrm{AlO}_{\mathrm{x}}$ catalysts were made by depositing Pt onto aluminum oxide. The aluminum oxide surface was prepared by oxidizing aluminum foil. 


\subsection{Oxidation of Aluminum Foils}

Aluminum foil was oxidized in $10^{-5}$ Torr of oxygen and at different temperatures; 25,300 and $500^{\circ} \mathrm{C}$. The Al AES peak shifted from $68 \mathrm{eV}$ to $58 \mathrm{eV}$ after oxidation. The reported AES energy of oxidized aluminum $\left(\alpha-\mathrm{Al}_{2} \mathrm{O}_{3}\right)$ is $51 \mathrm{eV}$ [21]. However, the oxidized aluminum peak remained at $58 \mathrm{eV}$ even after one hour of oxidation at $500^{\circ} \mathrm{C}$ in the oxidizing conditions used in this work. Figure 5.2 (a) shows the change of oxygen $(510 \mathrm{eV})$ to oxidized aluminum $(58 \mathrm{eV})$ peak ratio as a function of oxidation time. After one hour of oxidation in $10^{-5}$ Torr of oxygen, the ratio of oxygen to aluminum became about 0.09 regardless the oxidation temperature. Figure 2 (b) shows the change of the peak ratio of oxidized aluminum $(58 \mathrm{eV})$ to metallic aluminum $(68 \mathrm{eV})$. At higher temperatures, the metallic aluminum peak intensity decreased much faster. It seems that much thicker aluminum oxide layer was formed at higher temperatures. However, the ratio of aluminum to oxygen in the oxide layer did not change in the oxidation temperature range used in this work. AES results also show that no metallic aluminum present on the surface after oxidation.

The surface structure of the oxidized aluminum has not been performed. It was generally found that direct oxidation of the aluminum foil produced three dimensional aluminum oxide crystalline grains [16]. Jimenez-Gonzalez and Schmeisser showed, using XPS and transmission electron microscopy, that $\gamma$-alumina was formed on the surface in the similar conditions used to oxidize the aluminum foil in this work [22]. 

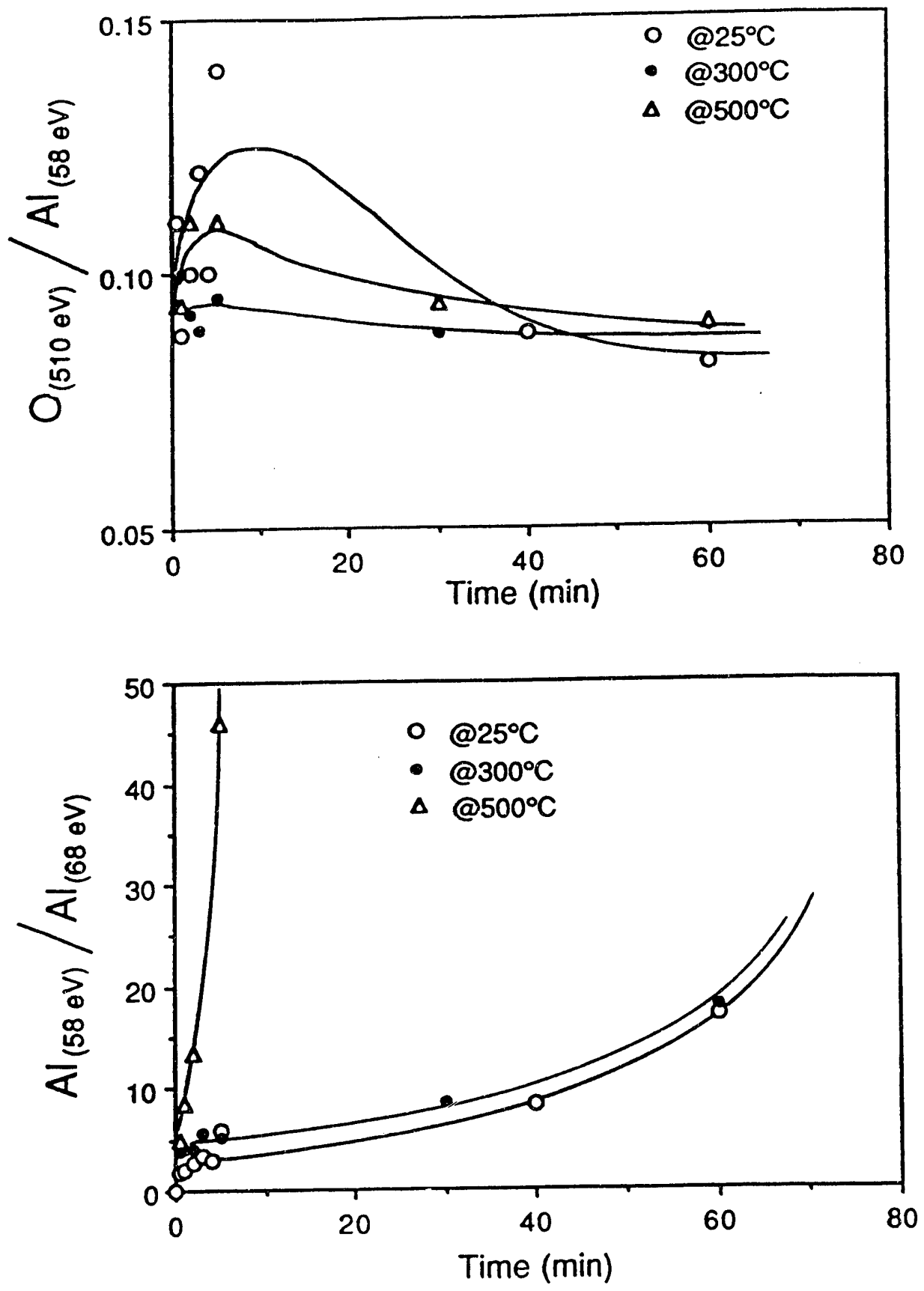

Figure 5.2 Change of AES signal of aluminum foil as a function of oxidation time. Oxygen pressure was $10^{-5}$ Torr and oxidation temperatures were 25,300 , and $500^{\circ} \mathrm{C}$. (a) The ratio of the $\mathrm{Al}$ to $\mathrm{O}$ AES peak. (b) The ration of the oxidized Al to metallic Al AES peak. 


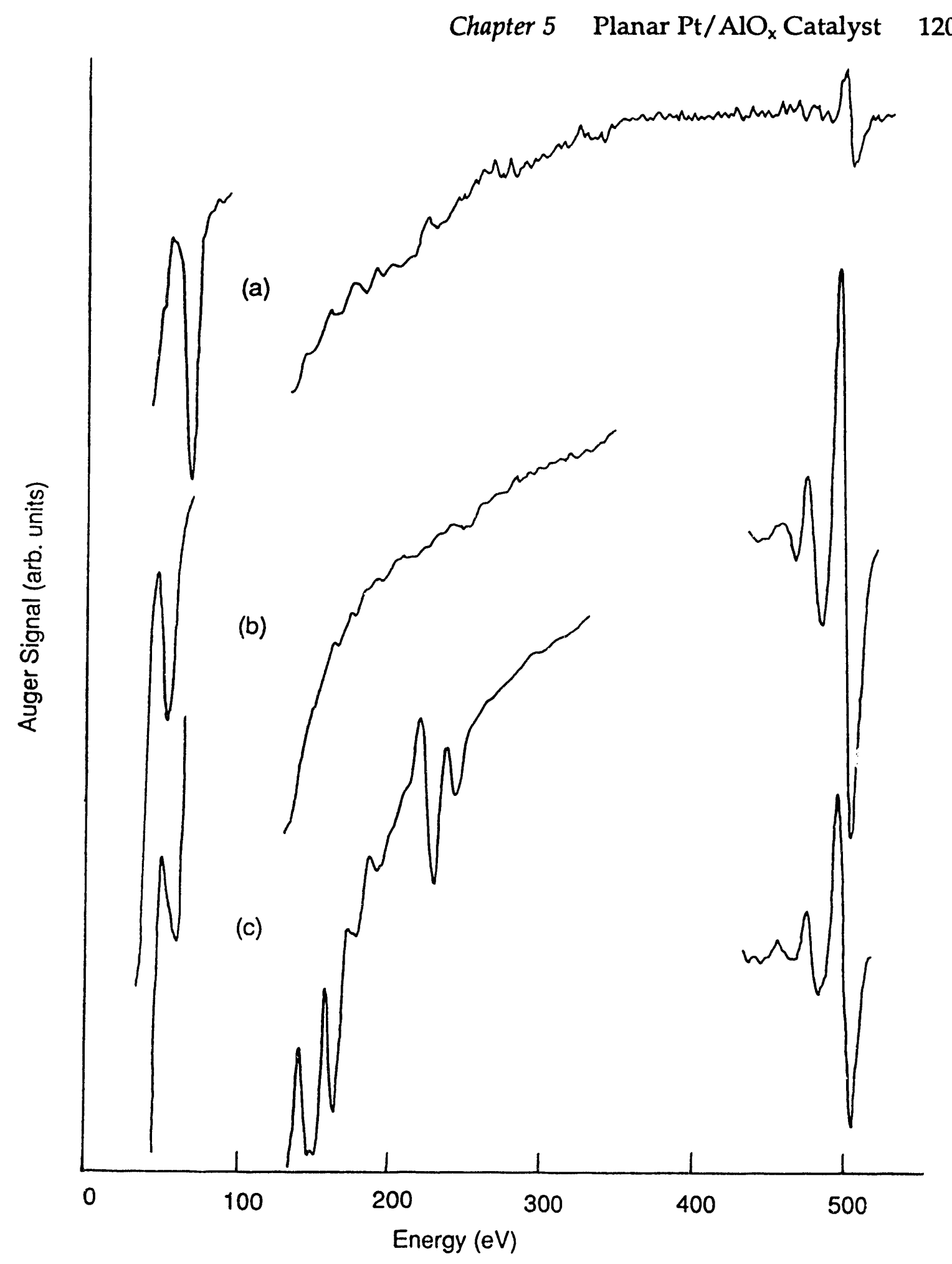

Figure 5.3 Auger spectra of aluminum foil. (a) Clean aluminum foil, (b) after oxidation in $1 \times 10^{-5}$ Torr oxygen at $500^{\circ} \mathrm{C}$ for one hour, (c) after deposition of $1 \times 10^{16} \mathrm{Pt}$ atoms $/ \mathrm{cm}^{2}$ on aluminum oxide. 


\subsection{Deposition of Pt on $\mathrm{AlO}_{\mathrm{x}}$}

Platinum was deposited on the aluminum oxide surface using a plasma deposition source. Figure 5.3 shows the change of Auger spectra of aluminum foil. The spectrum (a) is clean aluminum, (b) is oxidized aluminum, and the spectrum (c) is the $\mathrm{Pt} / \mathrm{Al}_{\mathrm{x}}$ surface with $1 \times 10^{16} \mathrm{Pt}$ atoms $/ \mathrm{cm}^{2}$ on the surface. The platinum coverage was estimated based on the evaporation rate of the plasma deposition source. The evaporation rate was determined from the deposition of Pt on Re as described in Chapter 3.

The change of Pt overlayer on the alumina surface was monitored with AES while heating slowly at a rate of $50 \mathrm{~K} / \mathrm{min}$ (Figure 5.4). In UHV, $\mathrm{Pt}$ overlayer is stable (in terms of the change of Auger spectra) up to $200^{\circ} \mathrm{C}$, but the $\mathrm{Pt}$ Auger signal decreased rapidly at temperatures higher than $200^{\circ} \mathrm{C}$. In 1 atm of $\mathrm{H}_{2}$, the Pt Auger signal decreased much faster upon heating. After heating up to $300^{\circ} \mathrm{C}$ in $1 \mathrm{~atm}$ of $\mathrm{H}_{2}$, the Auger spectrum of the surface did not show any $\mathrm{Pt}$ peaks. It is not clear that deposited platinum forms three dimensional islands on the aluminum oxide surface or it diffuses into bulk upon heating. However, it is very possible that platinum diffused into the aluminum oxide substrate because platinum and aluminum make binary alloys very easily [23]. Diffusion of surface $\mathrm{Pt}$ into alumina seems to be accelerated in reducing conditions because more metallic aluminum is available for alloying with $\mathrm{Pt}$. It was found that the $\mathrm{CO}$ adsorption area on the Pt-deposited alumina surface decreased after heating in hydrogen but restored the initial $\mathrm{CO}$ adsorption area after oxidation [24]. 
Chapter 5 Planar $\mathrm{Pt} / \mathrm{AlO}_{x}$ Catalyst 122

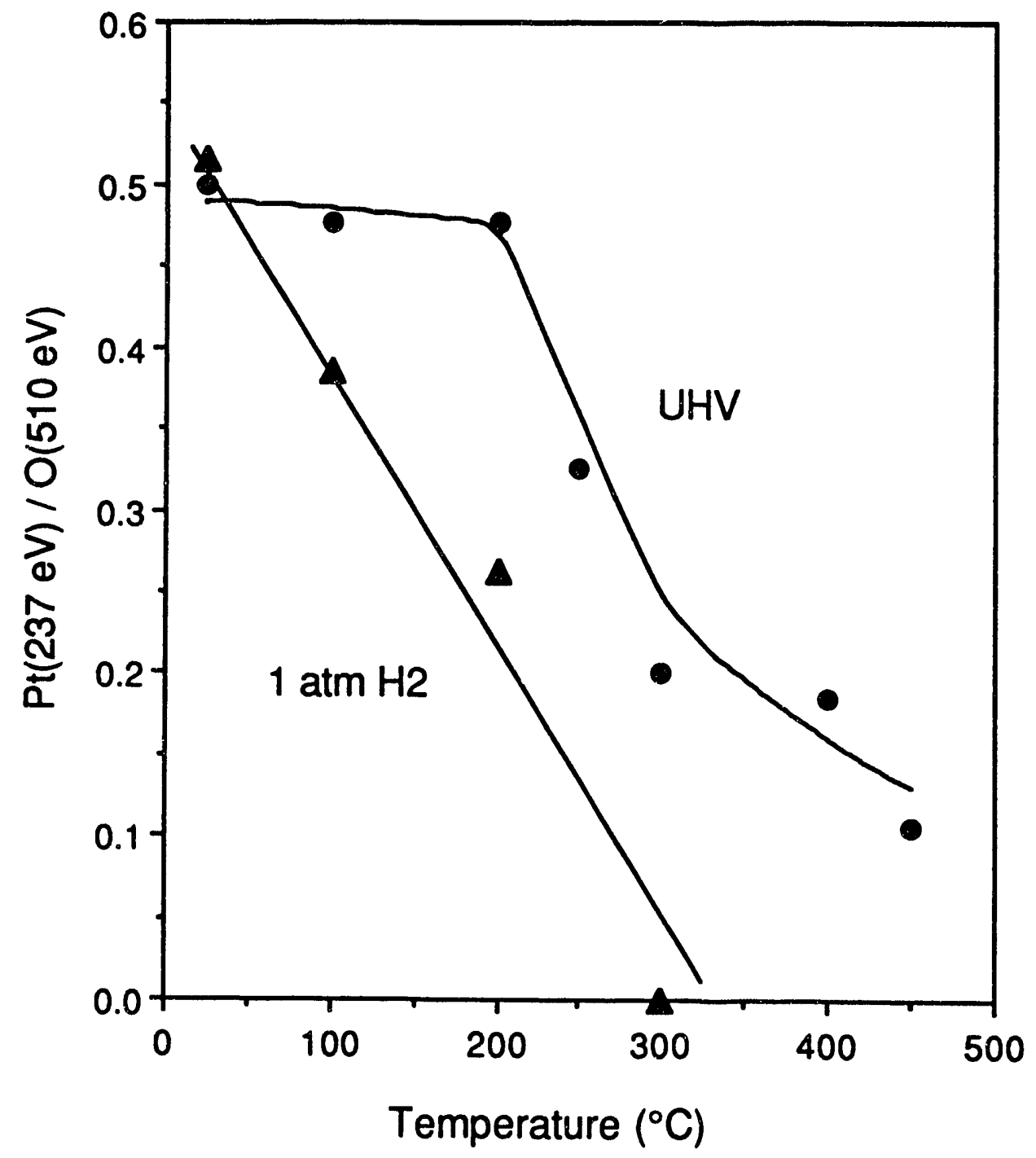

Figure 5.4 Change of $\mathrm{Pt}$ coverage on $\mathrm{AlO}_{\mathrm{x}}$ upon heating in UHV and in $1 \mathrm{~atm}$ of $\mathrm{H}_{2}$. 


\subsection{Conversion of 1-Butene on $\mathrm{Pt} / \mathrm{AlO}_{\mathrm{x}}$}

Conversion of 1-butene in hydrogen was performed over Pt-covered AlOx surfaces. The oxidized aluminum surfaces were prepared by oxidizing aluminum foil in $10^{-5}$ Torr of oxygen for 1 hour at $500^{\circ} \mathrm{C}$. Figure 5.5 shows Arrhenius plots for 1-butene isomerization on $\mathrm{AlOx}$ in the temperature range of 60 to $220^{\circ} \mathrm{C}$. The pressure of 1-butene was 200 Torr and same pressure of hydrogen was used. When the temperature was lower than $100^{\circ} \mathrm{C}$, selectivity for cis-2-butene over trans-2-butene was about 1.5. It was proposed that 1butene is adsorbed on the alumina surface as a gauche form [25]. The adsorption sites are a surface $\mathrm{O}^{2-}$ ion and underlying $\mathrm{Al}^{3+}$ ions. From this intermediate species, cis-2-butene is easier to be formed. At higher than $100^{\circ} \mathrm{C}$, however, more trans-isomer, which is thermodynamically more stable, was formed. The reaction also produced n-butane. However, the back ground reactivity was so high that hydrogenation activity of alumina could not be determined.

Same reaction was performed over Pt-covered AlOx surfaces at $140^{\circ} \mathrm{C}$. The products of the reaction were cis-2-butene, trans-2-butene, and n-butane. Figure 5.7 shows the change of selectivity for isomerization (cis- and transbutene) over hydrogenolysis ( $n$-butane) as a function of platinum coverage on alumina. It also shows the total conversion after 30 minutes of reaction. Selectivity for isomerization decreased as $\mathrm{Pt}$ coverage increased but cis/trans ratio remained close to 1 . 


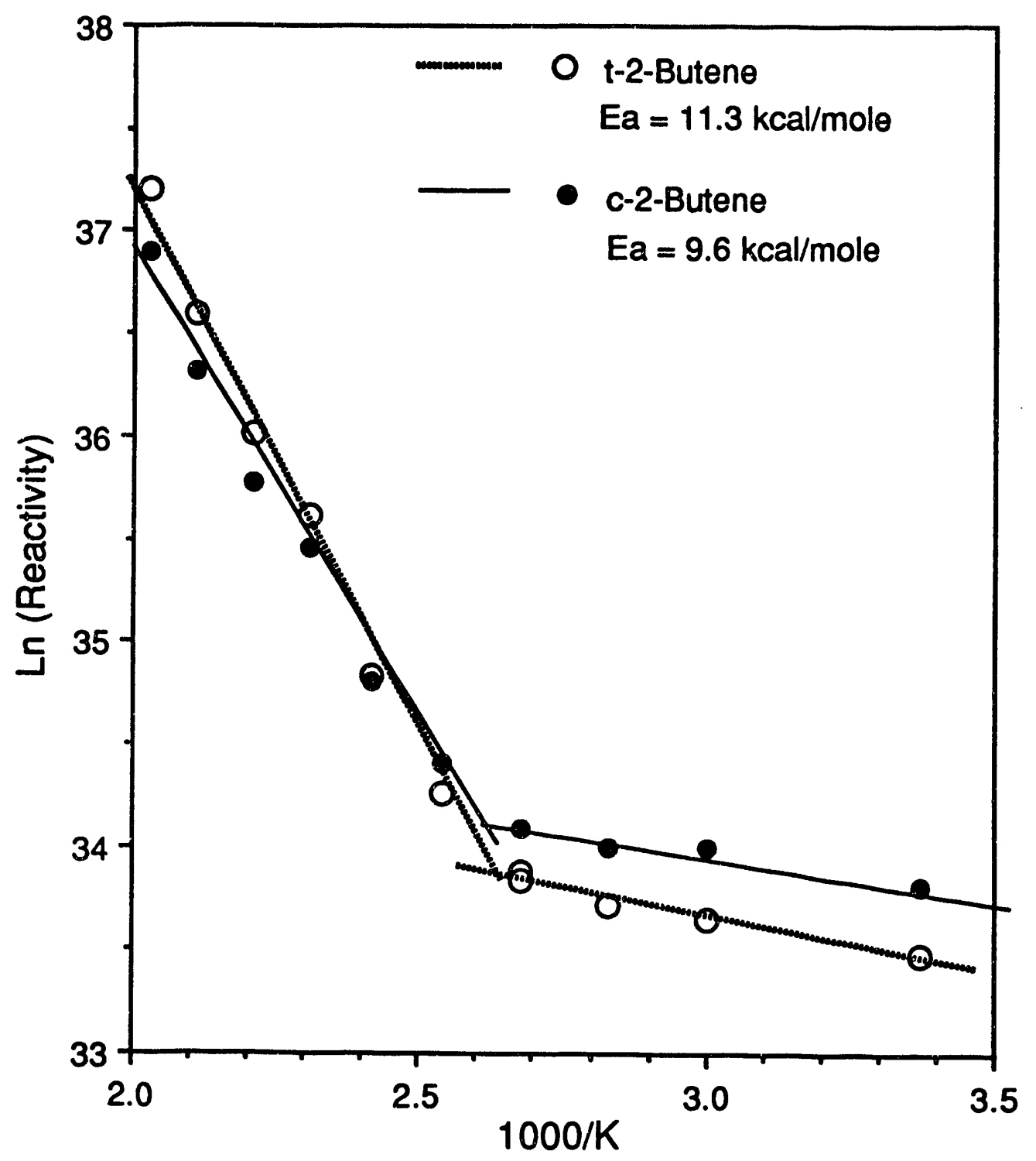

Figure 5.5 Arrhenius plots for 1-butene isomerization on $\mathrm{AlO}_{x} ; P_{1-b u t e n e}=200$ Torr and $P_{\text {hydrogen }}=200$ Torr. 


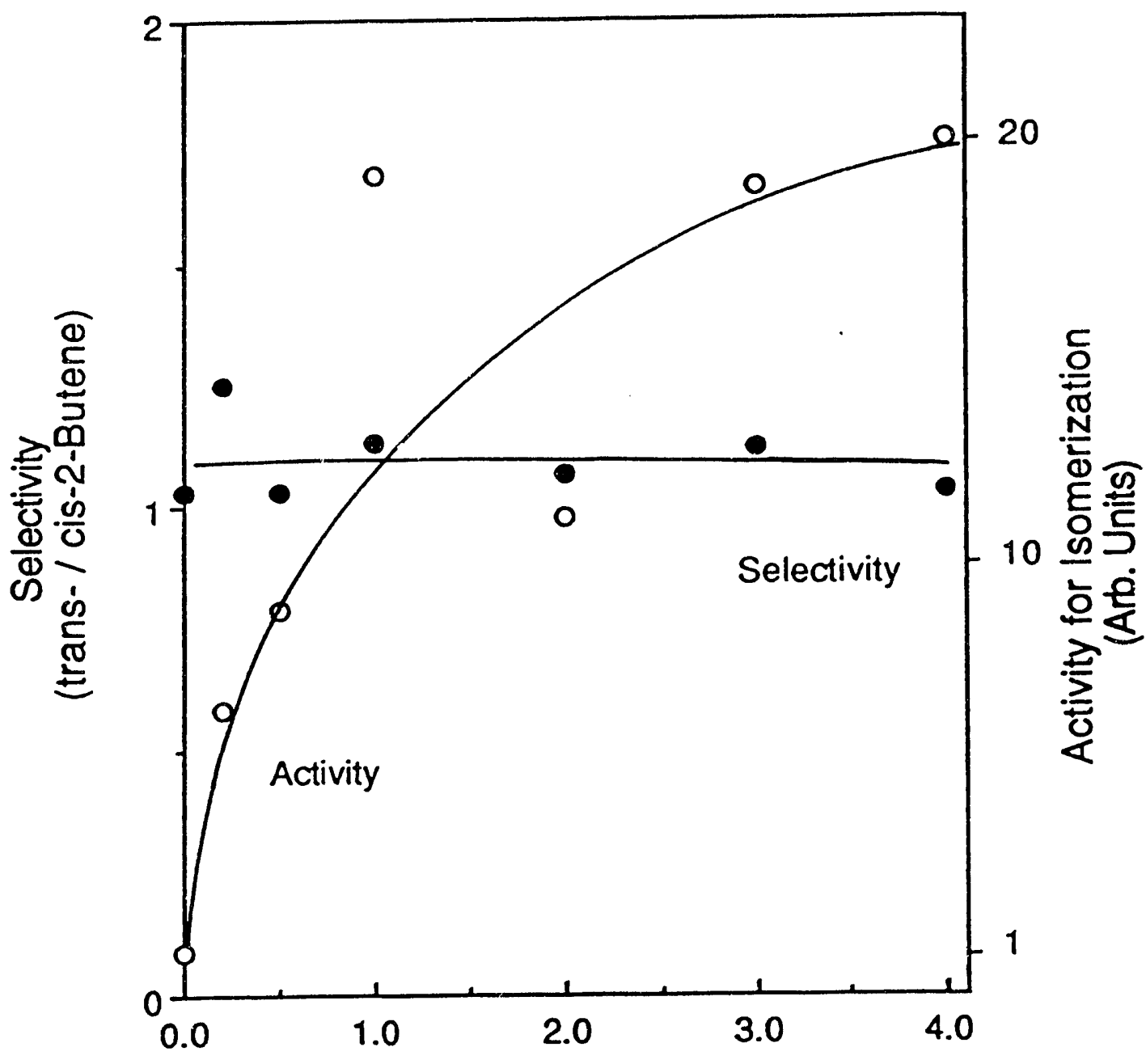

Pt Coverage on AlOx

$\left(10^{15} \mathrm{Pt}\right.$ atoms $\left./ \mathrm{cm}^{2}\right)$

Figure 5.6 Conversion of 1-butene over $\mathrm{Pt} / \mathrm{AlOx}$ catalysts. It shows the selectivity of isomerization (cis- and trans-2-butene) over hydrogenation (nbutane). Total conversion was determined after 30 minutes of reaction. Reaction conditions were $P_{1 \text {-butene }}=200$ Torr,,$P_{\text {hydrogen }}=200$ Torr, and temperature $=140^{\circ} \mathrm{C}$. 
Chapter 5 Planar $\mathrm{Pt} / \mathrm{AlO}_{x}$ Catalyst 126

\section{Reference}

[1] D.M. Little, "Catalytic Reforming", PennWell Books, Tulsa, Oklahoma (1985).

[2] K. Tanabe, M. Misono, Y. Ono, and H. Hattori, "New Solid Acids and Bases", Elsevier, Amsterdam (1989).

[3] F.G. Ciaputta and D.N. Wallace, Catal. Reo. 5 (1971) 67.

[4] P. Weisz, Ado. Catal. 13 (1962) 137.

[5] X. Bai and W.M.H. Sachtler, J. Catal. 129 (1991) 121.

[6] R.K. Oberlander in "Applied Industrial Caialysis", (B.E. Leach ed.), Academic Press, Orlando (1984) Vol.3, Chapter 4.

[7] D.L. Cocke, E.D. Johnson and R.P. Merrill, Catal. Reo. 26 (1984) 163.

[8] K. Wefers and F.M. Bell, "Oxides and Hydroxides of Aluminum", (Technical Faper No. 19), Alcoa, Pittsburgh (1972).

[9] F.A. Cotton and G. Wilkinson, "Advanced Inorganic Chemistry", John Wiley \& Sons, New York (1980).

[10] C. Kembell, H.F. Leach, and I.R. Shannon, J. Catal. 29 (1973) 99.

[11] O. Johnson, J. Phys. Chem. 59 (1955) 827.

[12] J.R. Schlup and R.W. Vaugham, J. Catal. 99 (1986) 304.

[13] H. Knozinger and C.P. Kaerlein, J. Catal. 25 (1972) 436.

[14] H. Hattori, O. Takahashi, M. Takagi, and K. Tanabe, J. Catal. 68 (1981) 132.

[15] R.K. Hart and J.K. Maurin, Surf. Sci. 20 (1970) 285.

[16] P. Hofmann, W. Wyrobisch, and A.M. Bradshaw, Surf. Sci. 80 (1979) 344.

[17] U. Memmert and P.R. Norton, Surf. Sci. 203 (1988) L689.

[18] C. S. K.o and R.J. Gorte, Surf. Sci. 155 (1985) 296. 
[19] B.G. Frederick, G. Apai, and I.N. Rhodin, Surf. Sci. 244 (1991) 67.

[20] J.W. Hightower and W.K. Hall, J. Phys. Chem. 71 (1967) 1014.

[21] L.E. Davis, N.C. MacDonald, P.W. Palmberg, G.E. Riach, and R.E. Wever, Eds., "Handbook of Auger Electron Spectroscopy", 2nd ed. Physical Electronics Ind., MN (1976).

[2] A. Jimenez-Gonzalez and D. Schmeisser, Surf. Sci. 250 (1991) 59.

[23] F.A. Shunk, "Constitution of Binary Alloys, Second Supplement", McGraw-Hill, New York (1969).

[24] Istvan Boszormenyi, Ph.D. Thesis, University of California, Berkeley (1992).

[25] J. Medema, J. Catal, 37 (1975) 91. 

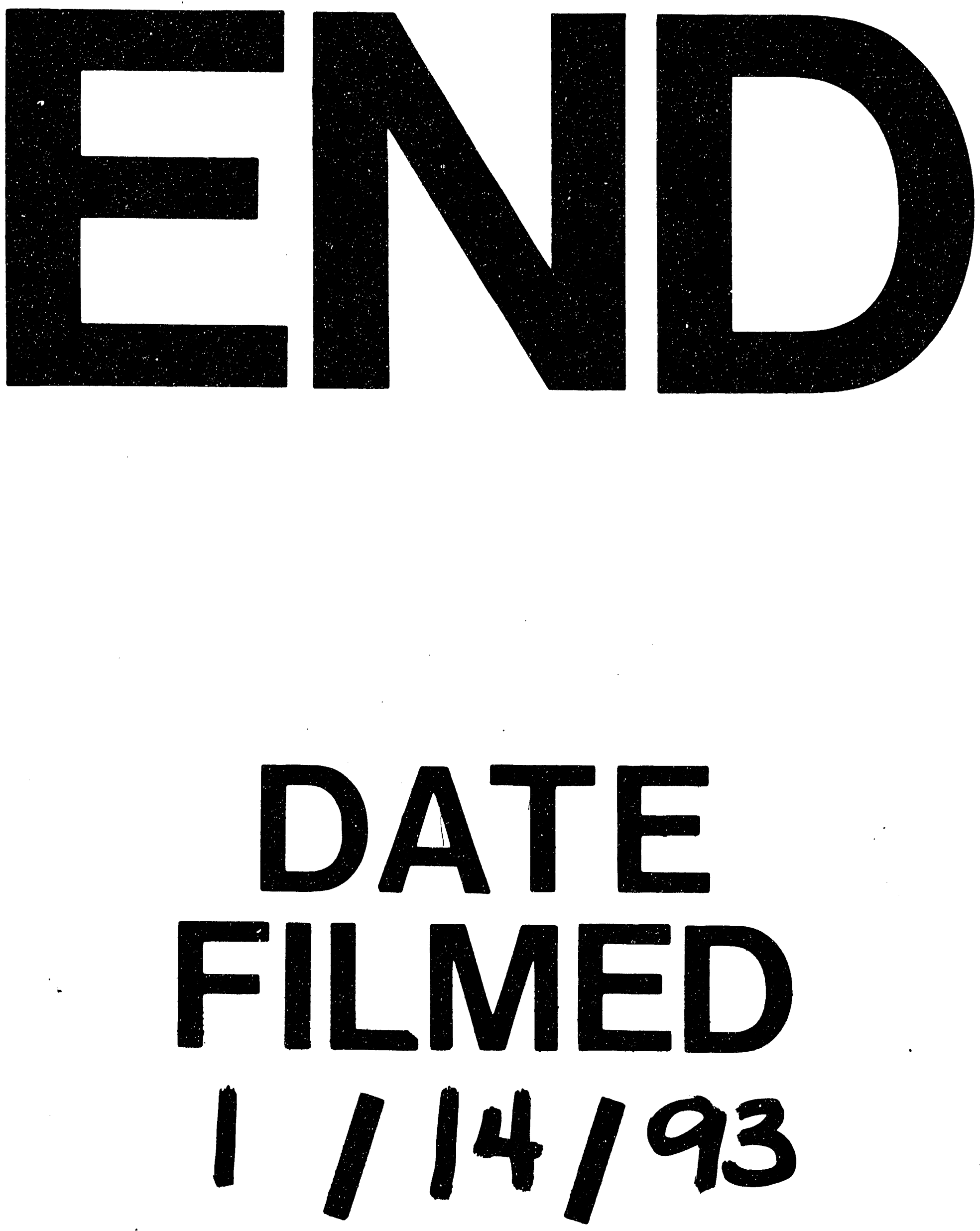

1 
